\title{
MODELING, SIMULATION AND OPTIMAL OC? OF ETHYLENE POLYMERIZATION \\ IN A HIGH-PRESSURE TUBULAR REACTOR
}

\author{
By
}

Frederick Zuojiang Yao, B. Eng.

Nanchang University

Nanchang, Jiangxi, People’s Republic of China, 1987
A Thesis

Presented to Ryerson University

in Partial Fulfillment of the

Requirements for the Degree of

Master of Applied Science

in

Chemical Engineering

Toronto, Ontario, Canada 2004

C2004 Frederick Zuojiang Yao 
UMI Number: EC53422

\section{INFORMATION TO USERS}

The quality of this reproduction is dependent upon the quality of the copy submitted. Broken or indistinct print, colored or poor quality illustrations and photographs, print bleed-through, substandard margins, and improper alignment can adversely affect reproduction.

In the unlikely event that the author did not send a complete manuscript and there are missing pages, these will be noted. Also, if unauthorized copyright material had to be removed, a note will indicate the deletion.

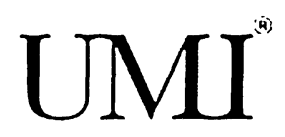

UMI Microform EC53422

Copyright 2009 by ProQuest LLC

All rights reserved. This microform edition is protected against unauthorized copying under Title 17, United States Code.

ProQuest LLC

789 East Eisenhower Parkway

P.O. Box 1346

Ann Arbor, MI 48106-1346 


\section{Author's Declaration}

I hereby declare that I am the sole author of this thesis.

I authorize Ryerson University to lend this thesis to other institutions or individuals for the purpose of scholarly research.

I further authorize Ryerson University to reproduce this thesis by photocopying or by other means, in total or in part, at the request of other institutions or individuals for the purpose of scholarly research. 


\section{Borrower's Page}

Ryerson University requires the signatures of all persons using or photocopying this thesis. Please sign below, and give address and date.

\begin{tabular}{|c|c|c|c|}
\hline Name (print) & Signature & Address & Date \\
\hline & & & \\
\hline & & & \\
\hline & & & \\
\hline & & & \\
\hline & & & \\
\hline & & & \\
\hline & & & \\
\hline & & & \\
\hline & & & \\
\hline & & & \\
\hline & & & \\
\hline & & & \\
\hline & & & \\
\hline & & & \\
\hline & & & \\
\hline & & & \\
\hline & & & \\
\hline & & & \\
\hline
\end{tabular}




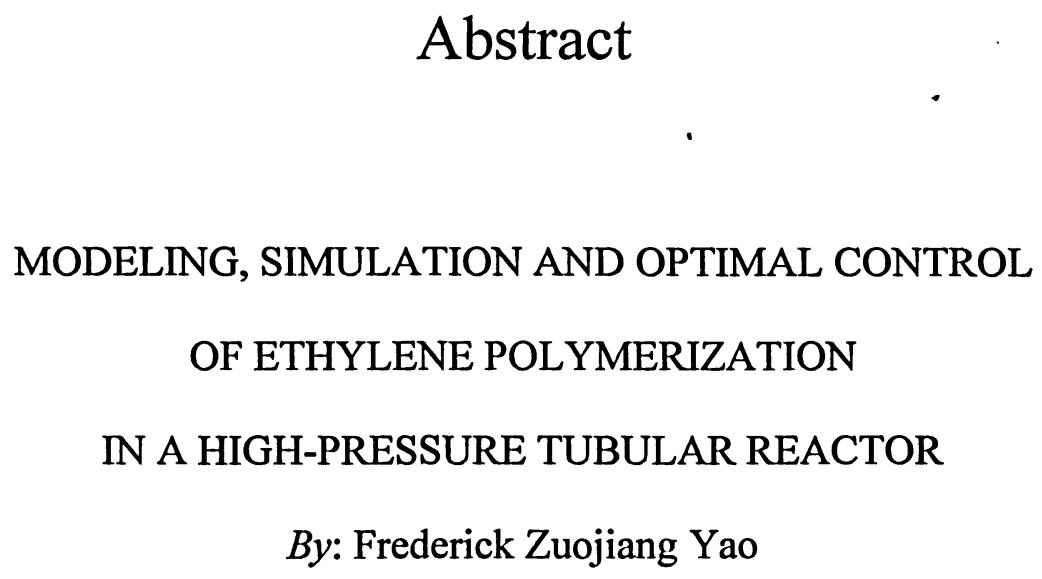

Master of Applied Science in Chemical Engineering, Ryerson University 2004

Low-density polyethylene (LDPE) is a very important material for the manufacture of engineering and commodity plastics. The products are usually produced in high-pressure free radical polymerization either by autoclave or by tubular processes. This study presents a kinetic model based on a postulated reaction mechanism to describe the evolution of monomer, initiator consumption and the average molecular weights of ethylene polymerization in a high-pressure polymerization tubular reactor. The variations in the density and viscosity of the reacting mixture along multiple injection points for an initiator are used along reactor length is explicitly taken into account. A simulation program is developed to solve the mathematical model and the results are compared with those reported earlier.

Further, the optimal control of the LDPE reactor is carried out using genetic algorithms to maximize monomer conversion using the jacket temperature of heat-exchange fluid as a control function along reactor length. The results indicate a $22-40 \%$ increase in the reduction of monomer concentration. 


\section{Acknowledgements}

I wish to express my gratitude to Dr. Ramdhane Dhib, Dr. Ali Lohi, and Dr. Simant R. Upreti, under whose guidance this research was successfully completed.

In presenting this work, a special thank goes to Dr. Simant R. Upreti with his friendly direction and strong support in computer programming for this research.

The partial financial support from the Department of Chemical Engineering of Ryerson University is gratefully acknowledged. 


\section{Table of Contents}

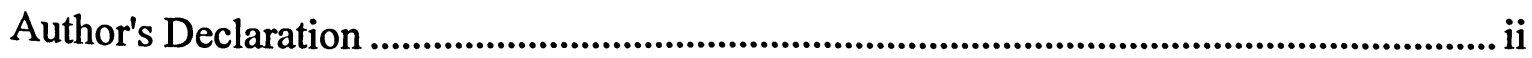

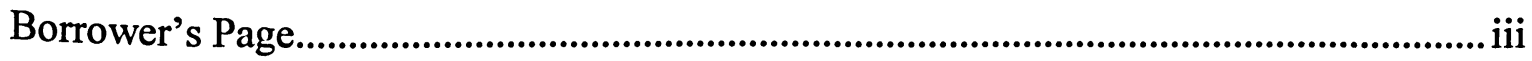

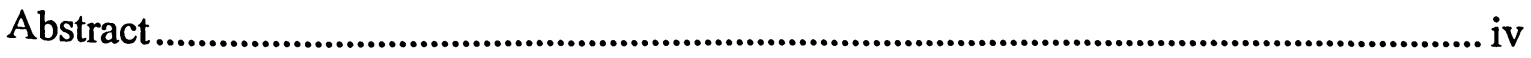

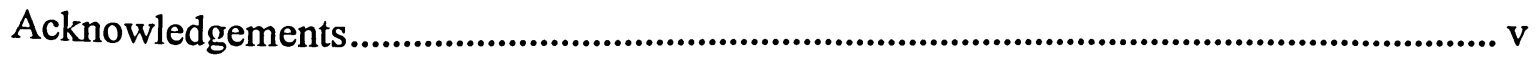

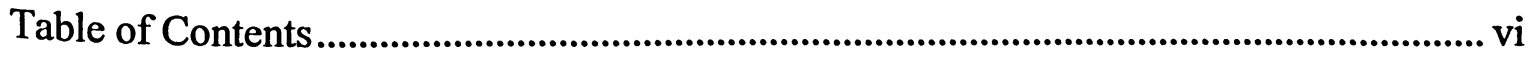

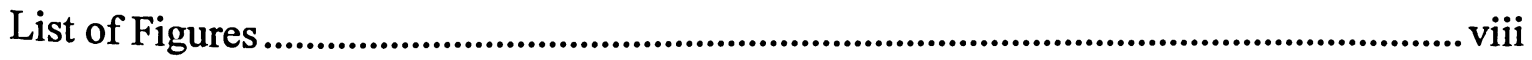

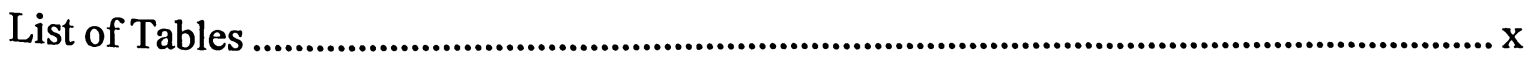

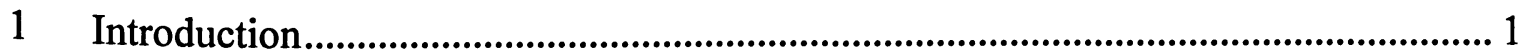

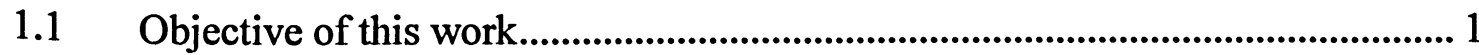

1.2 A summary of organization in this thesis .......................................................... 1

1.3 LDPE Technology and Its Background ............................................................... 2

1.4 Configuration of Polymerization Reactor ................................................................ 4

1.4.1 Basic types of polymerization reactor configuration ...................................... 4

1.4.2 The typical commercial tubular reactor .................................................... 6

1.5 Progress and Challenge............................................................................................ 7

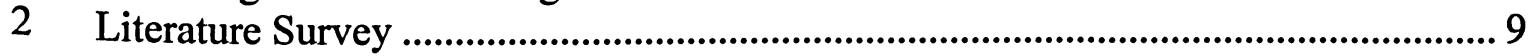

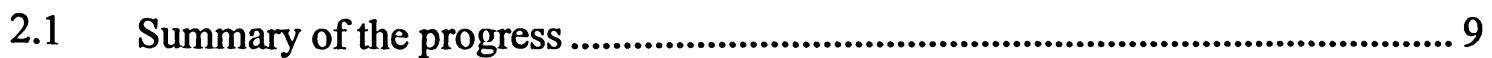

2.2 Challenge of the technology .............................................................................. 14

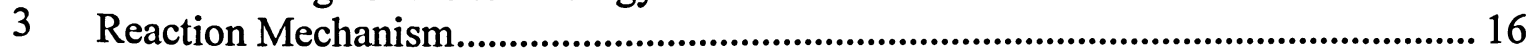

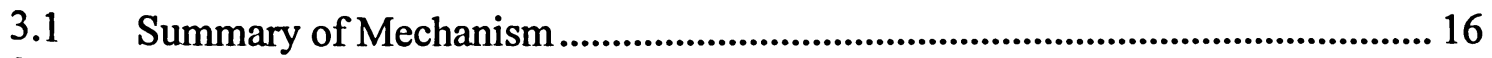

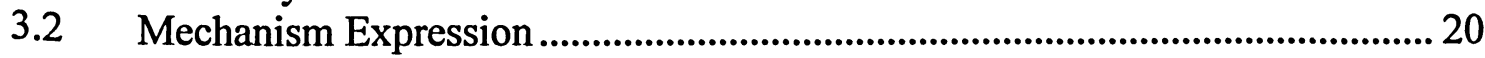

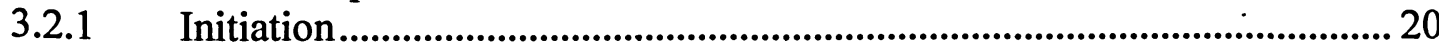

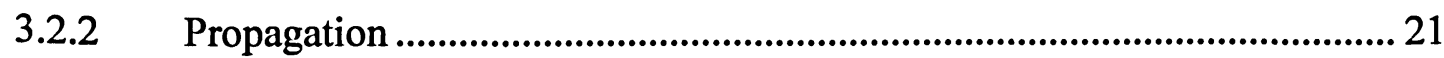

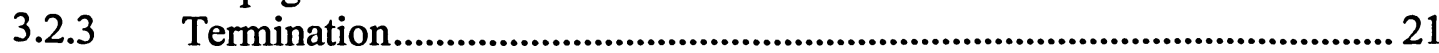

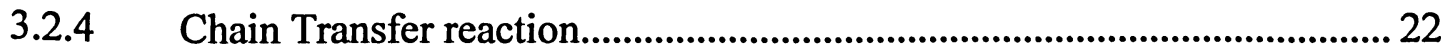

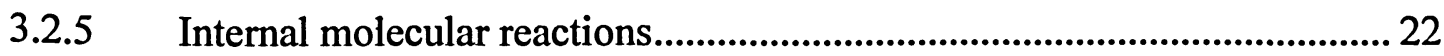

4 Mathematical Model Development................................................................... 24

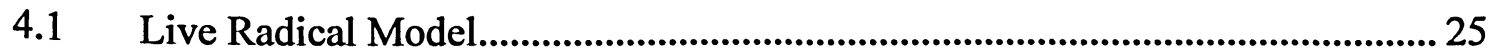

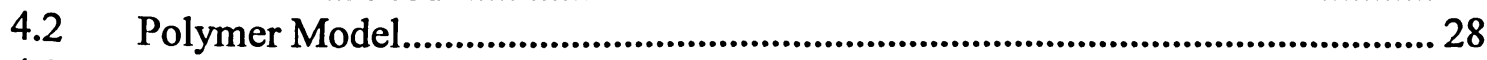

4.3 Mathematical Tubular Reactor Model .......................................................... 30

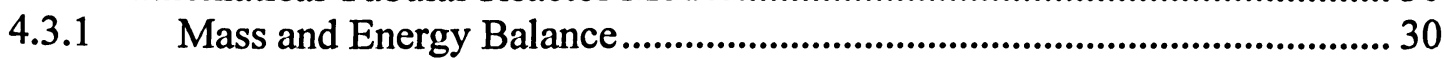

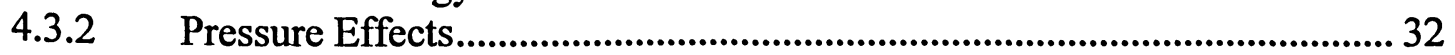




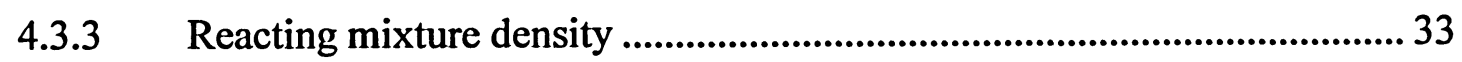

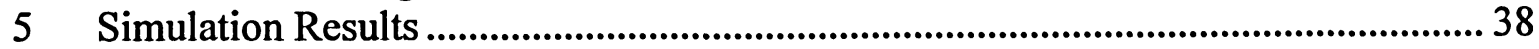

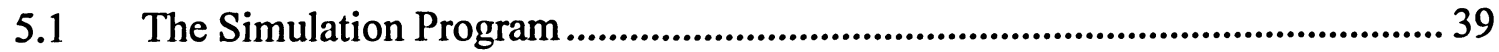

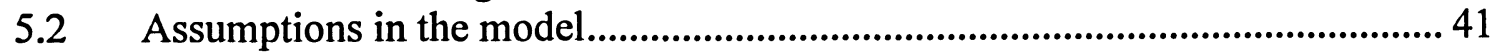

5.2.1 Heat Capacity ............................................................................................... 41

5.2.2 Heat Transfer Coefficient for the Whole Tubular Wall.............................. 41

5.2.3 Constant Reaction Pressure.................................................................... 41

5.2.4 Effect to multiple initiator injection........................................................ 42

5.2.5 Reaction heat............................................................................................... 42

5.3 Consideration of simulation parameters ........................................................... 42

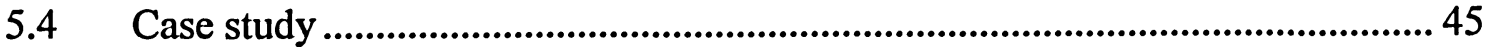

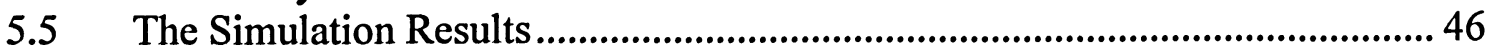

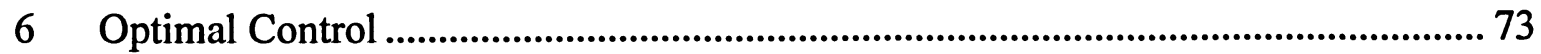

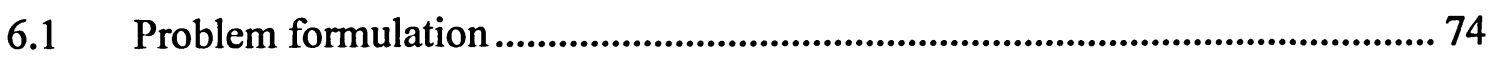

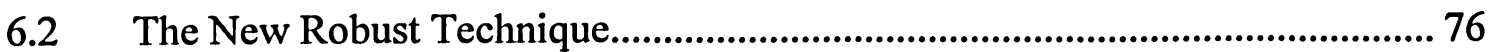

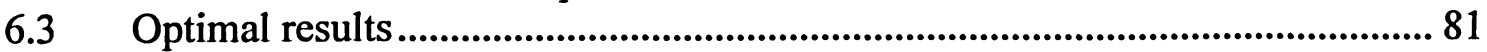

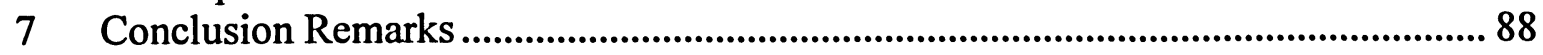

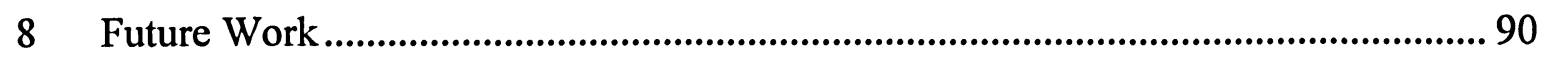

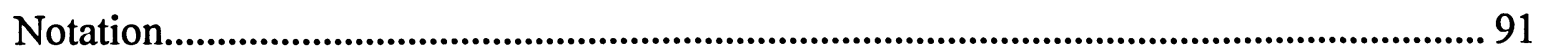

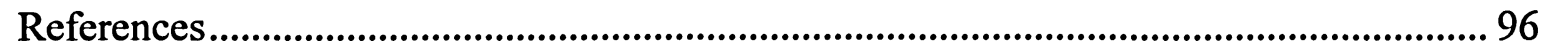

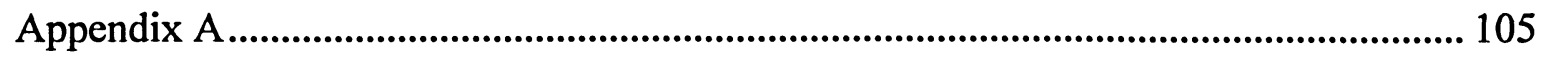

Fundamental Equations of a tubular reactor ............................................................... 105

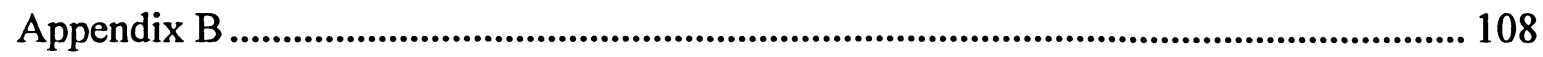

Physical Properties: Viscosity and Heat Transfer Model ............................................... 108

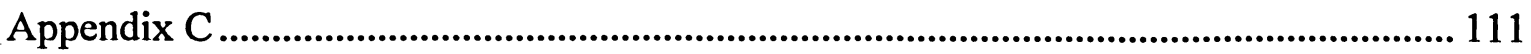

Least-Squares Polynomial Regression in Analysis of Density Modeling...................... 111

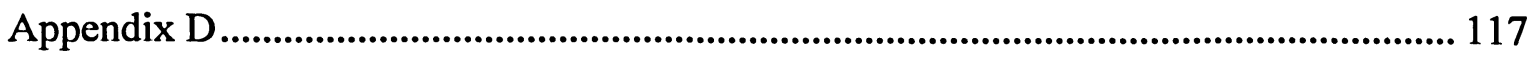

The Fourth and Fifth-Order Runge-Kutta Algorithm with Cash-Carp Development .... 117

Fourth-Order Runge-Kutta method.......................................................................117

Fifth-Order Runge-Kutta Method ............................................................................. 118

Carsh-Carp Runge-Kutta Method ......................................................................... 119 


\section{List of Figures}

Figure 1. Process Sheet of Low Density Ethylene Polymerization (Cervantes, et al., 2000) 3

Figure 2. Reactor in Multiple Configuration ...................................................................... 5

Figure 3. Reactor in Series Configuration ................................................................. 5

Figure 4. A multiple configuration of the commercial reactor (Lacunza, at al., 1998)..... 6

Figure 5. Monomer Densities from Experimental Data at Pressure versus Temperature 36

Figure 6. Modeled Monomer Densities after Data-Fitting to Polynomial Model ............. 37

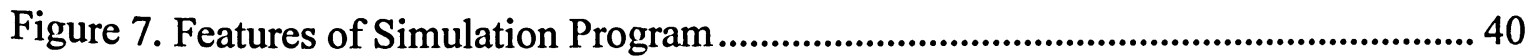

Figure 8. Comparison between conversions calculated from the boundary and direct methods 47

Figure 9. Velocity comparison calculated from boundary and direct methods ................. 48

Figure 10. Temperature Profiles of Reaction and Jacket............................................... 50

Figure 11. Profile of Monomer Conversion.................................................................... 51

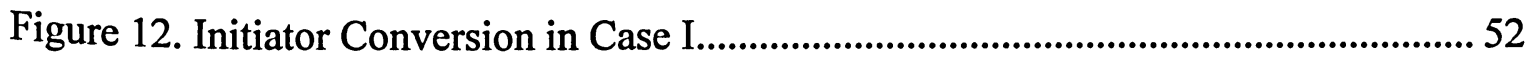

Figure 13. Average Molecular Weight ............................................................................... 53

Figure 14. Polydispersity Index versus Axial Coordinate .............................................. 54

Figure 15. Profile of Monomer Concentration in Reactor .................................................. 55

Figure 16. Variations of Multi-injection initiator and Initiator Concentration..................56

Figure 17. Temperature Profiles with One Injection in Case II.......................................... 58

Figure 18. Profile of Monomer Conversion in Case II .................................................... 59

Figure 19. Evolution of Initiator Conversion in Case II ..................................................60

Figure 20. Average Molecular Weight (MWD) in Case II ..............................................61 61 
Figure 21. Polydispersity Index with One Initiator Injection in Case II 62

Figure 22. Profile of Monomer Concentration in Case II............................................... 63

Figure 23. Variation of One Injection Initiator in Case II ............................................... 64

Figure 24. Polydispersity Index versus Axial Coordinate ................................................. 67

Figure 25. Monomer Conversions for different initiator concentrations ............................6 68

Figure 26. Monomer conversions for different inlet temperatures ....................................69 69

Figure 27. Monomer Conversion for different inlet monomer concentrations.................. 70

Figure 28. Algorithm Flow Chart ........................................................................................ 80

Figure 29. Optimal Profile for Jacket Temperature ............................................................... 83

Figure 30. Comparison of Fractional Change in Monomer Concentration with Non-

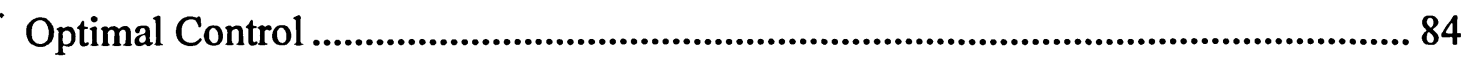

Figure 31. Reaction Temperature between Optimum and Non-optimum ......................... 85

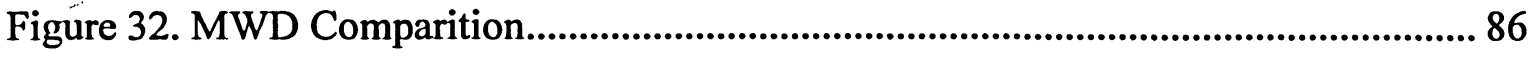

Figure 33. PDI Comparison between State Performance and Optimal Control ................ 87 


\section{List of Tables}

Table 1. Equations Used in Simulation Program.............................................................. 38

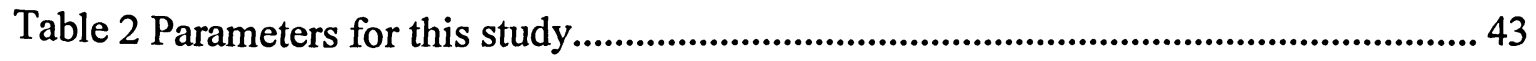

Table 3 Rate constant used in this work: $K=A^{*} \exp \left(-E / R_{1} T-\Delta v P / R_{2} T\right) \ldots \ldots \ldots \ldots \ldots \ldots \ldots \ldots . . . . . . . . . . .44$

Table 4 Decomposition rate constant initiator: $K_{d}=A_{1} \exp \left(-E_{1} / R_{1} T-\Delta v_{1} P / R_{2} T\right)$............. 44

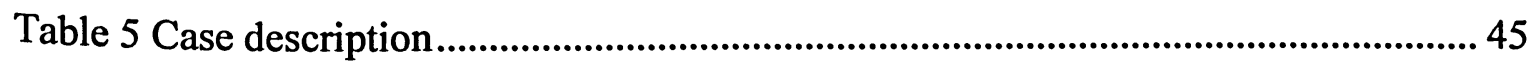

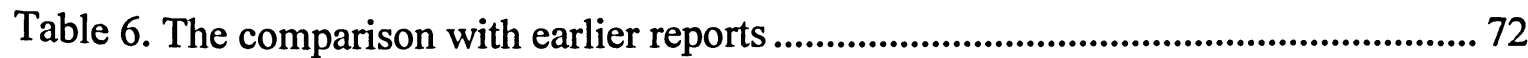

Table 7 Parameters used in the presented optimal control technique................................... 78 


\section{Introduction}

\subsection{Objective of this work}

The objective of this work is to review the mechanism of polymerization reaction, develop mathematic models for initiator, monomer, radicals and polymers after exploring industrial and literature data, and studying the operation parameters and kinetics from earlier reports. The simulation results are to be given based on proposed model using a self-developed program. Using genetic algorithms and process simulation model a new robust optimal control of maximizing fractional change in term of monomer concentration has been developed.

\subsection{A summary of organization in this thesis}

This thesis begins with an introduction of LDPE tubular technology, followed by a literature review, which reflects the recent scientific progress in this field. Based on previous results, the author has written the reaction mechanism for initiation, propagation and termination of the reactions, and then developed the mathematical model of kinetic tubular reactor, live radical and dead polymer.

The simulation and optimal control, which are included in Chapter 5 and Chapter 6, are the core parts of this thesis. A self-developed program is used to simulate the mathematical model and optimize operating conditions. It follows by the conclusion remarks and suggestions for future work. 
There are four Appendices as attachment. The Appendix A gives fundamental transport equations of a tubular reactor. The Appendix B lists the information of physical properties and heat transfer model used in the simulation model. Appendix $\mathrm{C}$ represents a Mathematic tool, least-squares polynomial regression, which is used to analyze and compare the density model. Finally, Appendix D summarizes the Runge-Kutta Algorithm used in this research work.

\subsection{LDPE Technology and Its Background}

Low-density polyethylene (LDPE), commonly produced in high-pressure free radical polymerization processes, is one of the most important polymers for manufacturing a wide range of engineering and commodity plastics due to its extraordinary electrical and impact properties, remarkable chemical inertness and moisture resistance, and adaptability to almost all plastic fabrication and processing methods. Its consumption accounts for the $40 \%$ of global polyethylene consumption, which reached about 35 million metric tons in 1994 and has been rapidly increasing at the rate of $7 \%$ per year over the past 15 years.

LDPE has been manufactured in a high-pressure process for several decades since the process was set up in the BASF Ludwigshafen plant in 1938. The process is characterized by very large ratios of length to diameter, better heat removal than in an autoclave reactor, very high axial velocity, high pressure in the range of $1000-3000$ atm and $100^{\circ} \mathrm{C}-325^{\circ} \mathrm{C}$ operating temperature. Figure 1 shows the production process. 


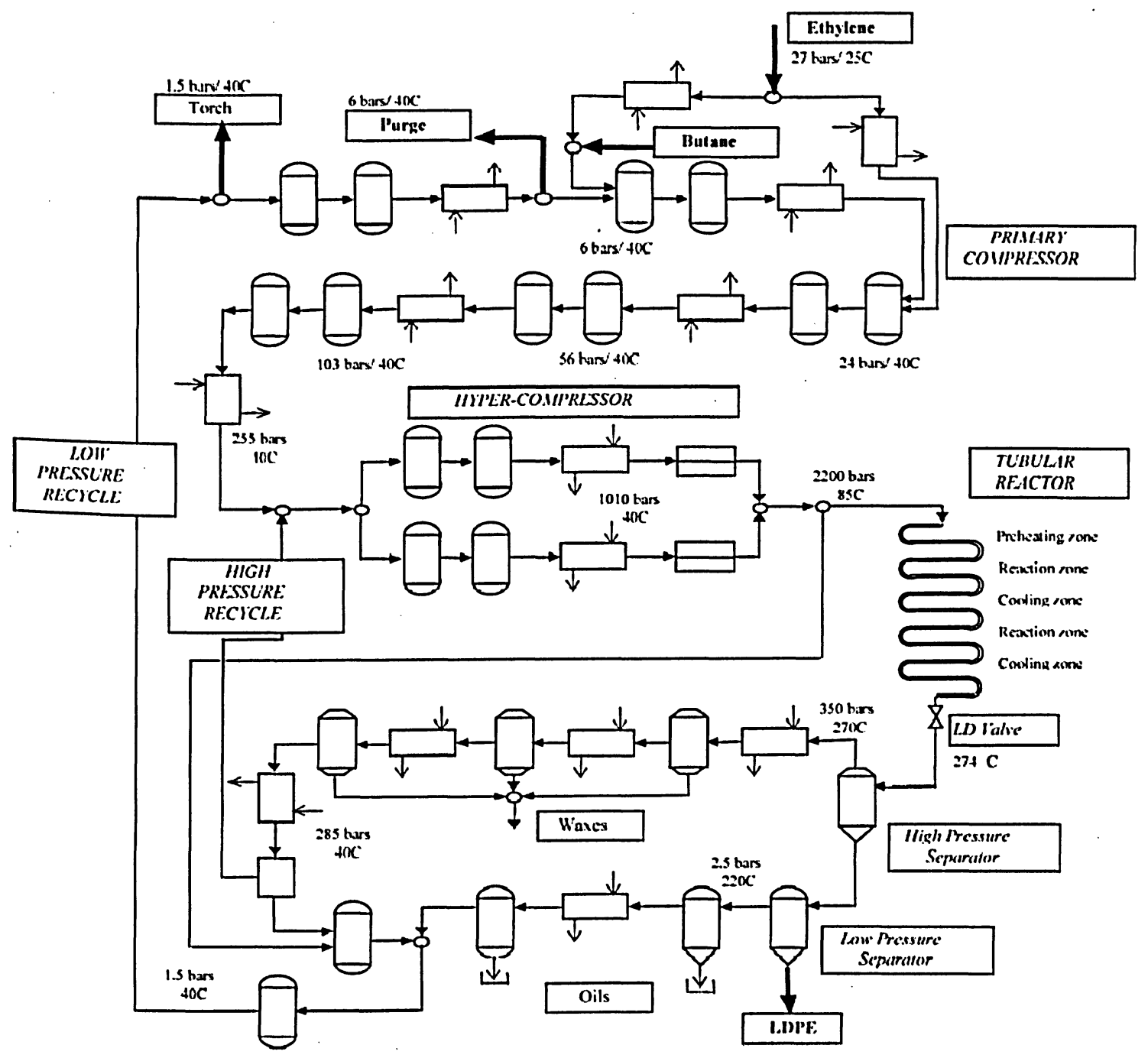

Figure 1. Process Sheet of Low Density Ethylene Polymerization (Cervantes, et al, 2000)

The LDPE tubular technology for LDPE production is also characterized by the low manufacturing cost due to several factors:

a) less expensive organic peroxides and oxygen can be used as initiators;

b) it is easier to reproduce process parameters due to absence of catalyst influence;

c) it is associated with high flexibility of the process and no substandard products are produced during grad change; 
d) there is no need to use the expensive $\alpha$-olefins, because in the process the formation of side branches in the polymer chain are generated by the radical polymerization process itself; and

e) simple upscale process - single line scale-up provide excellent results.

\subsection{Configuration of Polymerization Reactor}

Polymerization tubular reactor has several different configurations depending on the desired final product properties and technological requirements.

\subsubsection{Basic types of polymerization reactor configuration}

Generally, there are two basic types of tubular reactors:

A) Multiple type: configured by multiple cold gas feeds and multiple initiator injections; initiation is possible by oxygen and/or peroxide; and

B) Series type: configured by only one gas feed; multiple injections of peroxide initiators and/or oxygen.

Figure 2 and 3 illustrate these two configurations, respectively. 


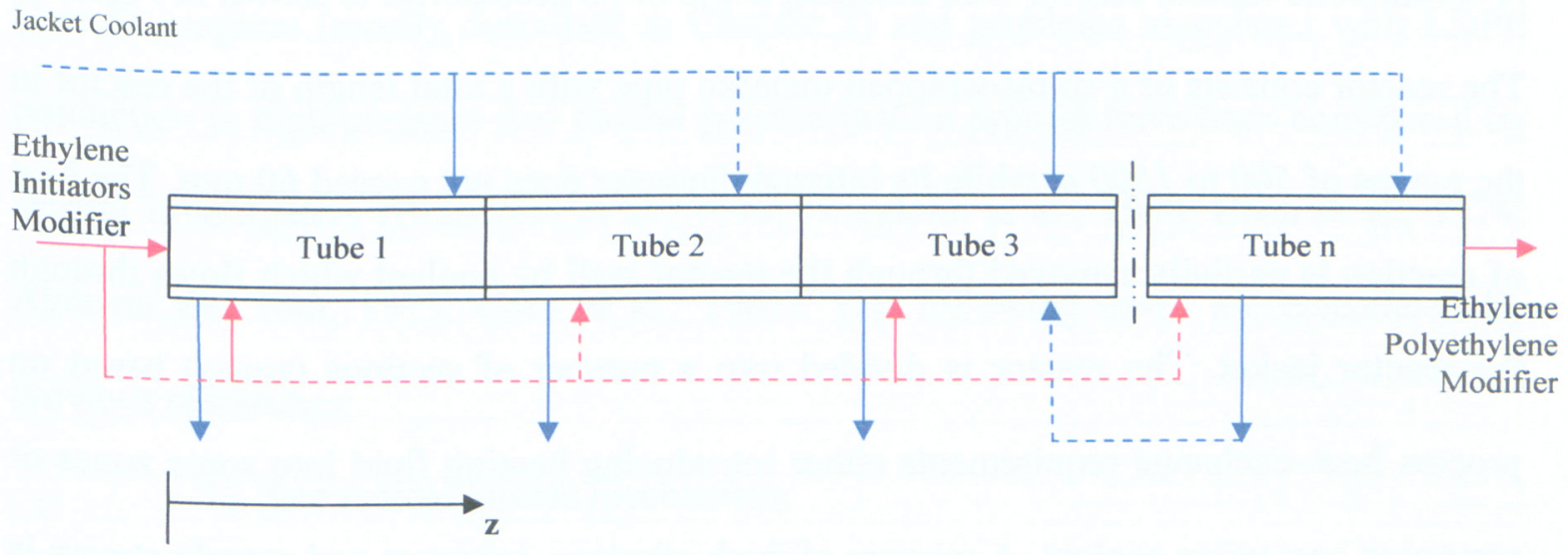

Figure 2. Reactor in Multiple Configuration

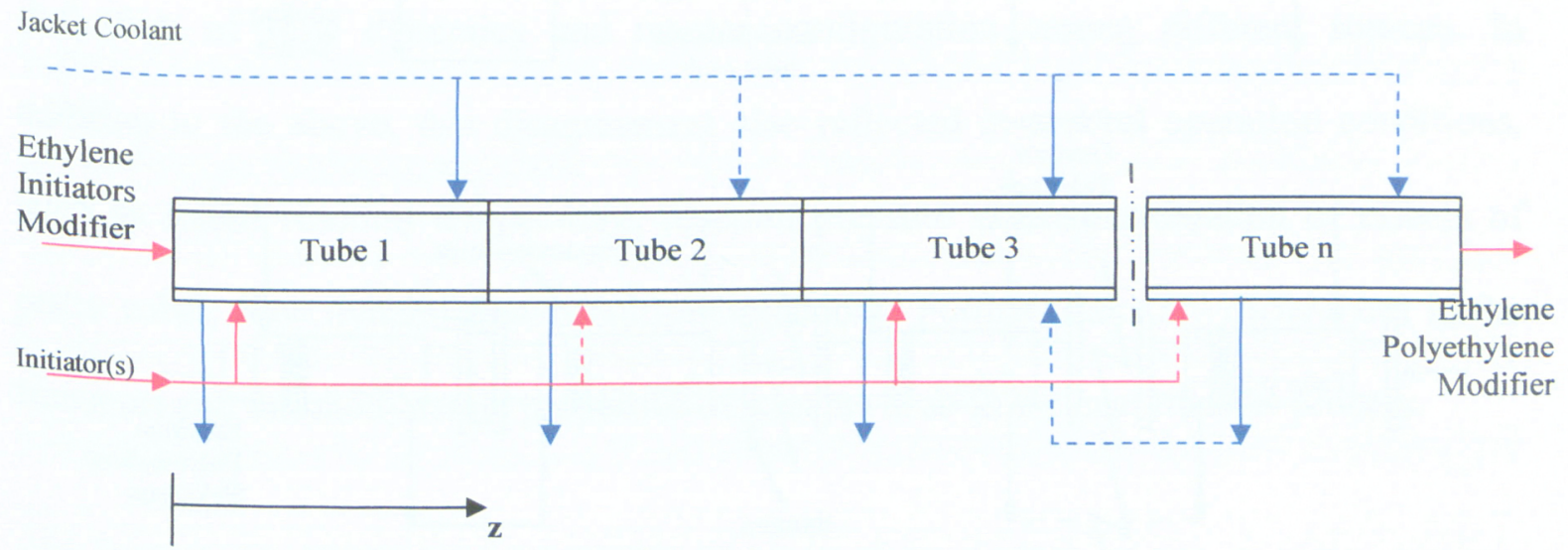

Figure 3. Reactor in Series Configuration 


\subsubsection{The typical commercial tubular reactor}

A commercial tubular reactor with detailing some of its accessories is shown in Figure 4. The reactor consists of a spiral-wrapped metallic pipe with a total length of the reactor in the ranges of 500 to $1500 \mathrm{~m}$ while its internal diameter does not exceed $60 \mathrm{~mm}$. The heat of reaction is partially removed through the reactor wall by coolant which flows through the reactor jacket. The reactor is divided into a number of sections (zones) based on process heat-exchange requirements either introducing heating fluid into some zones or removing heat using coolant. A mixture of fresh ethylene, initiators and recycle stream is compressed and fed to the reactor. Typically, there are multiple feed streams and initiator mixture injection points. The present conversion ranges from $9-29 \%$, depending on an actual reactor configuration and type of initiator.
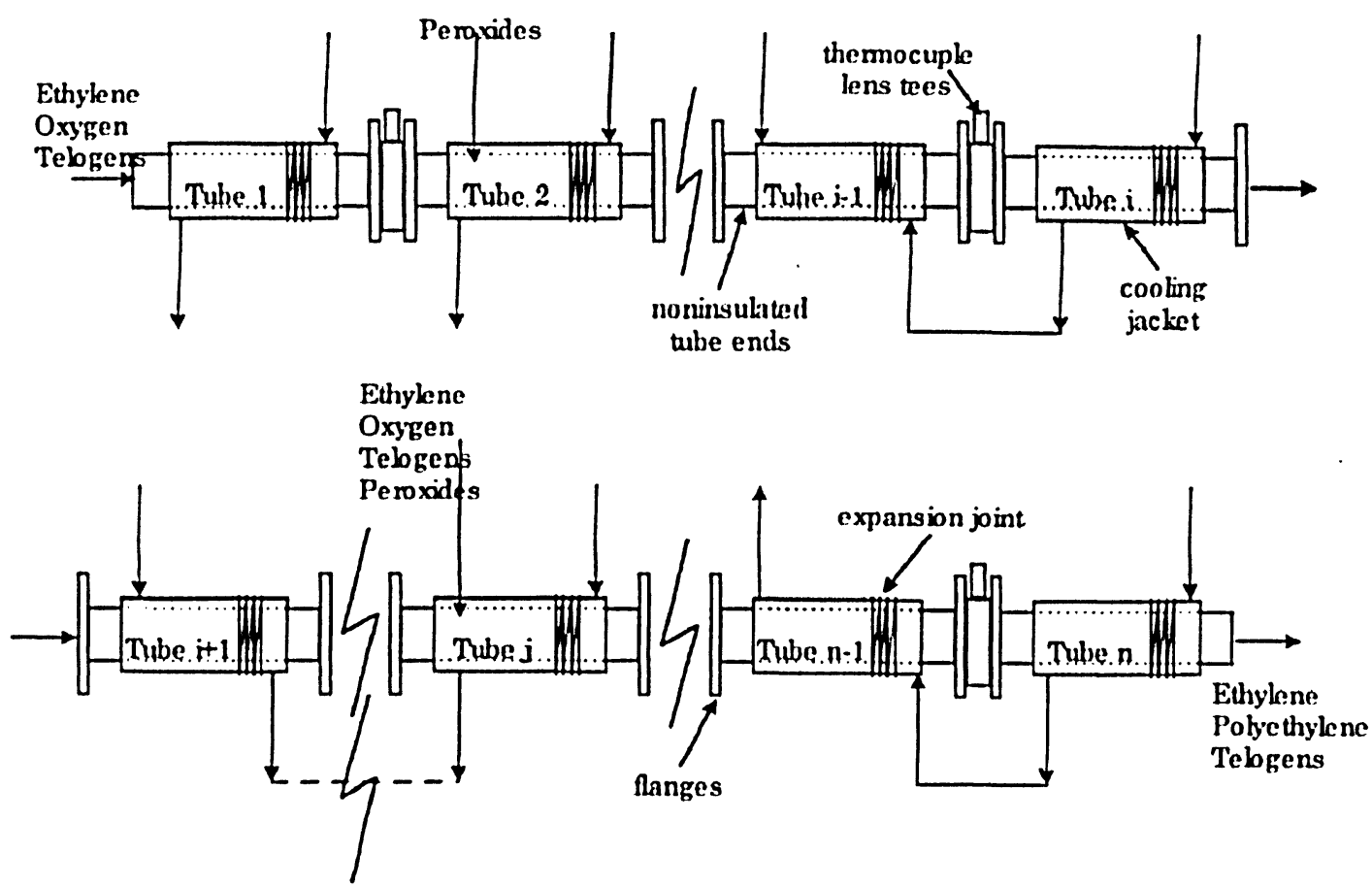

Figure 4. A multiple configuration of the commercial reactor (Lacunza, at al., 1998) 


\subsection{Progress and Challenge}

Current progress (mostly described in Chapter 2) and problems associated with LDPE production in high-pressure free radical polymerization process have been considered by several investigators (Brandolin et al., 1996; Brandolin et al., 1988; Chen et al., 1976; Agrawal and Han, 1975; Goto et al., 1981). The following cases are considered by previous researches:

1) free radical kinetic mechanism;

2) assumption of plug flow with no axial-dispersion;

3) equal reaction mixture gaseous phase, and

4) Steady - state hypothesis along the axial coordinate.

It is obviously shown that there are difficulties for a good formulation of a model for the process. These difficulties are reflected not only in the complexity of the reaction system, but also in the information associated with different sources. For example, there are lack of agreement on available kinetic constants, heat transfer factors and reactant viscosities, definition of flow dynamics and reactor configuration among different sources. In addition to the above, this disagreement also reflected in several operation conditions, such as initial reaction temperature, reaction pressure with consideration of effects of pulse valve, flow dynamics and multiple injections. Further, there are differences in the transport and thermodynamic properties of streams used in the heat transfer process.

This research develops a steady state model of a LDPE tubular reactor on the basis of a kinetic scheme, which takes into account important elementary reactions occurred due to 
the intense heat effects of ethylene polymerization. The model comprises of the molar balances of initiator, solvent, monomer, free radicals, and dead polymer in conjunction with the energy balances at reaction and jacket sides along the length of reactor. The model takes into account multiple initiator injection points, variable density, viscosity and velocity of reaction stream. The developed model uses data from the reported production plant to simulate an industrial, high pressure, non-isothermal LDPE tubular reactor. The temperature, pressure and conversion profiles along reactor length and the quality of LDPE in terms of number and weight average molecular weight are determined. Comparing to the method of Lorenzini et al., (1992), which used a novel method to obtain molecular weight distribution (MWD) by applying the mass balance, MWD moments and the long and short chain branching points and double bonds as separate species, this work applied direct calculation to obtain average molecular weight distribution in Section 5.5.

Further, the optimal control of the reactor satisfying various process constraints is carried out to maximize fractional change in term of monomer concentration using reactor jacket temperature as a control function. Genetic Algorithms are employed to define the optimal control objective, which is also subject to the developed mathematical model. By applying this strategy, the outlet optimal monomer conversion in term of monomer concentration are around $40 \%$ and $22 \%$ higher than the non-optimal one-shoot cases of low and high initiator concentrations, respectively. 


\section{Literature Survey}

Many researchers attempted to develop a model to describe high-pressure polymerization of ethylene by free radical process. Different investigators have reported their findings within wide range of parameters. Models that are developed in this field, recently, are using operating plant data as an input data to predict results obtained from actual plant. The simulation model which is combined with a control and optimization algorithm is much preferred in prediction of production properties; hence it can directly be related to process operations and production progress.

\subsection{Summary of the progress}

There are many disagreements in describing reaction kinetic, thermodynamic and transport properties of a LDPE tubular reactor. This has led a number of researchers (Chen et al., 1976; Shirodkar and Tsien 1986; Brandolin et al., 1988; Brandolin et al., 1996; Baltsas et al., 1998; Zabisky et al., 1992) to establish a unified model of ethylene polymerization in tubular reactor.

Agrawal and Han (1975) presented reactions of peroxide initiation, termination by combination, transfer to monomer, transfer to polymer and transfer to chain transfer agent and $\beta$-scission. They investigated the effect of axial mixing on the reaction, reaction temperature $(T)$, monomer conversion $(X)$, number average molecular weight $\left(M_{n}\right)$ and weight average molecular weight $\left(M_{w}\right)$ at $2500 \mathrm{~atm}$. They used kinetic parameters from 
their earlier data. However, they assumed that the physical properties of reacting stream are constant throughout the reactor.

Baltsas et al. (1998) studied the application of pseudo-kinetic constant model in combination with methods of moments, to model the multi-component free radical polymerization of ethylene in a high-pressure tubular reactor. The simulation results were found to be in agreement with experimental data. Kinetic mechanism for ethylene copolymerization and multi-component polymerization were presented. They obtained reaction temperature, monomer conversion, molecular weight, branching frequency, copolymer composition, heat transfer coefficient, relative solution viscosity along the reactor length.

Brandolin et al. (1988) presented an extensive review of previous works done on this topic and then developed a mathematical model for ethylene polymerization in a highpressure multi-zone tubular reactor using oxygen as initiator. They also used reaction kinetics of oxygen initiation, termination by combination, transfer to polymer, transfer to chain transfer agent and $\beta$-scission. The model prediction of monomer conversion, molecular weight and long chain branching $(L C B)$ for different configurations and a range of operation conditions were comparable to the experimental results.

Brandolin et al. (1996) improved their previous work of 1988 and presented an exhaustive mathematical model for the high-pressure polymerization of ethylene in tubular reactors of configuration similar to that encountered in actual commercial plants. 
They considered multiple injections of monomer, mixture of initiators and chain transfer agents together with realistic flux configurations. The model can predict temperature, concentrations of reactants and products and molecular properties as a function of reactor length. The calculated results agree with experimental and actual plant data within a $10 \%$ error.

Chen et al. (1976) reported the most comparative model to describe tubular high-pressure polyethylene reactor. They considered reactions of peroxide initiation, termination by combination, transfer to polymer and $\beta$-scission. Their model envisages monomer conversion, molecular weight and its distribution (MWD). In their calculations, they used another model which predicts physical properties of polymerization with respect to reaction conditions along the reactor length.

Goto et al. (1981) reported a comparable experimental result using a kinetic model for vessel and tubular reactors in LDPE production. The tubular reactor was modeled as a sequence of over 5000 CSTRs with no back-mixing and simulated the polymerization under various conditions. They used kinetic data for five types of initiators and considered reactions of peroxide initiation, termination, transfer to monomer, and transfer to polymer, transfer to chain transfer agent, $\beta$-scission of secondary and tertiary radicals and backbiting. They predicted results for reaction temperature, pressure, monomer conversion, stream density, molecular weight and chain branches corresponding to change in temperature of initiator which are well in agreement with the experimental results. 
Gupta et al (1985) also presented a simulation model of tubular reactor in LDPE. They considered mechanisms for reactions as peroxide initiation, termination, transfer to polymer, transfer to transfer agent, $\beta$-scission of secondary and tertiary radicals and backbiting in a single zone case as referred by Chen et al., (1976) and Goto et al., (1981) papers. The prediction is given in terms of reaction temperature, monomer conversion, molecular weight and its distribution along reactor length.

Hollard and Ehrlich (1983) presented a simulation model which considers reactions of peroxide, oxygen and thermal initiation, termination and $\beta$-scission similar to the works of Chen et al. (1976) and Takahashi and Ehrlich (1982). It was concluded that oxygen behaves as a fast initiator.

Lacunza et al. (1998) presented a more comprehensive estimation of the overall heat transfer coefficient by using appropriate energy balances and a good set of experimental data. They proposed a predictive mode, in which all flow regimes as well as fouling effects were taken into account based on industrial reactor data. The work is considered to be an extension of Brandolin et al., (1996).

Mavridis and Kiparissides (1985) applied a dynamic optimization method to a highpressure polyethylene tubular reactor considering peroxide initiation, termination by combination and disproportionation, transfer to monomer, transfer to polymer, transfer to transfer agent and $\beta$-scission mainly similar to work of Lee and Marano (1979). They also performed sensitivity study of parameters in order to obtain an optimized 
performance in multiple initiators. They concluded that steady state hypothesis (SSH) for radical concentration is a valid assumption.

Shirodkar and Tsien (1986) reported a computerized mathematical model that developed to simulate LDPE free radical polymerization at high-pressure in either one or two-zone tubular reactor. They used a set of non-linear differential equations based on theoretical polymerization kinetics applied to a reactor with previously known heat transfer profile. They considered reactions of peroxide initiation, termination by combination and disproportionation, transfer to monomer, transfer to polymer, transfer to chain transfer agent, $\beta$-scission and back biting. The predicted conversion and temperature profiles agreed with actual plant data within a $10 \%$ error.

Yoon and Rhee (1985) reported a study of LDPE tubular reactor with reaction mechanism of peroxide initiation, termination by combination and disproportionation, transfer to monomer and polymer. They studied optimal temperature profiles and concluded that the axial mixing may be neglected and SSH is a valid assumption. However, they assumed that the physical properties of reacting stream are constant throughout the reactor.

Zabisky et al. (1992) reported results from their LDPE tubular reactor model compared with data obtained from an actual commercial plant. Their mathematical model is based on reaction mechanism of peroxide and oxygen initiation, terminations by combination and disproportionation, transfer to monomer, transfer to polymer, transfer to chain 
transfer agent, $\beta$-scission of terminal \& backbone radicals and backbiting. Then they used commercial software, called 'TUBULAR ${ }^{\circledR}$, to simulate operational tubular reactors using multiple initiators and multiple feed points. The method of moments is used in conjunction with pseudo kinetic rate constant to allow calculation of average molecular weight. Their simulation results generated from the model were compared with plant data, and have shown encouraging prospects for industrial application.

\subsection{Challenge of the technology}

As can be seen from the above, although there are some progresses made in this area by several contributors and the availability of experimental information from several different industrial reactors which are featured by different configurations and operating conditions, the research in this field still has not advanced yet either in having a realistic model for the process or in obtaining reasonable results that are based on reasonable assumptions. Hence, work in this field may focus on the formulation of a realistic model for the process, so as to serve the engineering goal of good prediction of operation performance; and one could focus on process optimization of the reactor to choose the optimal operations, where multi-functional initiators can be considered in actual plant operation.

Based on the reviews of earlier reports, the contributions through this research are:

1. developed his own models for mathematical tubular reactor, live radical and dead polymer;

2. built the density model for reaction stream; 
3. simulated real world LDPE tubular reactor using its reacting data as an input; and

4. used a new robust optimal control technology to obtain a maximized monomer conversion in term of the concentration. The comparison between optimal control and non-optimal one-shoot cases is given in the result section. 


\section{Reaction Mechanism}

Free radical ethylene polymerization is carried out at high pressure and elevated temperature. Different mechanism and kinetic models are used by different researchers. Several research groups (Brandolin et al., 1988; Brandolin et al., 1996; Dhib and AlNidawy 2002; Chen et al., 1976; Goto et al., 1981; Hollard and Ehrlich, 1983; Tatsukami et al., 1980; and Zabisky et al., 1992) presented their mechanisms for the high-pressure polymerization of ethylene in tubular reactors. Some of these reactor configurations are similar to that encountered in industry.

\subsection{Summary of Mechanism}

The crucial thermodynamic setting in which the reaction should take place triggers a complicated chain of reactions. As reported by Dhib and Al-Nidawy (2002), the effects of thermal polymerization become important and cannot be neglected for reaction temperatures between $150^{\circ} \mathrm{C}$ to $250^{\circ} \mathrm{C}$. Transfer to non-saturated telogens such as propylene, generates radical having end double bonds, which favour long chainbranching. However, under intense heat effects, the growing polymer radicals may undergo $\beta$-scission or breaking-up at the secondary or tertiary carbon atoms in the backbone, which results dead polymer chains with low molecular weights, thus affecting the polymer properties. Besides, under these thermal conditions, organic peroxides especially those with more than one oxygen-oxygen bond may become unstable and 
undergo undesirable reactions, in which case either reaction mechanism or products are not easily predictable (Luft et al., 1977).

After surveying most of previous comparative works, which include the molecular weight, long and short chain branching (methyl, vinyl and vinylidene groups), this proposed kinetic mechanism attempts to account for the important elementary reactions that are likely to occur in the industrial tubular reactor. The reactions considered include initiation, propagation, termination, transfer to monomer and polymer, backbiting, $\beta$ scission, reactions with terminal double bonds, and run-away decomposition of monomer and polymer.

There are two initiation reactions to be considered. First, the decomposition of peroxide initiator forms two free radicals. The radicals grow rapidly by combining with monomers. Secondly, monomer may also thermally combine to form a radical in a high temperature $\left(150^{\circ} \mathrm{C}\right.$ to $\left.250^{\circ} \mathrm{C}\right)$, called thermal initiation reaction. Buback, M. (1980) reported this is a slow polymerization reaction in absence of initiators and it is a third order reaction [as shown in equation (2) in Section 3.2.1 below].

Propagation is a series of reactions occurring between monomer and radicals. Also to be considered is the propagation of terminal reaction by double-bonds even though the concentration of these terminal double bonds in relation to the concentration of all double bonds available as monomer is quite small (due to low conversion of monomer). 
Termination can occur by combination, disproportionation and thermal disproportionation. The reactions of termination by disproportionation, $\beta$-scission and transfer to monomer produce chain ends where double bonds exist. These double bonds might react with radicals, via a propagation reaction, producing internal radicals that can propagate to form long chain branches.

Although termination by disproportionation has been considered negligible by some investigators, others considered these in different forms. The reaction is either a combination by two radicals with the same or different chain length, or a disproportionation to form two different dead polymers, or radical thermal degradation to form a dead polymer and a free radical.

Chain transfer consists of a set of transfer reactions. These reactions could include: transfer to monomer, which forms a monomer transfer radical and a dead polymer chain; transfer to solvent (modifier) and/or agent, which forms a dead polymer chain and the transfer radical; and finally transfer to polymer, which leads to long chain branching because the reaction involves the transfer of reactivity from radical type to a monomer unit in a dead polymer chain to form a radical with the active centre along the chain. In the case where a monomer is present, propagation leads to long chain branching ( $L C B)$. For general phenomena, $L C B$ probably arises from abstraction by a growing radical of a hydrogen atom from the backbone of a polymer chain (Small et al., 1972). 
Internal molecular reaction consists of different reactions. An internal radical centre is a radical located on a backbone carbon atom and is generally formed by two reactions namely transfer to polymer and backbiting. These internal radical centers can, in theory, undergo all of the reactions that chain-end radicals do. Propagation leads to branches. According to Goto et al., (1981), the branch types depend on the formation mechanism of a) transfer to polymer which leads to long chain branches, and b) backbiting which leads to short chain branches. This is because the radical activity is transferred to a site along the same chain, and this site may propagate leaving a short chain branch. In another words, the growing radical carbons go back to its own chain, thus transforming the free radical back to another carbon from the growing end.

In addition, these internal radicals could undergo a $\beta$-scission reaction to form two smaller chains. Both $\beta$-Scission to secondary and/or tertiary radical are additional reactions to the propagation, in which the internal radicals may undergo scission to form two smaller radicals and dead polymer chains, one with a terminal double bond. Actual reaction may be a two-step reactions: the first step is the attack of a dead polymer chain by a radical, forming an internal radical; the second step is the $\beta$-scission reaction.

Decomposition occurs in a high temperature, where decomposition of monomer and polymer form a variety of lower molecular weight products. A runaway reactor may result in a huge pressure increase due to the rapid evolution of small molecules via these decomposition reactions. The phenomenon known as autocatalytic in nature not only occurs in decomposition of monomer and polymer but also in initiator. Generally, 
explosion or decomposition reaction results in high temperature where reactions become faster.

\subsection{Mechanism Expression}

In the following expressions, $M, P$ and $I$ stand for the monomer, the polymer and the initiator, and $m, p$ and $i$ stand for their reactive concentrations, respectively.

\subsubsection{Initiation}

As described in Section 3.1, the initiation includes initiator's initiation and thermal initiation of monomer.

Initiator

$$
\begin{aligned}
& I \stackrel{K_{\mathcal{d}}}{\longrightarrow} 2 R_{\text {in }} \cdot \\
& R_{\text {in }}+M \stackrel{K_{1}}{\longrightarrow} R_{1} \cdot
\end{aligned}
$$

Thermal Initiation

$$
3 M \stackrel{K_{t h}}{\longrightarrow} 2 R_{1}^{\cdot}
$$




\subsubsection{Propagation}

Propagation of monomer with radicals:

$$
R_{r}^{\bullet}+M \stackrel{K_{e}}{\longrightarrow} R_{r+1}^{\bullet} \quad r \geq 1
$$

Propagation of terminal reaction by double-bonds:

$$
R_{r}^{\bullet}+P_{s} \stackrel{K_{p d b}}{\longrightarrow} R_{r+s} \cdot \quad r \geq 1
$$

\subsubsection{Termination}

Termination by Combination

$$
R_{r}^{\bullet}+R_{s}^{\bullet} \stackrel{K_{c c}}{\longrightarrow} P_{r+s} \quad r, s \geq 1
$$

or by disproportionation:

$$
R_{r}^{\bullet}+R_{s}^{\bullet} \stackrel{K_{t d}}{\longrightarrow} P_{r}+P_{s} \quad r, s \geq 1
$$

or by thermal degradation: 


$$
R_{r+1} \stackrel{\bullet}{\stackrel{K_{\text {thd }}}{\longrightarrow}} P_{r}+R_{1}^{\bullet} \quad r \geq 1
$$

\subsubsection{Chain Transfer reaction}

Transfer to monomer:

$$
R_{r}^{\bullet}+M \stackrel{K_{m m}}{\longrightarrow} P_{r}+R_{1}^{\bullet} \quad r \geq 1
$$

Transfer to solvent:

$$
R_{r}^{\bullet}+S \stackrel{K_{m}}{\longrightarrow} P_{r}+R_{1}^{\bullet} \quad r \geq 1
$$

Transfer to polymer:

$$
R_{r}^{\bullet}+P_{s} \stackrel{K_{t p p}}{\longrightarrow} P_{r}+R_{s}^{\bullet} \quad r, s \geq 1
$$

\subsubsection{Internal molecular reactions}

Backbiting (intermolecular transfer): 


$$
R_{r} \stackrel{K_{b}}{\longrightarrow} R_{b r}^{\bullet} \quad r, b r \geq 1
$$

R-Scission to Secondary Radical:

$$
R_{r+1} \stackrel{K_{\beta}}{\longrightarrow} P_{r}+R_{1}^{\bullet} \quad r \geq 1
$$

B-Scission to tertiary Radical:

$$
R_{r+1} \stackrel{K_{\beta 1}}{\longrightarrow} P_{r}+R_{1} \cdot r \geq 1
$$




\section{Mathematical Model Development}

By applying molar and energy balances of monomer, initiator, and live and dead polymer as described in details in Appendix A, and three assumptions of
a. plug flow without axial-dispersion;
b. equal reaction mixture phase; and
c. steady-state hypothesis

for the reactor, it leads to an infinite set of coupled differential equations. To account for the average molecular weight distribution $(M W D)$ of the radical and polymer species, the method of moments may be employed to overcome this mathematical complexity. Konstadinidis et al. (1992) provided the comprehensive method to describe the polymerization of branched polymers based on several pioneer researches: Katz and Saidel, (1967); Saidel and Katz, (1968); Chen et al., (1976); Ray and Laurence, (1977). It recently used by Zabisky et al., (1992), Brandolin et al., (1996) and Dhib and Al-Nidawy (2002).

In this work, we focus on the steady state version of the balances derived in Appendix A. The reason is that the time required to reach a steady state in this plug flow reactor is negligible, and not at practical interest due to extremely high velocity and fast reaction kinetics.

The first four moments of the distribution are included in the balances for the complete MWD calculation, while the first three moments are included in the balances to calculate 
the number and weight molecular weights. This approach is similar to that applied by Zabisky et al., (1992) and Metzler et al., (1973).

\subsection{Live Radical Model}

The method of moments is a relatively simple method to calculate MWD. Moments of live radical chain length distribution are defined by writing balance on the radical of chain length $r$, multiplying each term by the appropriate power of $r$ and summing them from $r=0$ to $\infty$ :

$$
\lambda_{j}=\sum_{r=0}^{\infty} r^{j} R_{r}
$$

Performing molar balance of initiation radicals $(r=1)$ and live radicals whose chain length $r \geq 2$, gives the following two expressions:

$$
\begin{aligned}
& d R_{1} / d z= {\left[2 f_{i} k_{d} i+2 K_{t h} m^{3}-K_{p} m R_{1}-\left(K_{t c}+K_{t d}\right) R_{1} \sum_{s=1}^{\infty} R_{s}-K_{t r p} \mu_{1} R_{1}\right.} \\
&\left.+\left(K_{t r s} s+K_{t r m} m+K_{t h d}+K_{\beta}+K_{\beta 1}\right)\left(\sum_{r=1}^{\infty} R_{r}-R_{1}\right)-R_{1} \frac{d v}{d z}\right] / v \\
& d R_{r} / d z=\left[K_{p} m R_{r-1}-K_{p} m R_{r}-\left(K_{t c}+K_{t d}\right) R_{r} \sum_{r=1}^{\infty} R_{r}+\left(K_{t r s} s+K_{t r m} m+K_{t h d}+K_{\beta}+K_{\beta 1}\right) R_{r}\right. \\
&+
\end{aligned}
$$


By substituting Equation (15) and (16) into the general expression of radical moment equation

$$
d \lambda_{j} / d z=d R_{1} / d z+\sum_{r=2}^{\infty} r^{j}\left(d R_{r} / d z\right)
$$

a set of differential equations can be obtained:

$$
\begin{aligned}
d \lambda_{0} / d z= & \left(2 f_{i} K_{d} i+2 K_{t h} m^{3}-\left(K_{t c}+k_{t d}\right) \lambda_{0}^{2}-\lambda_{0} d v / d z\right) / v \\
d \lambda_{1} / d z= & {\left[2 f_{i} k_{d} i+2 K_{t h} m^{3}-\left(K_{t c}+K_{t d}\right) \lambda_{1} \lambda_{0}-\left(K_{t r m} m+K_{t r s} s+K_{t h d}+K_{\beta}+K_{\beta 1}\right) \lambda_{1}\right.} \\
& \left.+K_{p} m \lambda_{0}+K_{t r p}\left(\lambda_{0} \mu_{2}-\lambda_{1} \mu_{1}\right)-\lambda_{1} d v / d z\right] / v \\
d \lambda_{2} / d z= & {\left[2 f_{i} k_{d} i+2 K_{t h} m^{3}-\left(K_{t c}+K_{t d}\right) \lambda_{2} \lambda_{0}-\left(K_{t r m} m+K_{t r s} s+K_{\beta}+K_{t h d}+K_{\beta 1}\right) \lambda_{2}\right.} \\
& \left.+2 K_{p} m \lambda_{1}+K_{t r p}\left(\lambda_{0} \mu_{3}-\lambda_{2} \mu_{1}\right)-\lambda_{2} d v / d z\right] / v \\
d \lambda_{3} / d z= & {\left[2 f_{i} k_{d} i+2 K_{t h} m^{3}-\left(K_{t c}+K_{t d}\right) \lambda_{3} \lambda_{0}-\left(K_{t r m} m+K_{t r s} s+K_{\beta}+K_{\beta 1}\right) \lambda_{3}\right.} \\
& \left.+3 K_{p} m \lambda_{2}+K_{t r p}\left(\lambda_{0} \mu_{4}-\lambda_{3} \mu_{1}\right)-\lambda_{3} d v / d z\right] / v
\end{aligned}
$$

For the radical moments, many researchers (Mavridis and Kiparissides 1985; Yoon and Rhee, 1985) find that there is a little difference in results when SSH or non - SSH is 
made. Moreover, the $\lambda_{j}$, for $\mathrm{j}=0,1,2,3$, are in the range of $10^{-5} \sim 10^{-7}$, hence it may be assumed:

$$
d\left(\lambda_{j} v\right) / d z=0 \text { for } j=0,1,2 \text { and } 3
$$

Therefore, the live radical concentrations may be given by the following algebraic equations using equations (17) to (21):

$$
\begin{aligned}
& \lambda_{0}=\left(\frac{2 f_{i} K_{d} i+2 K_{t h} m^{3}}{K_{t c}+K_{t d}}\right)^{1 / 2} \\
& \lambda_{1}=\frac{2 f_{i} K_{d i} i+2 K_{t h} m^{3}+K_{p} m \lambda_{0}+K_{t r p} \lambda_{0} \mu_{2}}{\left(K_{t c}+K_{t d}\right) \lambda_{0}+\left(K_{t r m} m+K_{t r s} s+K_{t h d}+K_{\beta}+K_{\beta 1}\right)+K_{t r p} \mu_{1}} \\
& \lambda_{2}=\frac{2 f_{i} K_{d i} i+2 K_{t h} m^{3}+2 K_{p} m \lambda_{1}+K_{t r p} \lambda_{0} \mu_{3}}{\left(K_{t c}+K_{t d}\right) \lambda_{0}+\left(K_{t r m} m+K_{t r s} s+K_{t h d}+K_{\beta}+K_{\beta 1}\right)+K_{t r p} \mu_{1}} \\
& \lambda_{3}=\frac{2 f_{i} K_{d i} i+2 K_{t h} m^{3}+3 K_{p} m \lambda_{2}+K_{t p p} \lambda_{0} \mu_{4}}{\left(K_{t c}+K_{t d}\right) \lambda_{0}+\left(K_{t r m} m+K_{t r s} s+K_{t h d}+K_{\beta}+K_{\beta 1}\right)+K_{t r p} \mu_{1}}
\end{aligned}
$$

The solution to molecular weight distribution was also employed by Zabisky et al., (1992), Dhib and Al-Nidawy (2002).

Notice should be made that these equations include several variables, such as $m, i$ and $\mu_{j}$ $(j=0,1,2$, and 3$)$, which are involved in polymer model and reactor model as described below. 


\subsection{Polymer Model}

Similarly, based on equation (10), (12) and (13), balance on the polymer chains of length $r$, gives:

$$
\begin{aligned}
d p_{r} / d z= & {\left[K_{t d} R_{r} \sum_{s=1}^{\infty} R_{S}+\frac{1}{2} K_{t c} \sum_{s=1}^{r-1} R_{r-s} R_{s}+K_{t h d} R_{r}\right.} \\
& +K_{t r p}\left(R_{r} \mu_{1}-\lambda_{0} r \sum_{s=1}^{r-1} p_{s}\right)+\left(K_{t r s} s+K_{t r m} m+K_{\beta}+K_{\beta 1}\right) R_{r} \\
& \left.-p_{r} \frac{d v}{d z}\right] / v
\end{aligned}
$$

Applying the defined moments of the polymer size distribution equation, which multiplies (27) by the appropriate power of $r$ and then sum:

$$
\mu_{j}=\sum_{r=1}^{\infty} r^{j} p_{r}
$$

gives:

$$
\begin{aligned}
d \mu_{0} / d z= & {\left[K_{t d} \lambda_{0}^{2}+\frac{1}{2} K_{t c} \lambda_{0}^{2}+\left(K_{t r s} s+K_{t r m} m+K_{b}+K_{\beta}+K_{\beta 1}\right) \lambda_{0}\right.} \\
& \left.+K_{t h d} \lambda_{0}-\mu_{0} d \rho / d z\right] / d z \\
d \mu_{1} / d z & =\left[K_{t d} \lambda_{0} \lambda_{1}+K_{t c} \lambda_{0} \lambda_{1}+\left(K_{t r s} s+K_{t r m} m+K_{b}+K_{\beta}+K_{\beta 1}\right) \lambda_{1}\right. \\
& \left.+K_{t h d} \lambda_{1}+K_{t r p}\left(\lambda_{1} \mu_{1}-\lambda_{0} \mu_{2}\right)-\mu_{1} d \rho / d z\right] / d z
\end{aligned}
$$




$$
\begin{aligned}
d \mu_{2} / d z & =\left[K_{t d} \lambda_{0} \lambda_{2}+K_{t c}\left(\lambda_{0} \lambda_{2}+\lambda_{1}^{2}\right)+\left(K_{t r s} s+K_{t r m} m+K_{b}+K_{\beta}+K_{\beta 1}\right) \lambda_{2}\right. \\
& \left.+K_{t h d} \lambda_{2}+K_{t r p}\left(\lambda_{2} \mu_{1}-\lambda_{0} \mu_{3}\right)-\mu_{2} d \rho / d z\right] / d z
\end{aligned}
$$

It is observed that there is a higher moment, $\mu_{3}$, in equation (31). Therefore it may not be a closed solution available for solving the above equations. However, several investigators (Zabisky et al., 1992; Dhib and Al-Nidawy, 2002) applied the closure method of Hulburt and Katz (1964), which gives:

$$
\mu_{3}=\frac{\mu_{2}}{\mu_{1} \mu_{0}}\left(2 \mu_{2} \mu_{0}-\mu_{1}^{2}\right)
$$

to obtain a solution for equations (29) to (31). Comparing simulation result and the data from actual commercial plant, Zabisky et al., (1992) found that the above formulation is applicable.

Numerical solution of these equations allows the computation of some of the product properties, such as:

Number-average molecular weight:

$$
\overline{M_{n}}=M_{w m} \frac{\mu_{1}+\lambda_{1}}{\mu_{0}+\lambda_{0}}
$$

Weight-average molecular weight: 


$$
\overline{M_{w}}=M_{w m} \frac{\mu_{2}+\lambda_{2}}{\mu_{1}+\lambda_{1}}
$$

where, $\mathrm{M}_{\mathrm{wm}}$ is the monomer molecular weight.

\subsection{Mathematical Tubular Reactor Model}

Once stream of reactant mixture enters the reactor and reactions proceed, the monomer and initiators are continuously consumed to produce polymer. A set of reactions as explained in 3.2 will take place and concentrations as well as densities will be changed along the reactor length. Following balance equations are used in development of the model.

\subsubsection{Mass and Energy Balance}

The changes are described by a set of high nonlinear differential equations obtained by applying mass and energy balance (Appendix A, Bird et al., 1960; Yao et al., 2004; and Luyben 1990). The equations are as follow:

(A) Mass balance

The overall mass balance 


$$
\begin{gathered}
\frac{d}{d z}(\rho v)=0 \\
\Rightarrow \quad \frac{d v}{d z}=-\frac{v}{\rho} \frac{d \rho}{d z}
\end{gathered}
$$

Peroxide initiator

$$
d(i v) / d z=-2 f_{i} k_{d} i
$$

$\Rightarrow \quad d i / d z=-\left(2 f_{i} K_{d} i+i d v / d z\right) / v$

Monomer (from equations of (3), (2) and (8), respectively)

$$
\begin{gathered}
d(m v) / d z=-K_{p} m \lambda_{0}-2 K_{t h} m^{3}-K_{t r m} m \lambda_{0} \\
\Rightarrow \quad d m / d z=-\left(K_{p} m \lambda_{0}+2 K_{t h} m^{3}+K_{t r m} m \lambda_{0}+m d v / d z\right) / v
\end{gathered}
$$

Solvent

$$
d s / d z=-\left(K_{t r s} s \lambda_{0}+s d v / d z\right) / v
$$

(B) Energy balance 
Energy balance results in the temperature profiles and the concerned heat transfer issues, which include reaction temperature and jacket temperature.

In heating and reaction zones:

$$
d T / d z=\frac{1}{\rho C_{p} v}\left(\left(-\Delta H_{p} K_{p} m \lambda_{0}\right)-\frac{4 U}{D_{i n}}\left(T-T_{c}\right)\right)
$$

In cooling zones:

$$
d T / d z=\frac{1}{\rho C_{p} v}\left(-\frac{4 U}{D_{i n}}\left(T-T_{c}\right)\right)
$$

Jacket Temperature in a Single Liquid Phase:

$$
d T_{c} / d z=\frac{\pi U D_{i n}\left(T-T_{c}\right)}{\rho_{c} C_{p c} G_{c}}
$$

\subsubsection{Pressure Effects}

From the definition of the fanning friction factor for turbulent flow (Re is in the range of $1 \times 10^{5}$ to $1 \times 10^{6}$ ) with consideration of linear velocity of reacting stream, pressure profile in reaction mixture can be expressed as: 


$$
d P / d z=-\rho\left(\frac{2 f_{r} v^{2}}{D_{i n}}+v \frac{d v}{d z}\right)
$$

where, $f_{r}$ is the fanning friction factor, which is in the range of:

$$
0.01>f_{r}>0.0791 / \operatorname{Re}^{1 / 4}
$$

Pressure drop across the pulse valve (Pulse valve effects):

$$
\Delta P_{P V_{1}}=\Delta P_{P V_{i-1}}\left(1+\alpha\left(\frac{P_{f_{i}}-P_{f_{1-1}}}{P_{f_{1-1}}}\right)\right)
$$

Hence, the reaction pressure changes to:

$$
P=P_{f_{1}}-\Delta P_{P V_{1}} e^{-\beta\left(t-t_{p}\right)}
$$

\subsubsection{Reacting mixture density}

Benedict et al., (1940) developed a so called BWR model to predict density values of pure and impure ethylene mixture. A regression method (Brandolin et al., 1988) normally 
has been employed to simulate the density of reacting mixture feed, which may be expressed as a polynomial function:

$$
\rho=a+b T+c T^{2}+d P+e P^{2}+f T P
$$

where, $a, b, c, d, e$ and $f$ depend on the mixture composition and can be fitted to experimental data as reported by Goldman, K. (1969) using differential equation derived from equation (48) above:

$$
d \rho / d z=b \frac{d T}{d z}+2 c T \frac{d T}{d z}+d \frac{d P}{d z}+2 e P \frac{d P}{d z}+f\left(T \frac{d P}{d z}+P \frac{d T}{d z}\right)
$$

As can be seen from Figure 5 and Figure 6, using Equation (48) results to a lower density prediction at high pressure range (above $1200 \mathrm{~atm}$.). Hence, this model can not used as a prediction model.

Due to this shortcoming of the least-square, the density of reacting mixture as suggested by Chen, et al., 1976 can be expressed as the equation (B9), which is employed in this study. Hence, we can express the density as a function of monomer concentration, temperature, pressure and distance along the reactor length, $\rho=\rho(m, T, P, z)$, which can be detailed as the following equation in a constant pressure:

$$
\partial \rho / \partial z=\frac{\partial \rho}{\partial T} \frac{\partial T}{\partial z}+\frac{\partial \rho}{\partial m} \frac{\partial m}{\partial z}
$$


where,

$$
d \rho / d T=\frac{0.01436 \mathrm{~m} \times 10^{-4}-2.5245 \times 10^{-4}+(31.6967-1.25 \mathrm{~m}) \times 10^{-8} T-99.8877 \times 10^{-12} T^{2}}{\left(0.710-4.475 \times 10^{-4} T\right)^{2}\left(0.949+4.988 \times 10^{-4} T\right)^{2}}
$$

and

$$
\frac{\partial \rho}{\partial m}=0.028\left(1-\frac{0.710-4.475 \times 10^{-4} T}{0.949+4.988 \times 10^{-4} T}\right)
$$

These sub-models as showed from Equation (50)-(52) are used in development of the ethylene polymerization in a high pressure tubular reactor as applied in Chapter 5. They are obviously a combination of the methods of Chen et al., (1976) and Benedict et al., (1940). 
Experimental Density from Data in "Goldman, K. (1969)" pp150-167

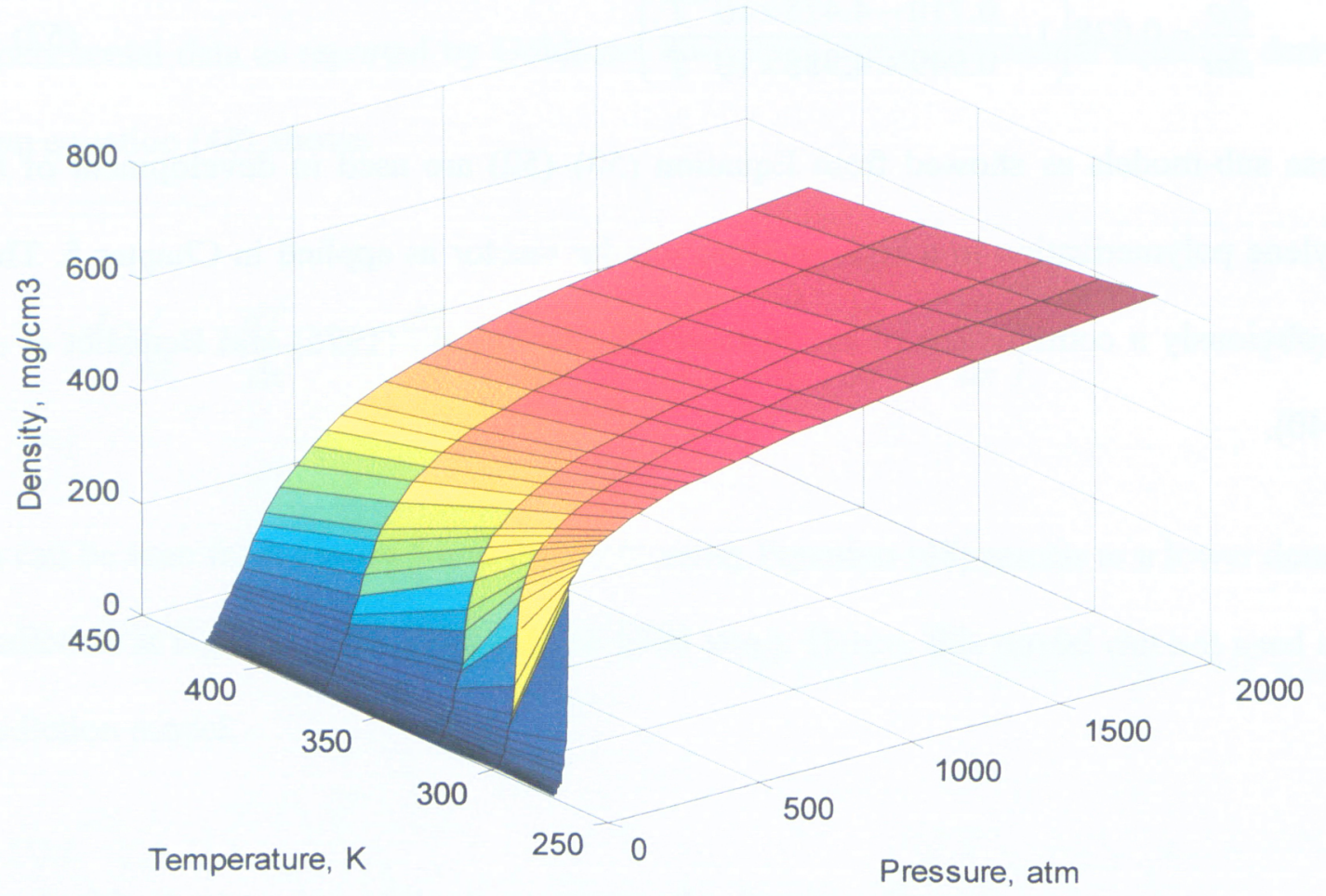

Figure 5. Monomer Densities from Experimental Data at Pressure versus Temperature 
Data-Fitted Density using "Least-Square" Method

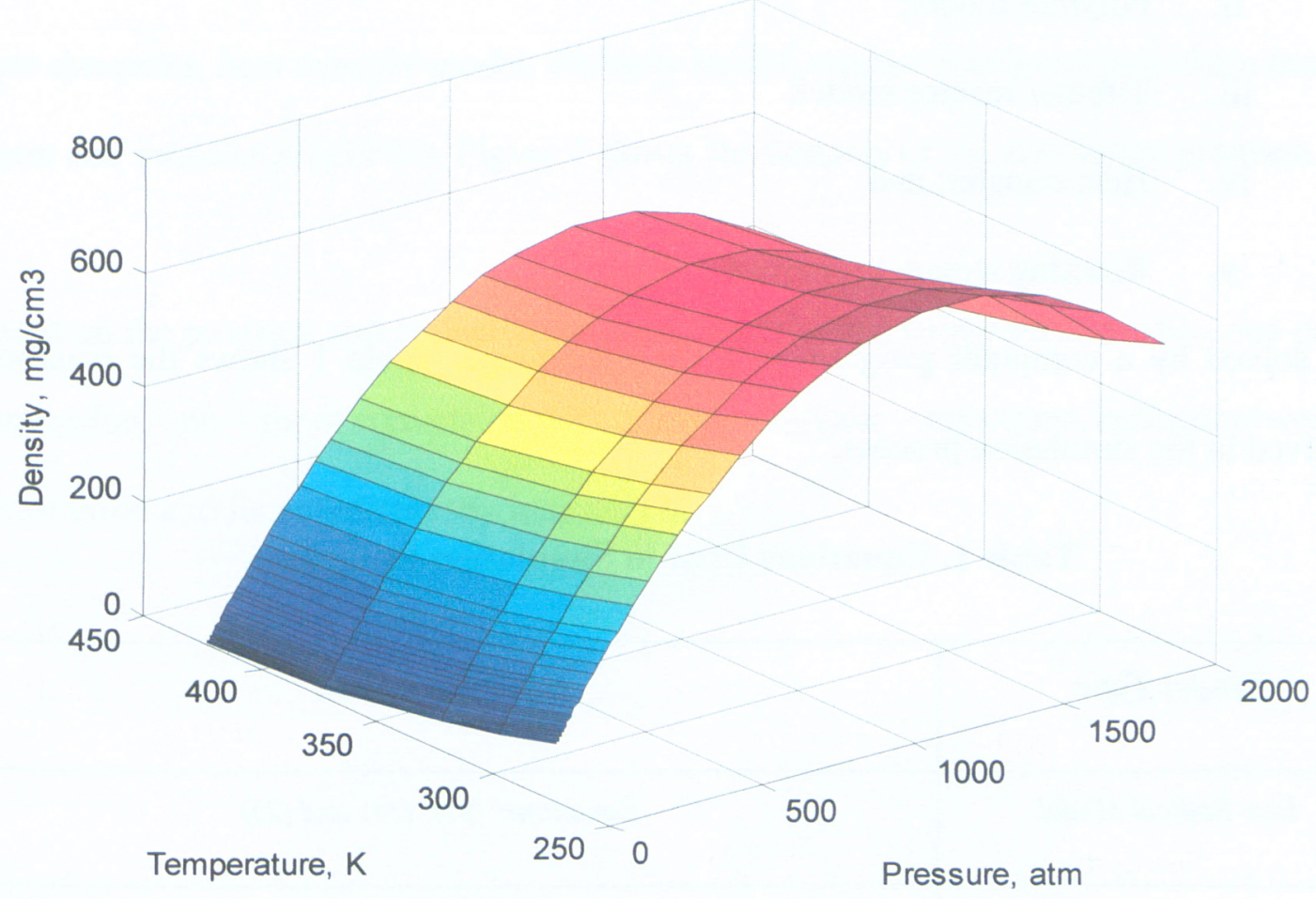

Figure 6. Modeled Monomer Densities after Data-Fitting to Polynomial Model 


\section{Simulation Results}

The developed mathematical model for free radical ethylene polymerization in a multizone tubular reactor, which consists of

i. Radical model;

ii. Polymer model;

iii. Tubular reactor model;

iv. Heat transfer; and

v. Reacting stream properties

was solved by a computer program in a $C++$ language. Table 1 shows the equations involved in the simulation process.

Table 1. Equations Used in Simulation Program

\begin{tabular}{|c|c|}
\hline Model Type & Equations Used \\
\hline Live Radical Model & Equations: (23), (24) and (25) \\
\hline Polymer Model & Equations: (29)-(34) \\
\hline Tubular Reactor Model & Equations: (36), (38), (40), (41), (42)-(44) and (50)-(52) \\
\hline Heat Transfer Model* & Equations: (53), (B12), (B14) and (B17) \\
\hline Viscosity, Flow Dynamics* & Equations: (B4)-(B6), (B11), (B13) and (B15) \\
\hline Physical Properties*, Others & Equations: (B4)-(B10) and (55)-(57) \\
\hline
\end{tabular}

*Subjects to all these items in Appendix B are involved in simulation and could not be separated. 


\subsection{The Simulation Program}

The simulation program uses a fifth-order Runge-Kutta Fehlberg method (see Appendix D) with Case-Carp parameters, and adaptive step control in $C++$ language. In order to have a successful simulation, a large number of physical, chemical and thermodynamic data has to be collected and determined with consideration of polymerization kinetics, flow dynamics, heat transfer model, viscosity model, reactor configuration, chain transfer agent and initiator properties. Figure 7 shows the features of the simulation program.

Based on the program and collected data, we can calculate temperature profile, one pass conversion, one - shoot conversion with multiple initiator - injections, molecular weight distribution and its polydispersity index, $P D I$. 


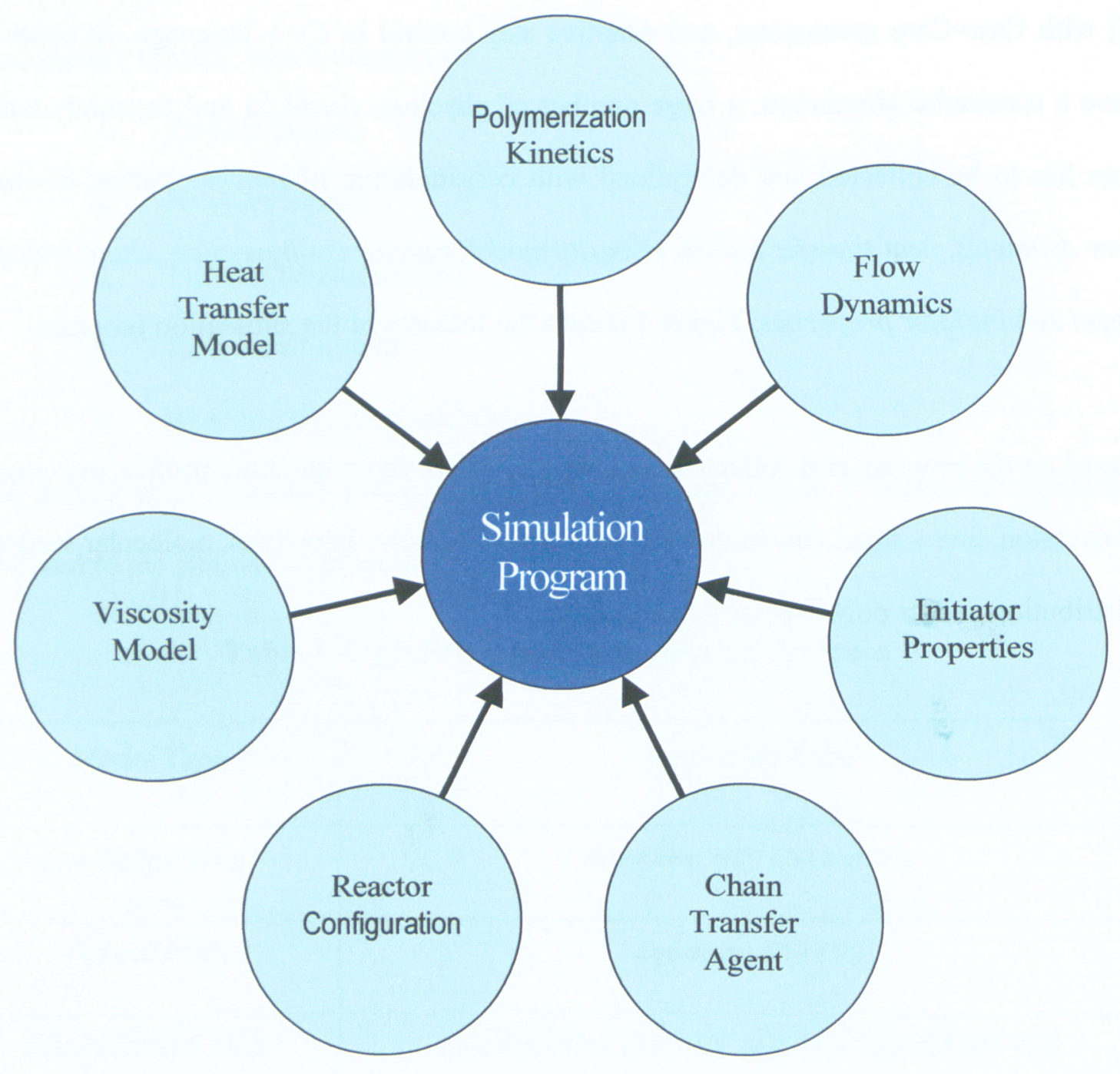

Figure 7. Features of Simulation Program 


\subsection{Assumptions in the model}

In order to simplify simulation process, the following assumptions are made.

\subsubsection{Heat Capacity}

The heat capacity of the reaction mixture is the mass weighted sum of the heat capacities of the pure components.

\subsubsection{Heat Transfer Coefficient for the Whole Tubular Wall}

With taking the film convection coefficient at the jacket side, metal wall coefficient and fouling effect into a whole wall coefficient $h_{w}$, the following overall heat transfer coefficient (Chen, et al., 1976) is assumed to be given by:

$$
\frac{1}{U}=\frac{1}{h_{i}}+\frac{1}{h_{w}}
$$

where, $h_{i}$ is the calculated heat transfer coefficient in reacting side; $h_{w}$ is the selected coefficient from experimental data. The simulation results of Gupta, et al., (1985) indicated that the value of $h_{w}$ doesn't affect temperature profile and the final product properties in a large scale reactor. Hence in this work a constant value is assumed.

\subsubsection{Constant Reaction Pressure}

Some researchers (Brandolin et al., 1988; Zabisky et al., 1992; Brandolin et al., 1996) considered the pulse valve effect to the reaction pressure, which causes around $10 \%$ of pressure change. In this study, we assume that the reaction pressure is a constant. 


\subsubsection{Effect to multiple initiator injection}

Comparing to reacting stream, the amount of injected initiator is very small; hence it can be assumed that its effect to flow dynamic, viscosity, heat transfer is negligible.

\subsubsection{Reaction heat}

It is assumed that propagation is the only thermally relevant step (Brandolin, et al., 1988) to be considered in energy balance.

\subsection{Consideration of simulation parameters}

Current literature reports a very wide range of values for each kinetic parameter. Moreover, each research group uses industrial or experimental data, such as conversions, temperature profiles and molecular properties, to adjust the constants. As a result, each set of parameters can be only used for the calculation of a typical reactor and can not be used for scale up or for the design of new reactors having different configuration or for those reactors which have different operating conditions.

It's observed that it is very important to select the activation energy carefully to avoid simulation overshoot. It seems that the numerical solution is very sensitive to combination of high activation energy and high temperature.

Table 2 shows operating parameters, which is typically used in industrial reactors. The rate constants in Table 3 were carefully selected from Dhib and Al-Nidawy (2002) and 
Brandolin et al., (1996). Some data used in the model were in discrete format. Different best-fill models were developed and tested for the available ranges before application in the simulation model.

Dioctanoyl Peroxide (Seidl et al., 1981; Dhib and Al-Nidawy 2002) is the only initiator which is used in this study. The related parameters are listed in Table 4.

Table 2 Parameters for this study

\begin{tabular}{lll}
\hline Symbol & Unit & Parameter Value \\
\hline$-\Delta H_{p}$ & cal/mol & 23,000 \\
$f$ & - & 0.65 \\
$f_{p d b}$ & - & 0.40 \\
$D_{\text {in }}$ & $\mathrm{cm}$ & 5.06 \\
$L$ & $\mathrm{~cm}$ & 127,000 \\
$m_{o}$ & $\mathrm{~mol} / \mathrm{l}$ & 19.41 \\
$i_{o}$ & $\mathrm{~mol} / \mathrm{l}$ & $1.5 \times 10^{-3}$ \\
$T_{o}$ & ${ }^{\circ} \mathrm{C}$ & 140 \\
$T_{c o}$ & ${ }^{\circ} \mathrm{C}$ & 139 \\
$v_{o}$ & $\mathrm{~cm} / \mathrm{s}$ & 1,880 \\
$P$ & $\mathrm{~atm}$ & 2,000 \\
\hline
\end{tabular}


Table 3 Rate constant used in this work: $K=A^{*} \exp \left(-E / R_{1} T-\Delta v P / R_{2} T\right)$

\begin{tabular}{llll}
\hline Rate constant & $A$ & $E(\mathrm{cal} / \mathrm{mol})$ & $\Delta v\left(\mathrm{~cm}^{3} / \mathrm{mol}\right)$ \\
\hline$K_{t h}$ & $6.04 \times 10^{3}(1 / \mathrm{s})$ & $72,945.00$ & 0.00 \\
$K_{p}$ & $9.90 \times 10^{5}(1 / \mathrm{mol} \cdot \mathrm{s})$ & $4,210.00$ & -5.60 \\
$K_{t c}$ & $4.35 \times 10^{8}(1 / \mathrm{mol} \cdot \mathrm{s})$ & $3,650.00$ & 9.20 \\
$K_{t r m}$ & $1.20 \times 10^{5}(1 / \mathrm{mol} \cdot \mathrm{s})$ & $14,400.00$ & -20.00 \\
$K_{t r p}$ & $1.80 \times 10^{8}(1 / \mathrm{mol} \cdot \mathrm{s})$ & $9,400.00$ & 0.00 \\
$K_{\beta}$ & $1.40 \times 10^{9}(1 / \mathrm{mol} \cdot \mathrm{s})$ & $19,100.00$ & -9.90 \\
$K_{\beta l}$ & $4.40 \times 10^{9}(1 / \mathrm{s})$ & $19,100.00$ & -9.90 \\
$K_{t d}$ & $3.246 \times 10^{8}(1 / \mathrm{mol} \cdot \mathrm{s})$ & 242.00 & 0.00 \\
$K_{t r s}$ & $5.6 \times 10^{7}(1 / \mathrm{s})$ & $10,032.00$ & 9.90 \\
$K_{p d b}$ & $1.40 \times 10^{6}(1 / \mathrm{s})$ & $6,100.00$ & 0.00 \\
$K_{b}$ & $3.25 \times 10^{5}(1 / \mathrm{s})$ & $7,474.00$ & 0.00 \\
\hline$W h$ & &
\end{tabular}

Where, $R_{1}=1.9872 \mathrm{cal} / \mathrm{mol} \cdot \mathrm{K}, R_{2}=82 \mathrm{~cm}^{3} \mathrm{~atm} / \mathrm{mol} \cdot \mathrm{K}$

Table 4 Decomposition rate constant initiator: $K_{d}=A_{1} \exp \left(-E_{1} / R_{1} T-\Delta v_{1} P / R_{2} T\right)$

\begin{tabular}{llcl}
\hline Initiator & $A_{1}(1 / \mathrm{s})$ & $E_{1}(\mathrm{cal} / \mathrm{mol})$ & $\Delta v_{1}\left(\mathrm{~cm}^{3} / \mathrm{mol}\right)$ \\
\hline Dioctanoyl Peroxide & $2.2925 \times 10^{14}$ & $30,131.70$ & 5.9 \\
\hline Where, $R_{I}=1.9872 \mathrm{cal} / \mathrm{mol} \cdot \mathrm{K}, R_{2}=82 \mathrm{~cm}^{3} \mathrm{~atm} / \mathrm{mol} \cdot \mathrm{K}$ &
\end{tabular}




\subsection{Case study}

In this research work, it used two cases for simulation of LDPE tubular reactor with the design parameters described in Table 5. For both of them, an inlet temperature of $140^{\circ} \mathrm{C}$ of reactant stream in the similar inlet initiator concentration but different initiator concentration at the stages was selected. A series configuration is used in the two case studies.

Also the effects of different inlet temperatures, jacket temperatures and monomer and initiator concentrations could be analyzed for these two cases.

Table 5 Case description

\begin{tabular}{lll}
\hline Items & CASE I & CASE II \\
Ratio L/D $i$ & $2.51 \times 10^{4}$ & $2.51 \times 10^{4}$ \\
Number of heat exchange zones & 6 & 2 \\
Location of monomer injection point, $\mathrm{cm}$ & 0 & 0 \\
Initiator concentration at inlet, mol/ & $15 \times 10^{-4}$ & $15 \times 10^{-4}$ \\
Initiator injection point locations $\left(\times 10^{4}\right), \mathrm{cm}$ & $2,4,6,8,10$ & 5 \\
Initiator concentration injected to, mol/ & $5 \times 10^{-4}$ & $15 \times 10^{-4}$ \\
Volumetric flowrate of fluid in jacket, $l / \mathrm{s}$ & 1.2 & 1.2 \\
\hline
\end{tabular}




\subsection{The Simulation Results}

Chen et al., 1976 suggested using one of the following two equations of the macroscopic molar balances on initiator and monomer

$$
\begin{aligned}
& v_{0} i_{0}=\left(\lambda_{0} / 2+\mu_{0}+i\right) v \\
& v_{0} m_{0}=\left(\lambda_{1}+\mu_{1}+m\right) v
\end{aligned}
$$

in simulation process.

In this study, the integrated velocity directly from the overall mass balance, as shown in equation (36), was used. The comparison between the boundary conditions and the direct integration on conversion and velocity are given in Figure 8 and Figure 9, respectively, indicating that there is a little difference between the two methods.

Here, the author defines monomer and initiator conversions as:

$$
\begin{aligned}
& X=\left(1-\frac{m v}{m_{0} v_{0}}\right) \times 100 \\
& X_{i}=\left(1-\frac{i v}{i_{0} v_{0}}\right) \times 100
\end{aligned}
$$

In this study, Figures 10 to 16 are the results of simulation process in Case I. Figure 10 shows the temperature profiles of both reaction and jacket sides. One can easily explore that with each initiator injection at equal interval location, the reaction temperature reaches a new height with difference in reaction and jacket temperatures changed more and more sharply. It reflects the features of thermal dynamics and kinetics of both monomer and initiator: the initiator decomposition reaction goes faster with temperature 


\section{Comparison in Conversion}

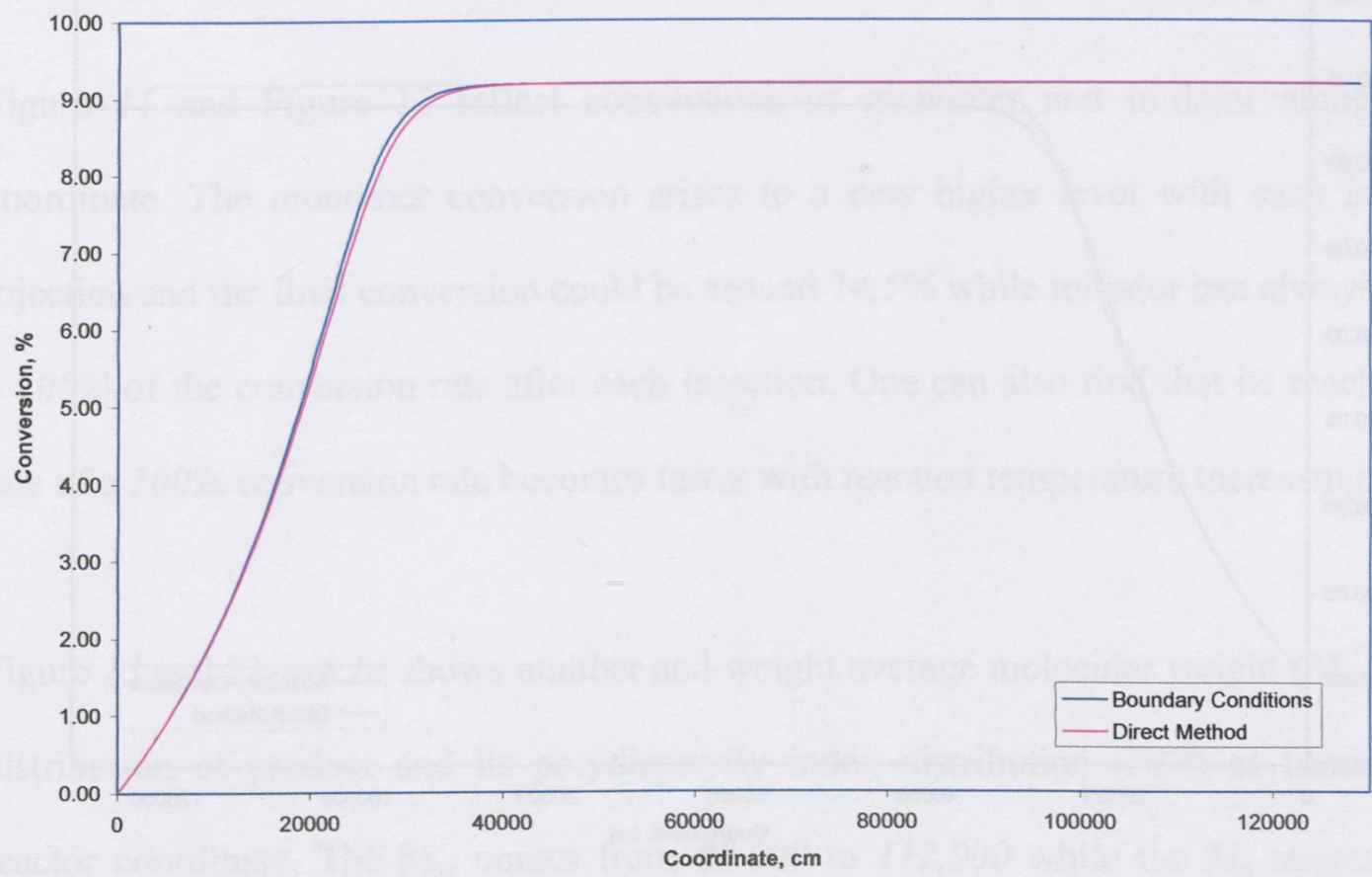

Figure 8. Comparison between conversions calculated from the boundary and direct methods 
Velocity Comparison

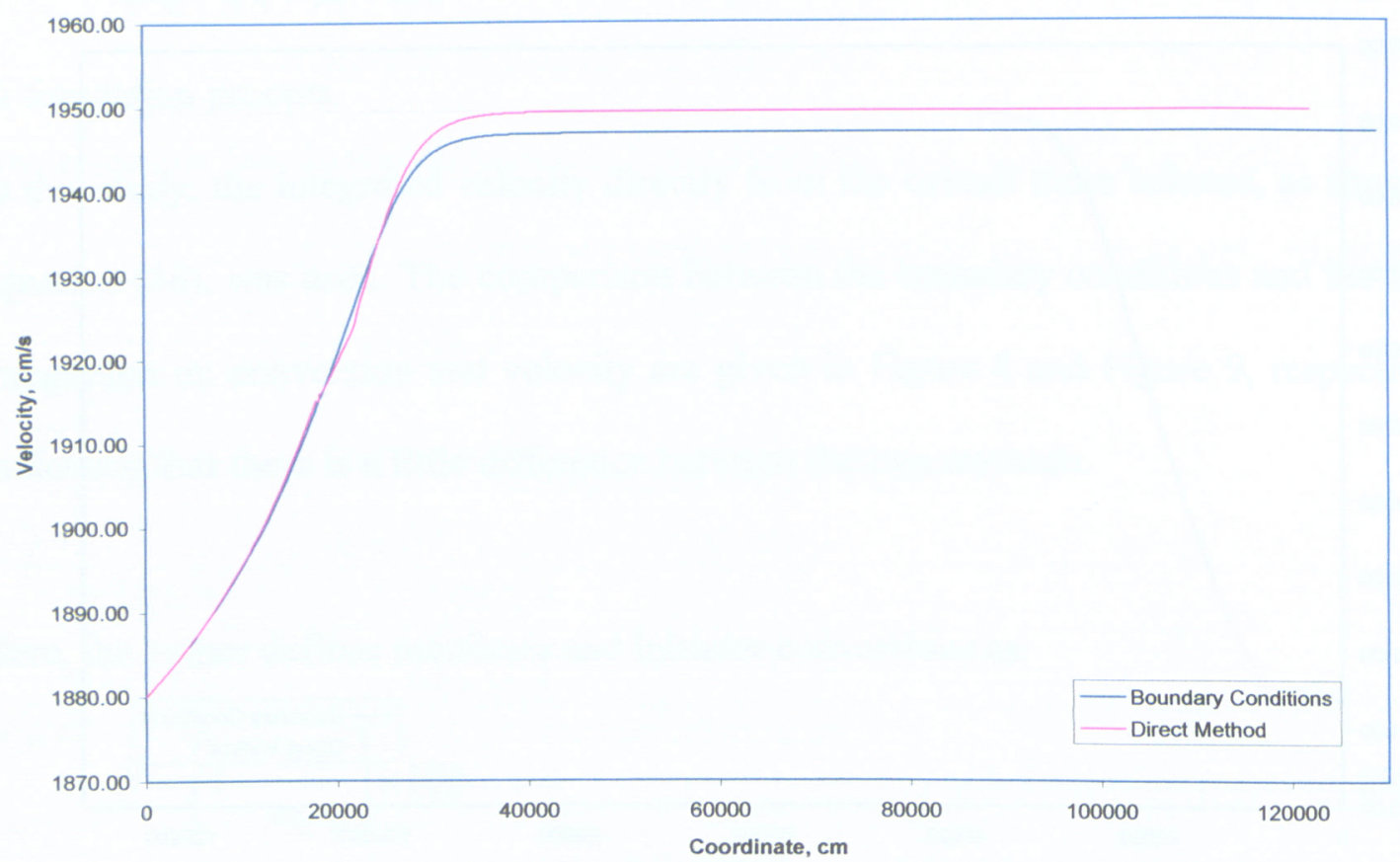

Figure 9. Velocity comparison calculated from boundary and direct methods 
increasing; the rate of polymerization reaction increases with higher concentration of primary free radicals and higher reaction temperature.

Performance of jacket temperature shows good simultaneous heat transfer, compared to reaction temperature. Inlet coolant temperatures for each exchange zone remain at the same level $\left(139^{\circ} \mathrm{C}\right)$. It was then increased along reactor axis and reached an asymptotic value with heat exchange between reacting mixture and jacket coolant.

Figure 11 and Figure 12 reflect conversions of monomer and initiator along axial coordinate. The monomer conversion arises to a new higher level with each initiator injection and the final conversion could be around $14.5 \%$ while initiator can always reach a $100 \%$ of the conversion rate after each injection. One can also find that its reaching to rate of a $100 \%$ conversion rate becomes faster with reaction temperature increasing.

Figure 13 and Figure 14 shows number and weight average molecular weight $\left(M_{n} \& M_{w}\right)$ distribution of product and its polydispersity index distribution $(P D I)$ as function of reactor coordinate. The $\mathrm{M}_{\mathrm{w}}$ ranges from 80,000 to 112,000 while the $M_{n}$ ranges from 35,000 to 54,000 with $P D I$ ranged from 2.0 to 2.5 , which is a very narrow zone as desired by industry.

Figure 15 and 16 show monomer and initiator concentrations along the tubular reactor. As can be seen the monomer concentration is continuously reducing after each initiator injection point. Also note that initiator is consumed faster and faster due to high temperature along the reactor. 
Temperature Profile

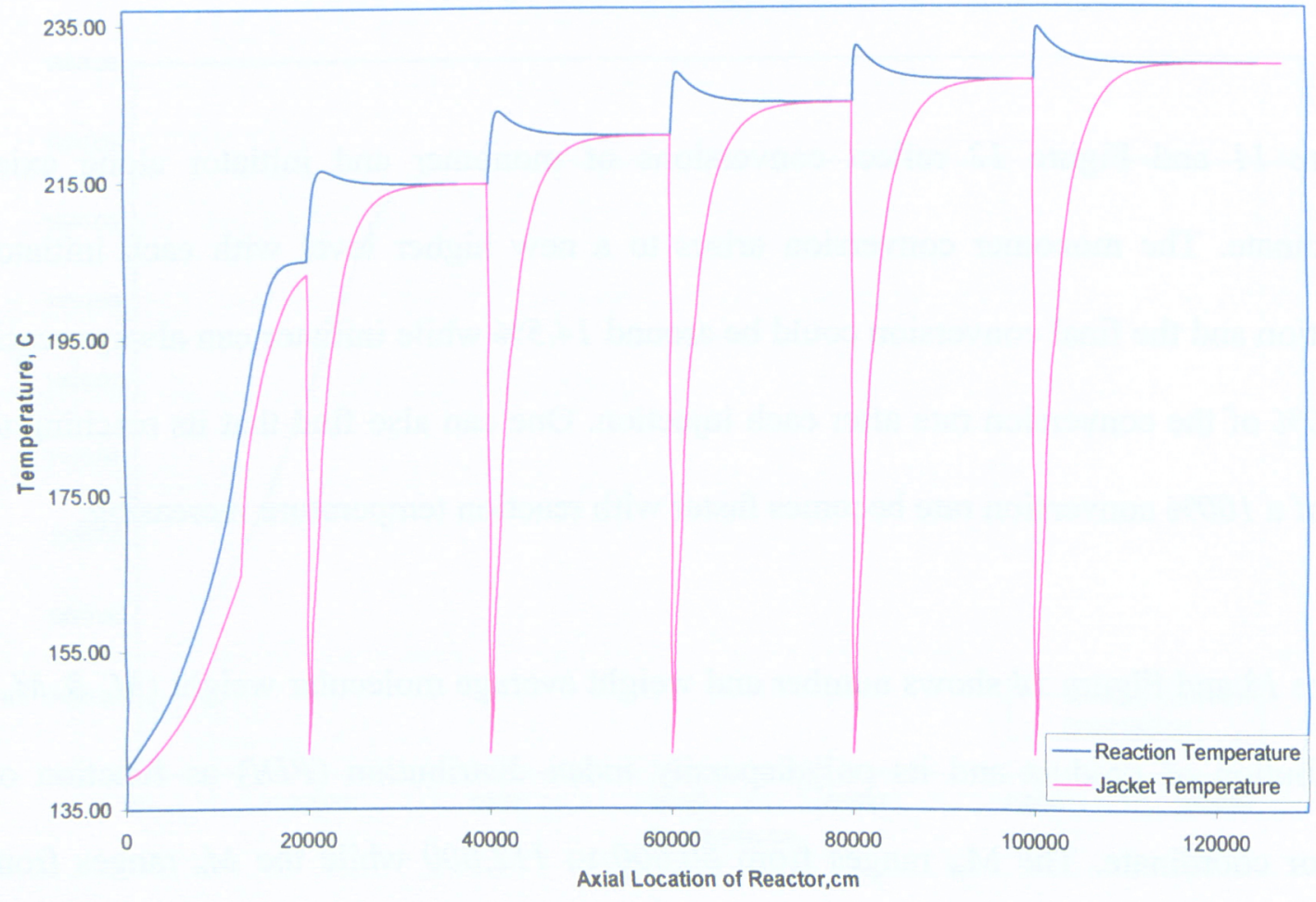

Figure 10. Temperature Profiles of Reaction and Jacket 


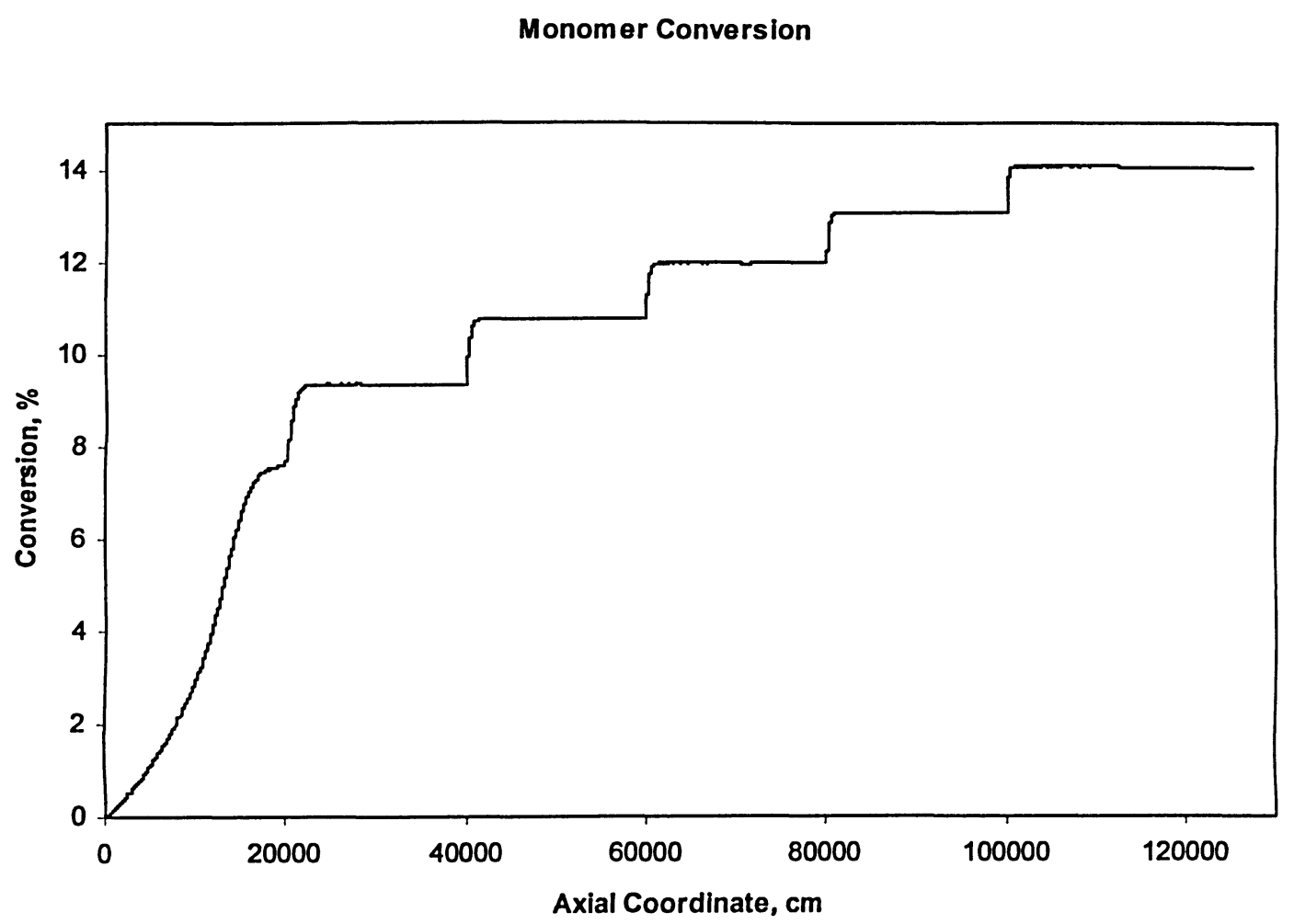

Figure 11. Profile of Monomer Conversion 
Initiator Conversion

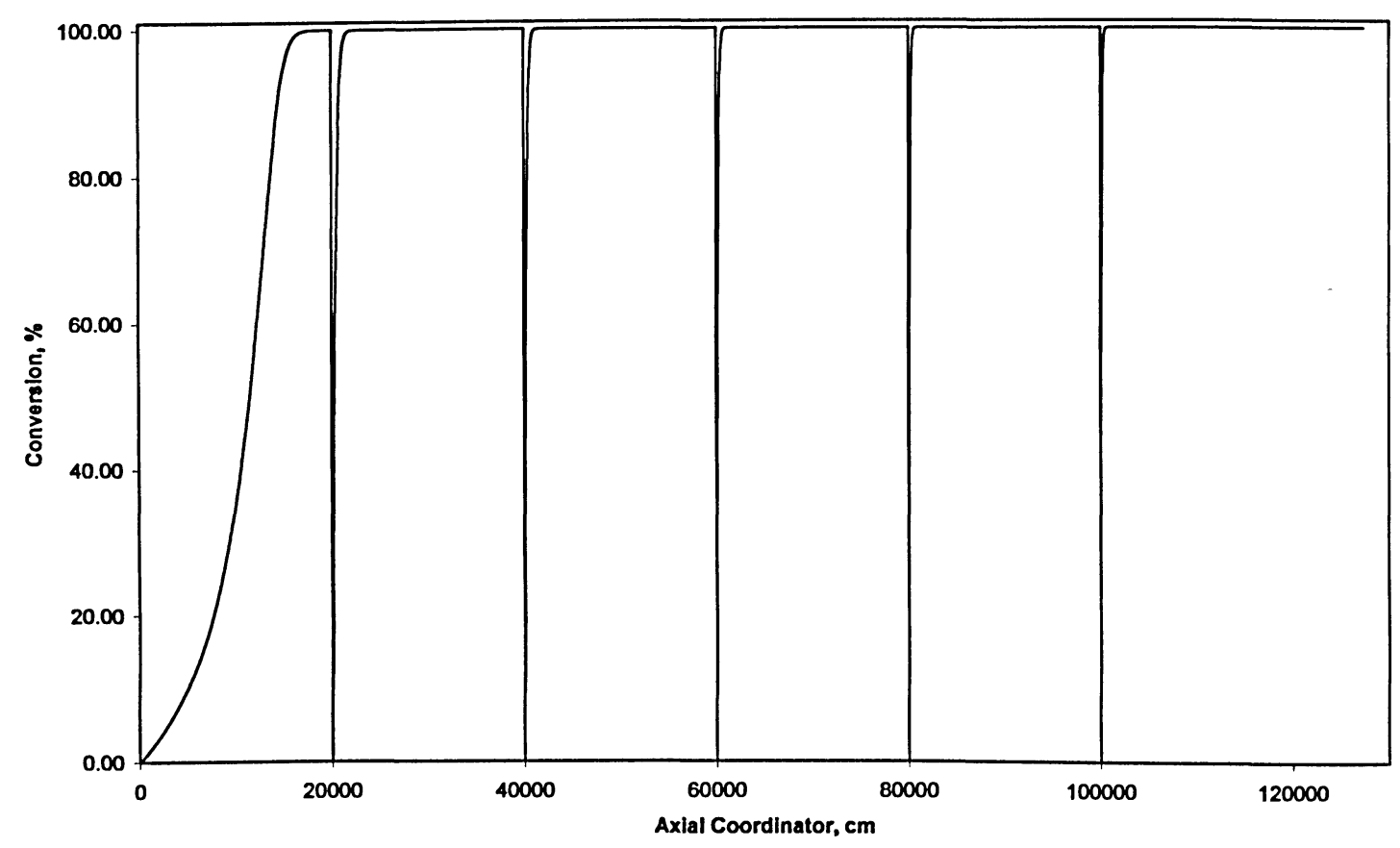

Figure 12. Initiator Conversion in Case I 
MWD Performance

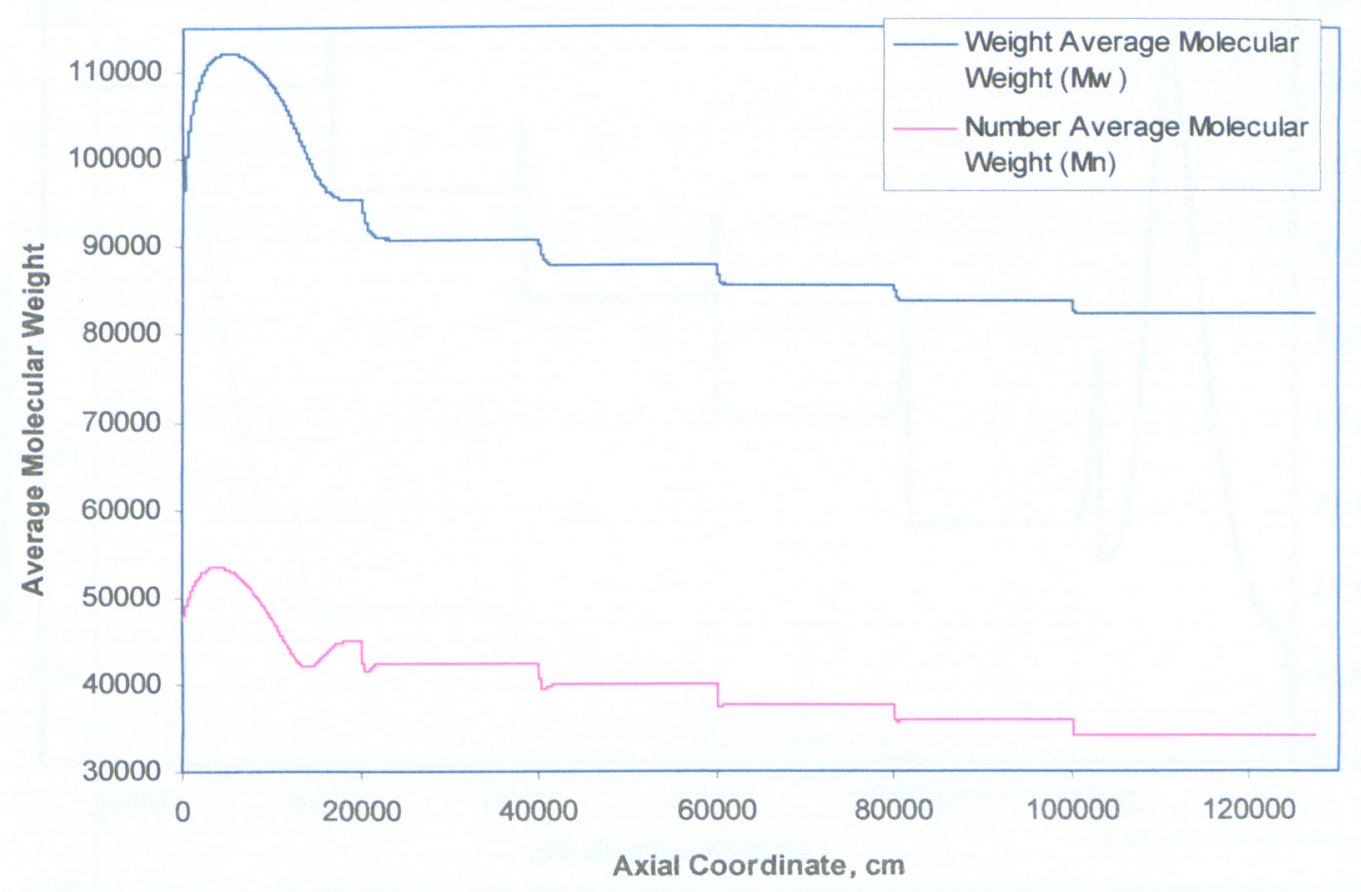

Figure 13. Average Molecular Weight 
Polydispersity index

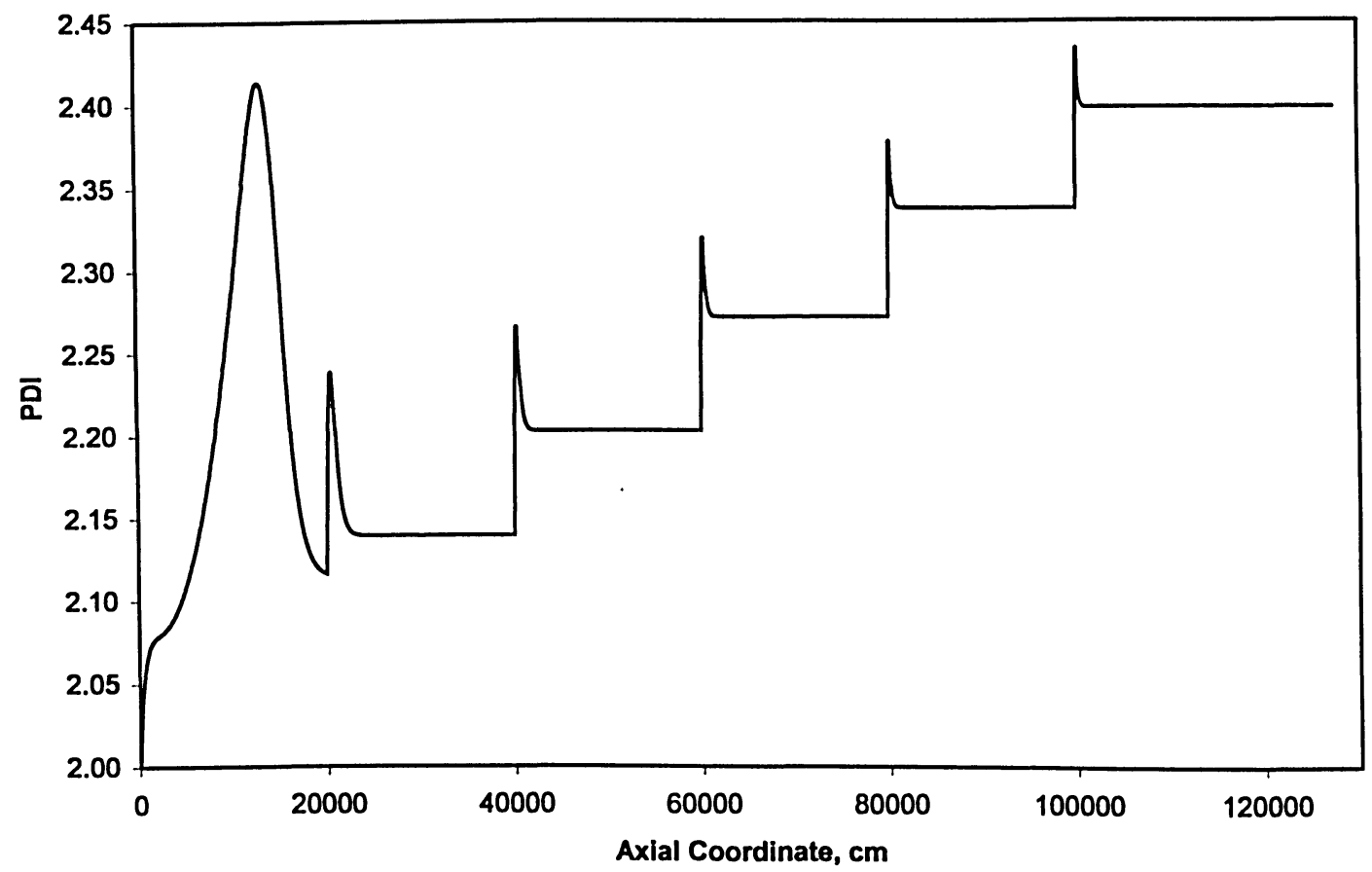

Figure 14. Polydispersity Index versus Axial Coordinate 
Monomer Contribution

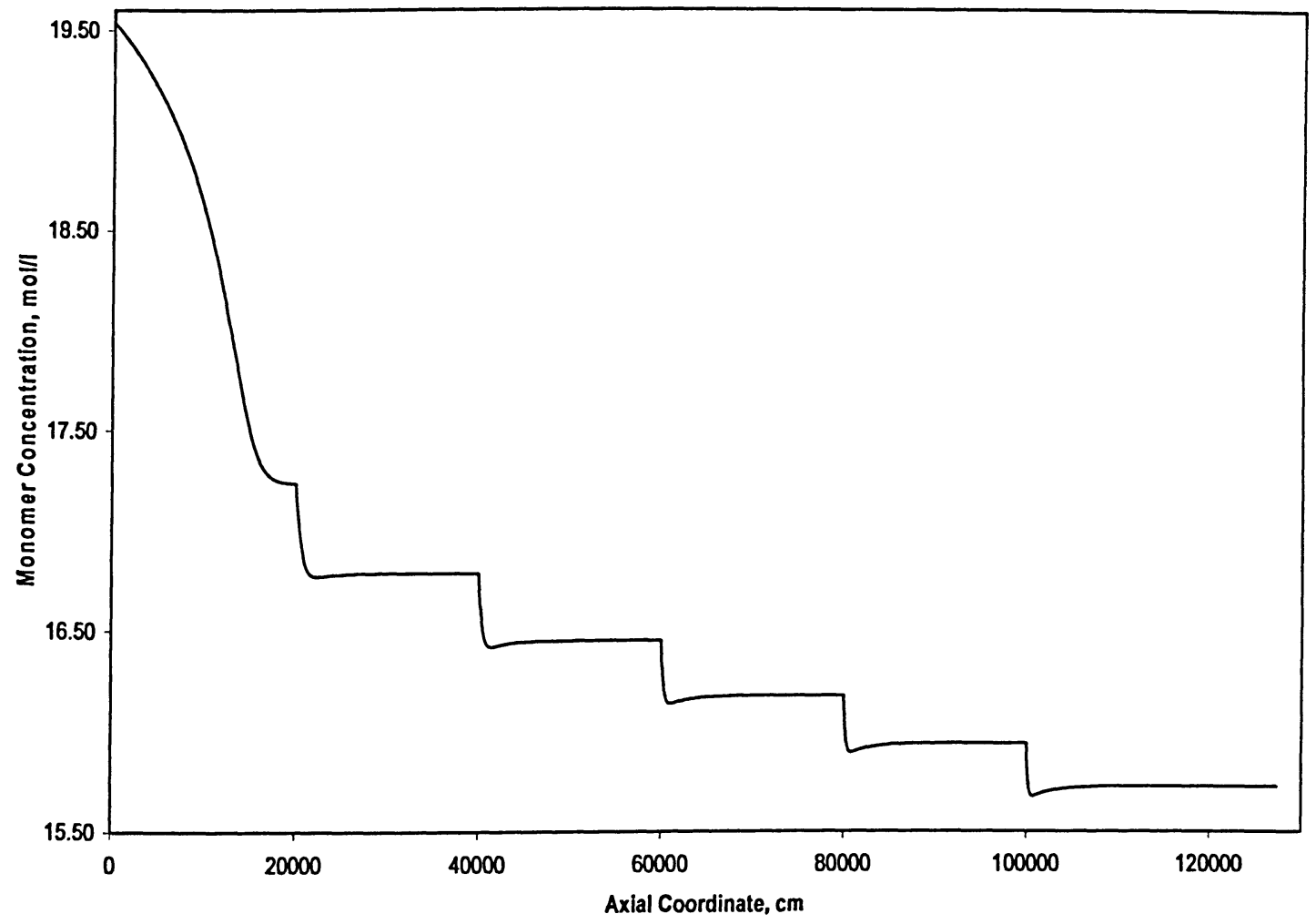

Figure 15. Profile of Monomer Concentration in Reactor 
Initiator Contribution

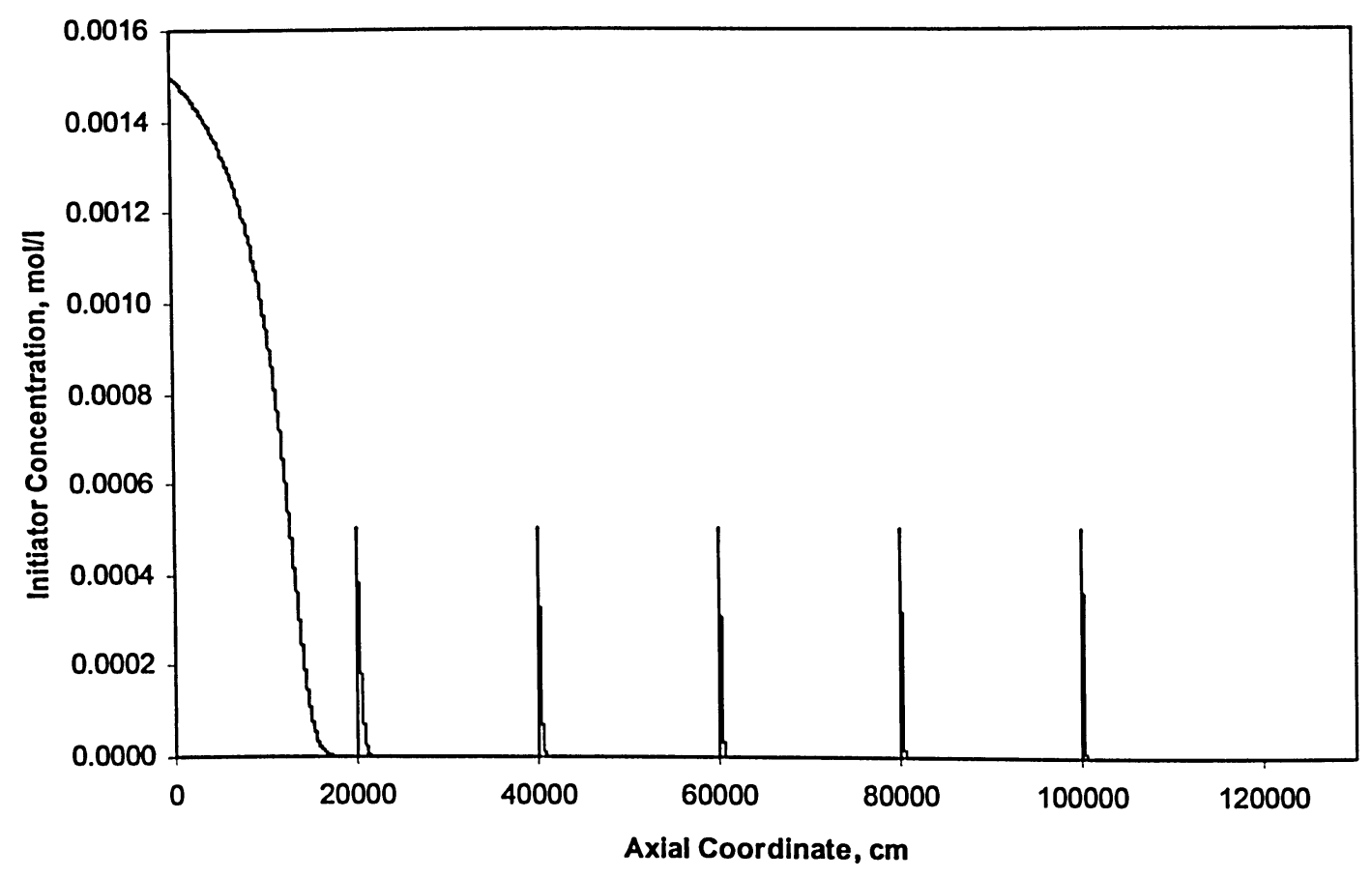

Figure 16. Variations of Multi-injection initiator and Initiator Concentration 
Comparing with Case I above, in Case II, the simulation results are illustrated in Figure 17 to Figure 23, the reactor is divided into two heat exchange zones with a middle initiator injection point at $50,000 \mathrm{~cm}$. The same initiator concentration, $15 \times 10^{-4} \mathrm{~mol} / 1$, is used initially and at the injection point. As illustrated in Figure 17, both of reaction and jacket temperatures have a similar performance: the reaction temperature rises to $205^{\circ} \mathrm{C}$ with a steep rising and goes to an equilibrium with jacket temperature at that point, and reach to $225^{\circ} \mathrm{C}$ after another injection of initiator. It is known that a properly higher temperature will speed polymerization reaction and increase monomer conversion. This is what a commercial plant desired for a tubular reactor. In this simulation study, the reaction temperature always remains in the optimal range (Mavridis and Kiparissides 1985; Asteasuain et al., 2001) for the two cases. With each initiator injection, the reaction temperature increased to a higher value.

It confirms that a good fluid mechanic and dynamic performance can enforce heat exchange either in mostly removing reaction heat generated by polymerization reaction or heating reaction mixture along with heat exchange dynamics; therefore it becomes the factor who affects temperature distribution in reactor, which is known as key parameter to control the $M W D$ and $P D I$ of the product. As described later on, a process optimization methodology is used to find a temperature distribution along the reactor in order to obtain products with optimum properties.

Accompanied with reaction temperature, jacket temperature also plays an important role in tubular reactor. It not only affects reaction temperature but also affects monomer conversion and final product properties, such as average molecular weight distribution, long chain and short chain branch in the whole tubular reactor. 
Temperature Profile

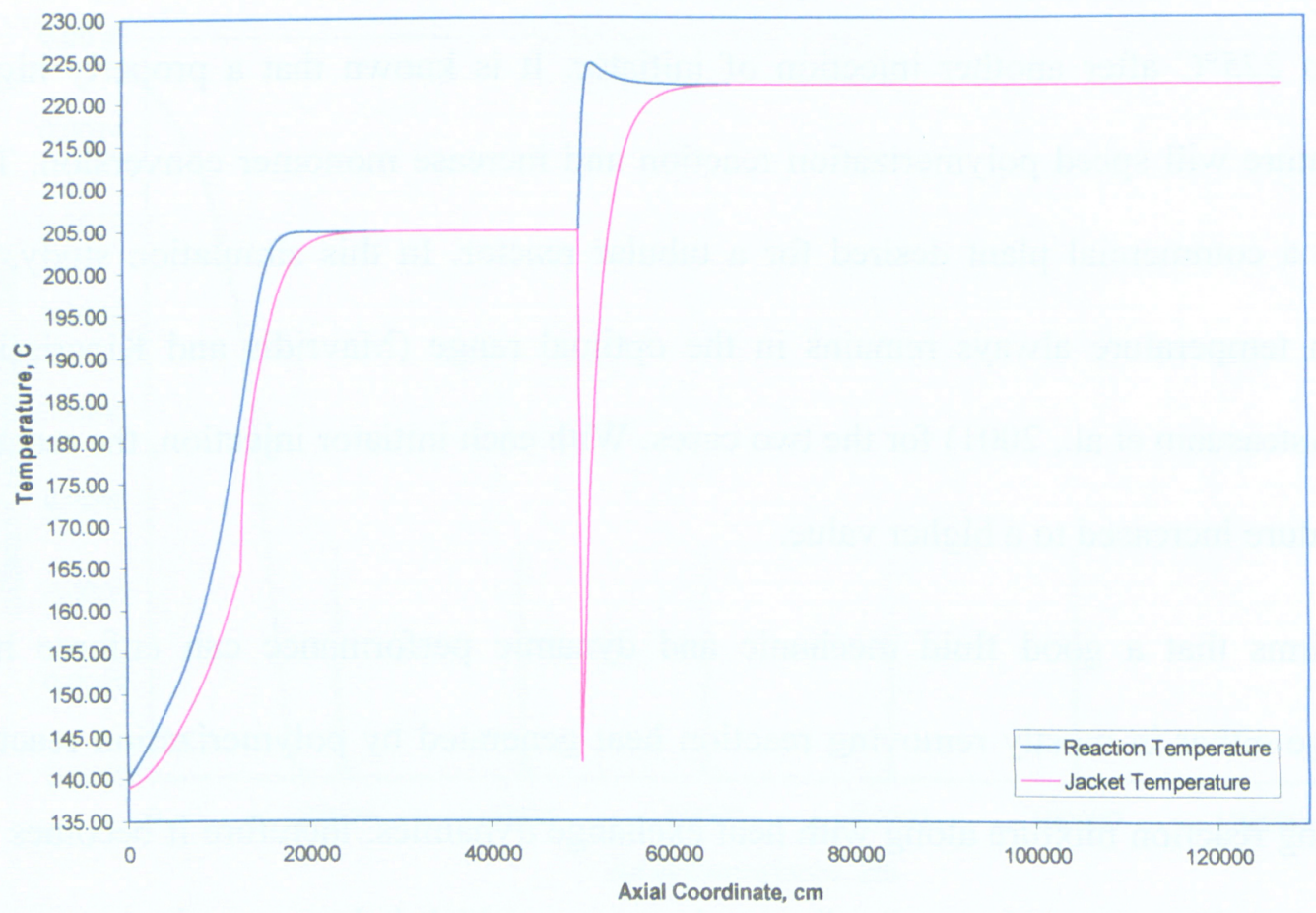

Figure 17. Temperature Profiles with One Injection in Case II 
Monomer Conversion

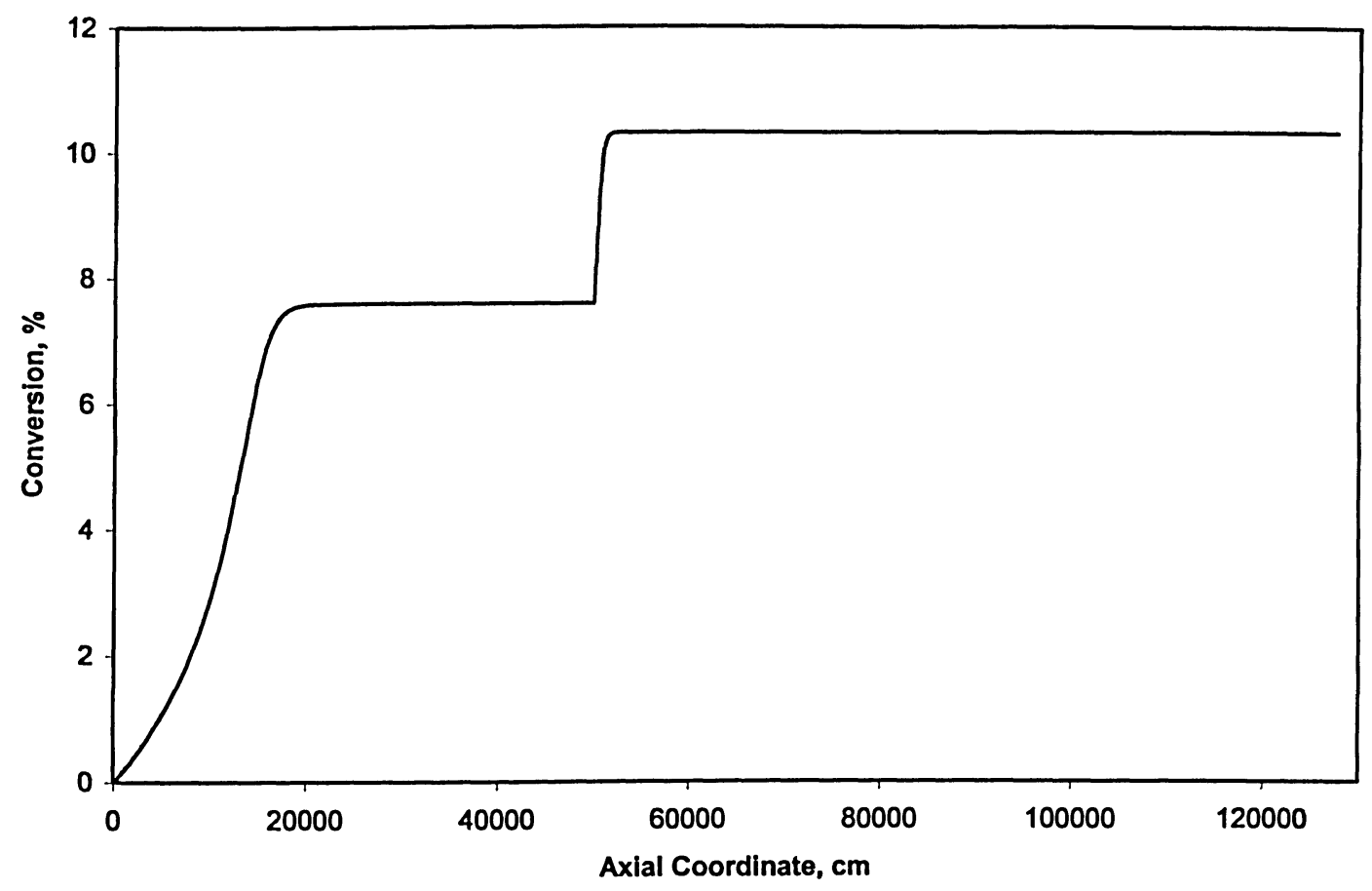

Figure 18. Profile of Monomer Conversion in Case II 
Initiator Contribution

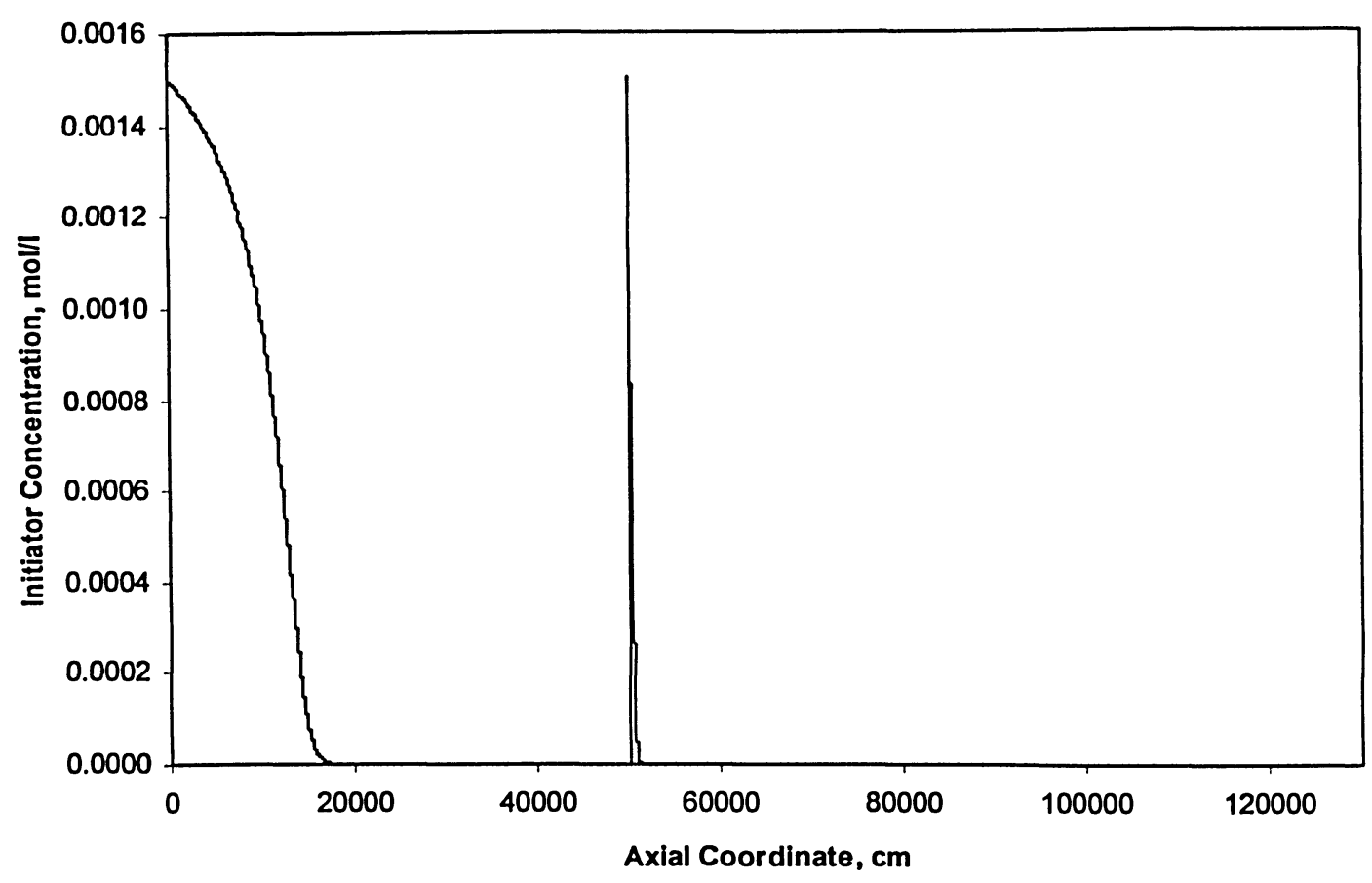

Figure 19. Evolution of Initiator Conversion in Case II 
The monomer conversion can reach close to $10.5 \%$ while the first step is slightly below $7.9 \%$ as shown in Figure 18. It shows that initiator conversion tends to $100 \%$ gently from the reactor inlet point and reached to $100 \%$ rapidly after the middle initiator injection, as in Figure 19, which is same as the performance in Case I.

The molecular weight distribution, $M_{n}$, drops to its lower level to 32,000 and the upper level remained the same as in Case I; $M_{w}$ rises to its lower level up 90,000 (slightly higher than 82,000 in Case I) with the same upper level as in Case I. Due to the performance above, the $P D I$ range becomes wider from 2.0 to 2.8 , which is shown in Figure 21. Figure 22 and Figure 23 shows the distribution of monomer and initiator concentration in this tubular reactor.

MWD Performance

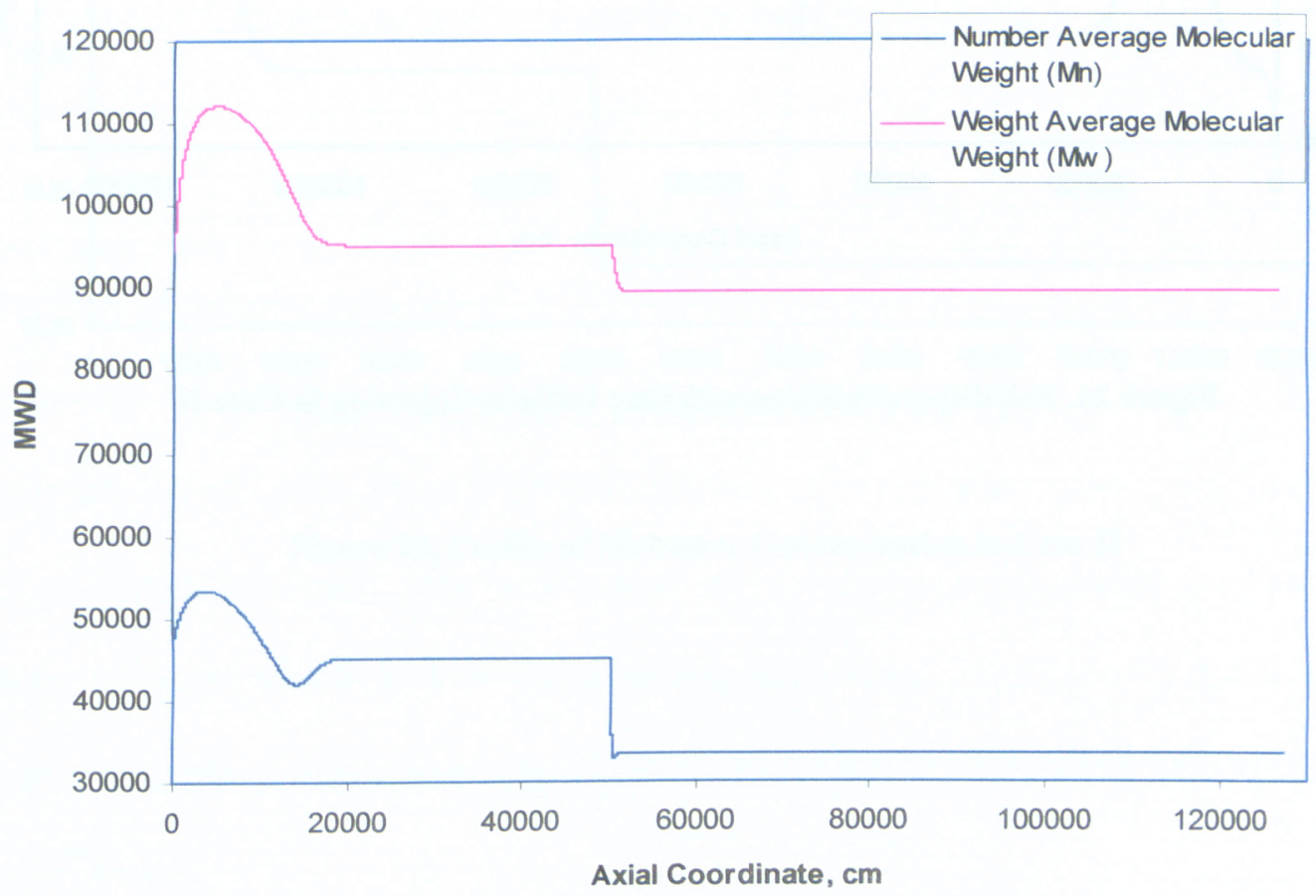

Figure 20. Average Molecular Weight (MWD) in Case II 
Polydispersity Index

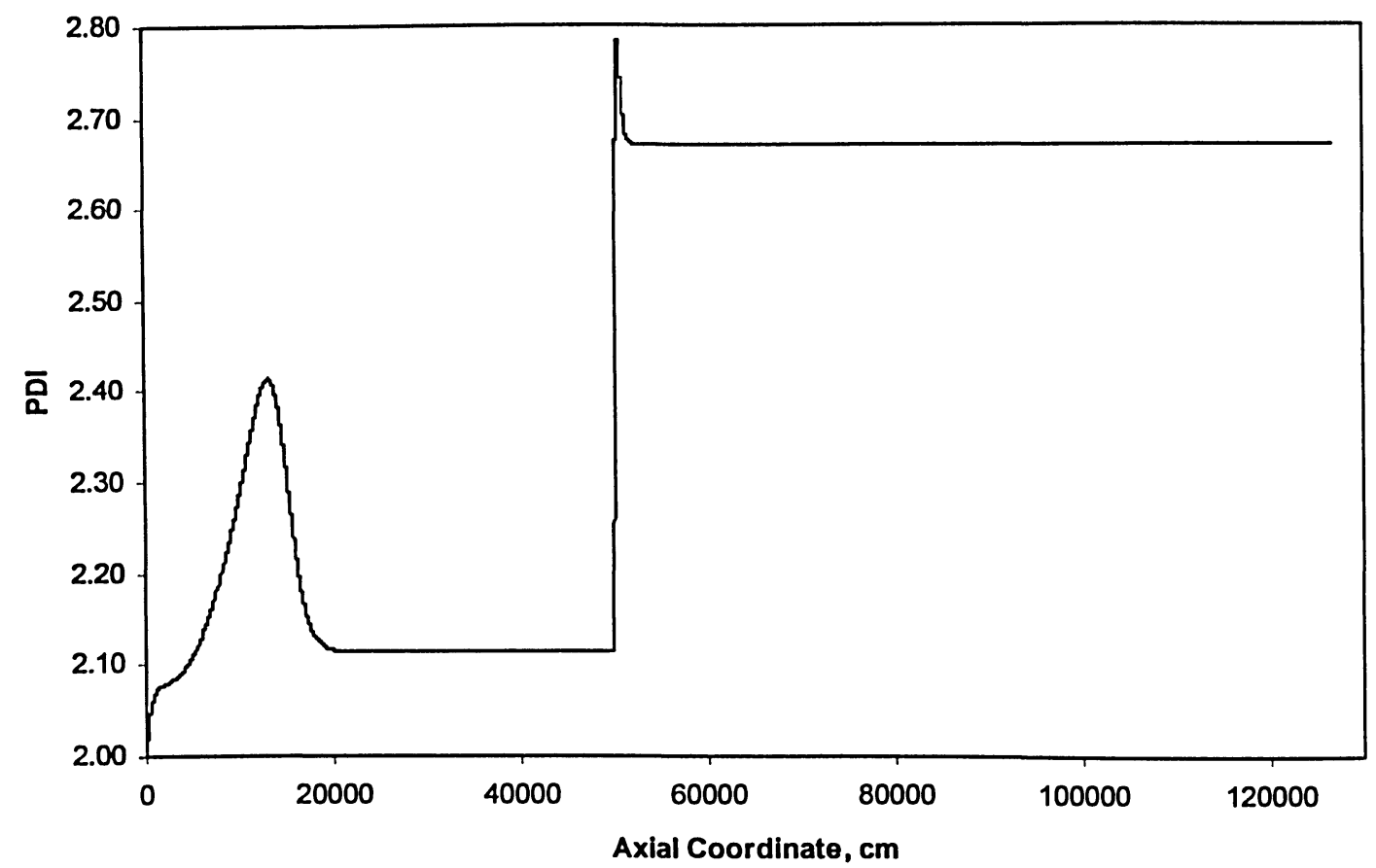

Figure 21. Polydispersity Index with One Initiator Injection in Case II 
Monomer Contribution

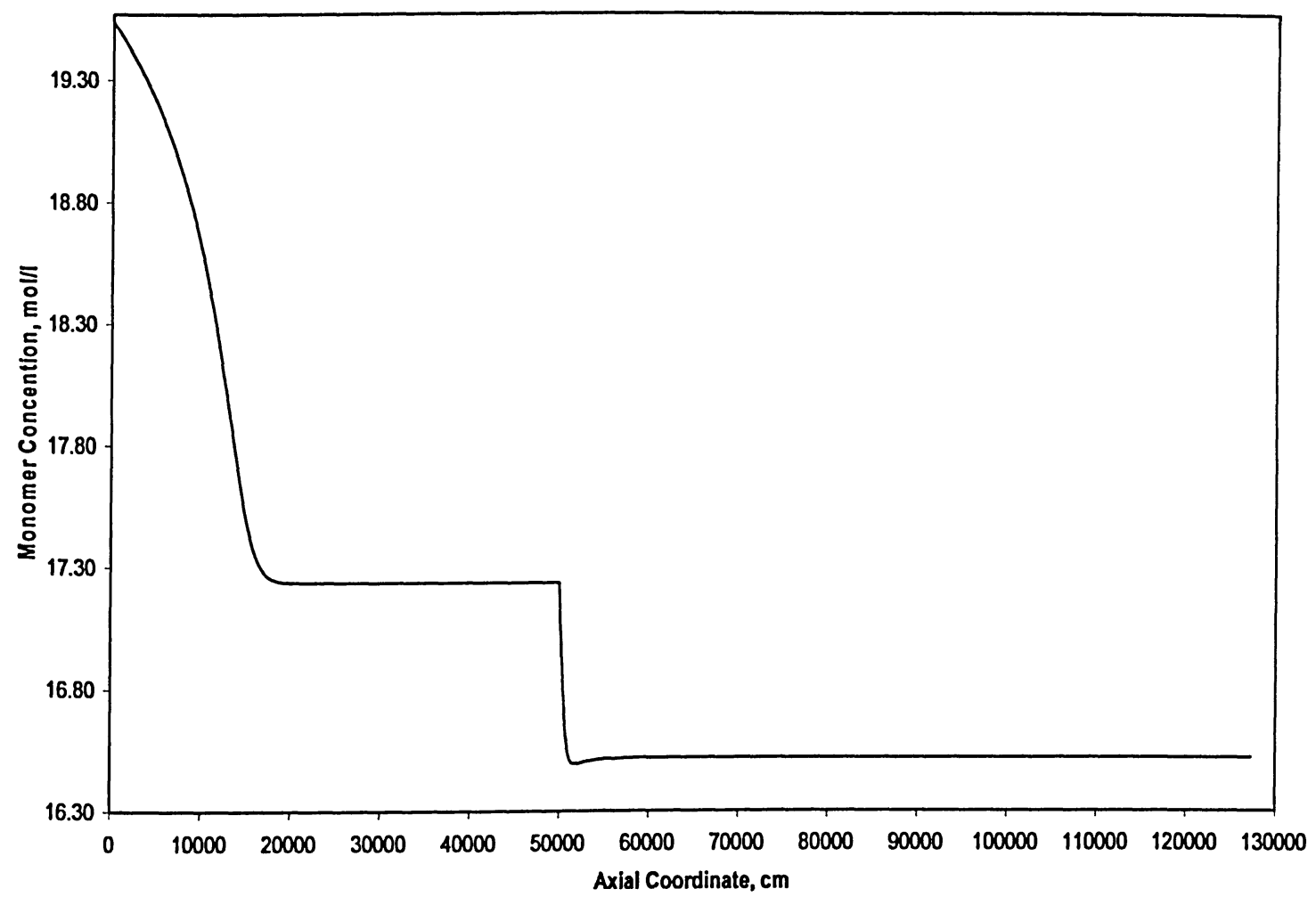

Figure 22. Profile of Monomer Concentration in Case II 
Initiator Contribution

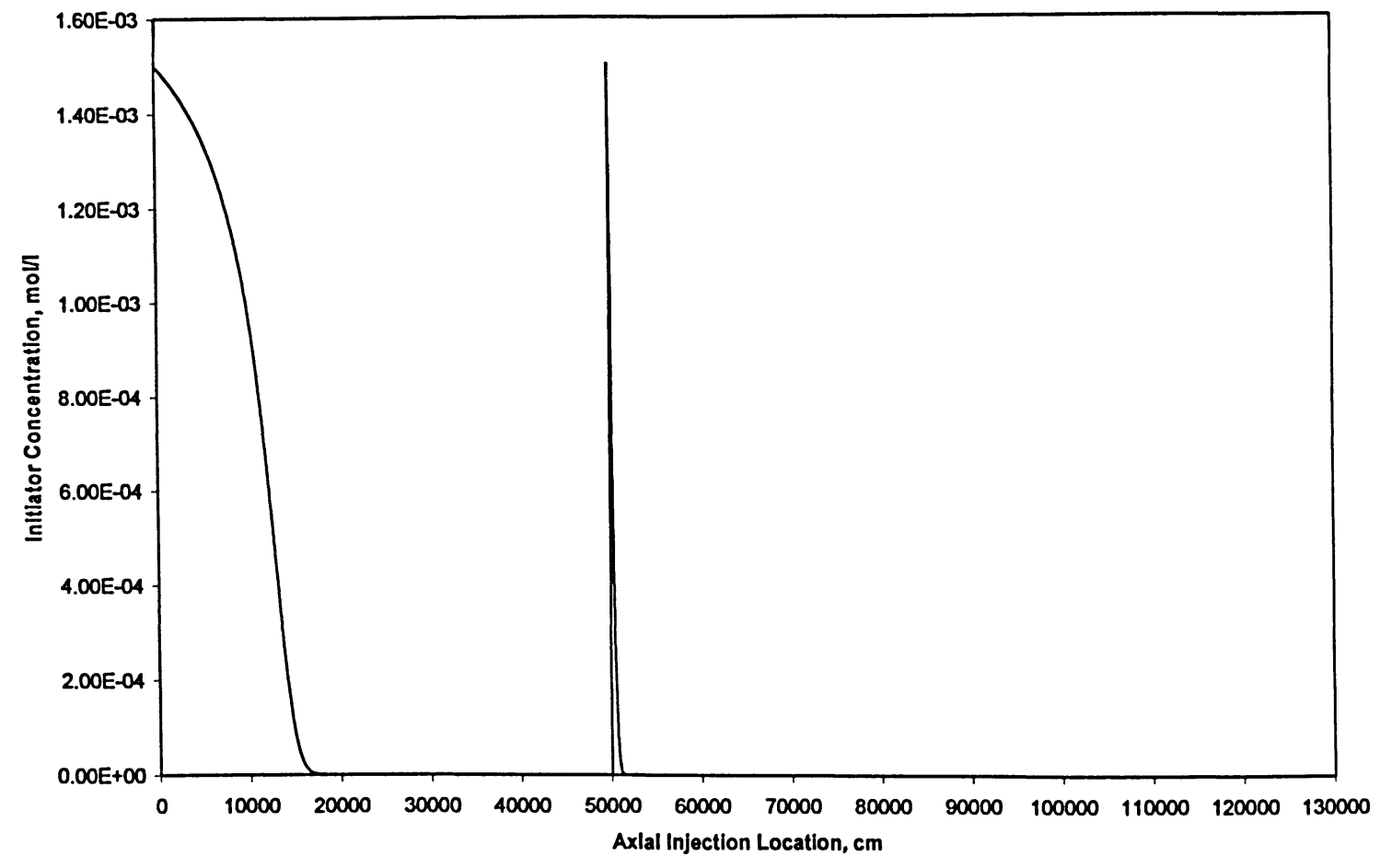

Figure 23. Variation of One Injection Initiator in Case II 
In Figures 10, 14, 16, 17, 19, 21, 23 and 24, several peaks occur in the temperature, concentration, $M W D$ and $P D I$. Its location and height depend on design parameter, such as reactor configuration, reactor capability, the diameter of tubular reactor and initial conditions, which are initial velocity, temperature, concentrations of monomer and initiators. These peaks are always accompanied with a simultaneous depletion of all the initiators and coolant inlet temperature change in different heat exchange zones. It is also found that the final product properties, such as density, $M_{n}, M_{w}, P D I$, etc. are not related to the velocity.

Note that higher concentration of initiator will accelerate polymerization reaction, therefore benefits the higher monomer conversion, but it results average molecular weight distribution of $M_{n}$ and $M_{w}$ to decrease. On the other hand, higher concentration of initiator will also divergences polydispersity index $(P D I)$, which is observed by exploring Figure 24, a merge of Figure 14 and Figure 21.

The effect of initiator concentration on conversion is also studied separately. In this study the gaseous mixture entered at $110^{\circ} \mathrm{C}$. The initiator concentration is varied according to Figure 25. In all cases, there is another initiator injection point with $5 \times 10^{-4} \mathrm{~mol} / \mathrm{l}$ at 80 , $000 \mathrm{~cm}$ from the inlet. The conversion of monomer is increased as the initiator concentration increased. It is also notable that the second injection of initiator at 80,000 $\mathrm{cm}$ does not affect conversion when initial concentration of initiator is low, i.e. below $14 \times 10^{-4} \mathrm{~mol} / \mathrm{l}$. 
The effect of initial mixture temperature on conversion was studied through Case II. As shown in Figure 26, the inlet temperature varies from $120^{\circ} \mathrm{C}$ to $160^{\circ} \mathrm{C}$ (in Case II, the inlet temperature was $140^{\circ} \mathrm{C}$ ). The higher the temperature the higher rate of polymerization but it corresponds to lower conversion. This phenomenon of temperature effect still remained after injection at $50,000 \mathrm{~cm}$. It is obviously that a lower inlet temperature of compressed reactant stream causes a higher first level monomer conversion in the first reaction zone but takes longer time to reach reaction equilibrium. The average molecular weight, including $M_{n}$ and $M_{w}$, were led to be a slightly higher by these phenomena. It is also easy to explore those by taking a close look at Figure 13 and Figure 20.

Effect of change in monomer concentration on conversion although noticeable from Figure 27 (Case II with different monomer concentration at inlet) but it is not as effective as temperature or initiator concentration. This may not be true when monomer concentration is reduced or increased tremendously. 
Polydispersity Index Distrubution

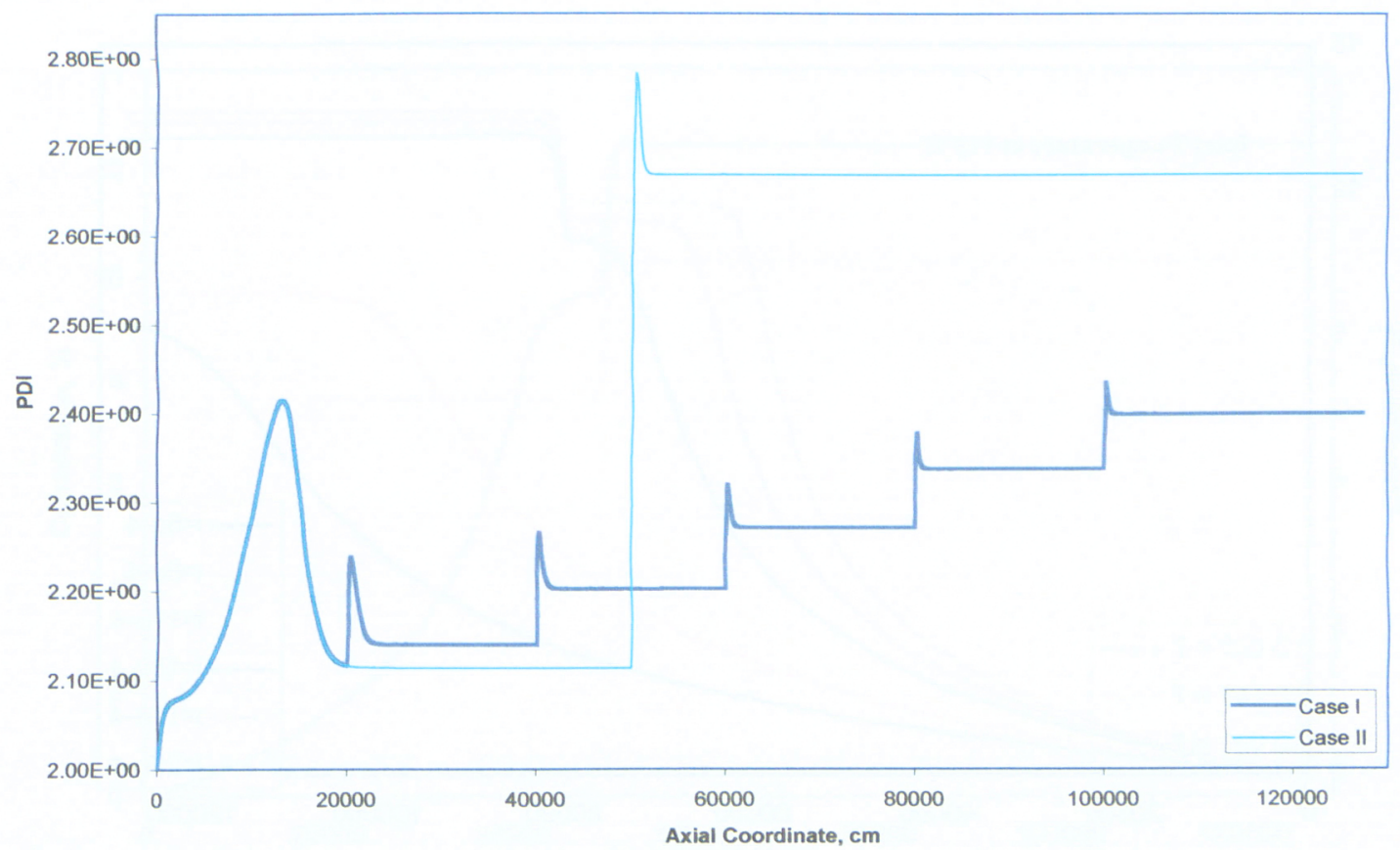

Figure 24. Polydispersity Index versus Axial Coordinate 
Effects for Different Initiator Concentrations

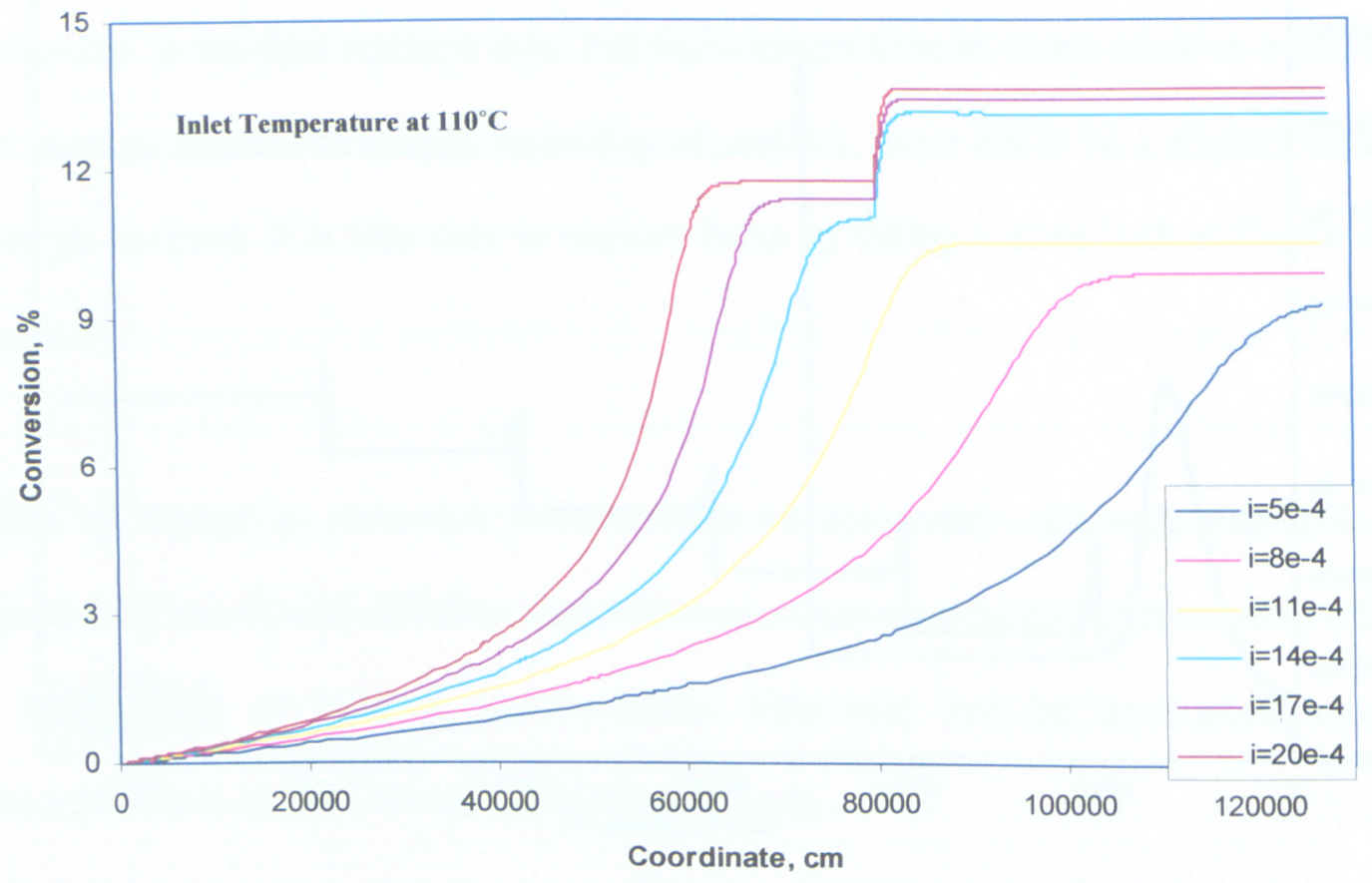

Figure 25. Monomer Conversions for different initiator concentrations 


\section{Com parision for Different Tem perature}

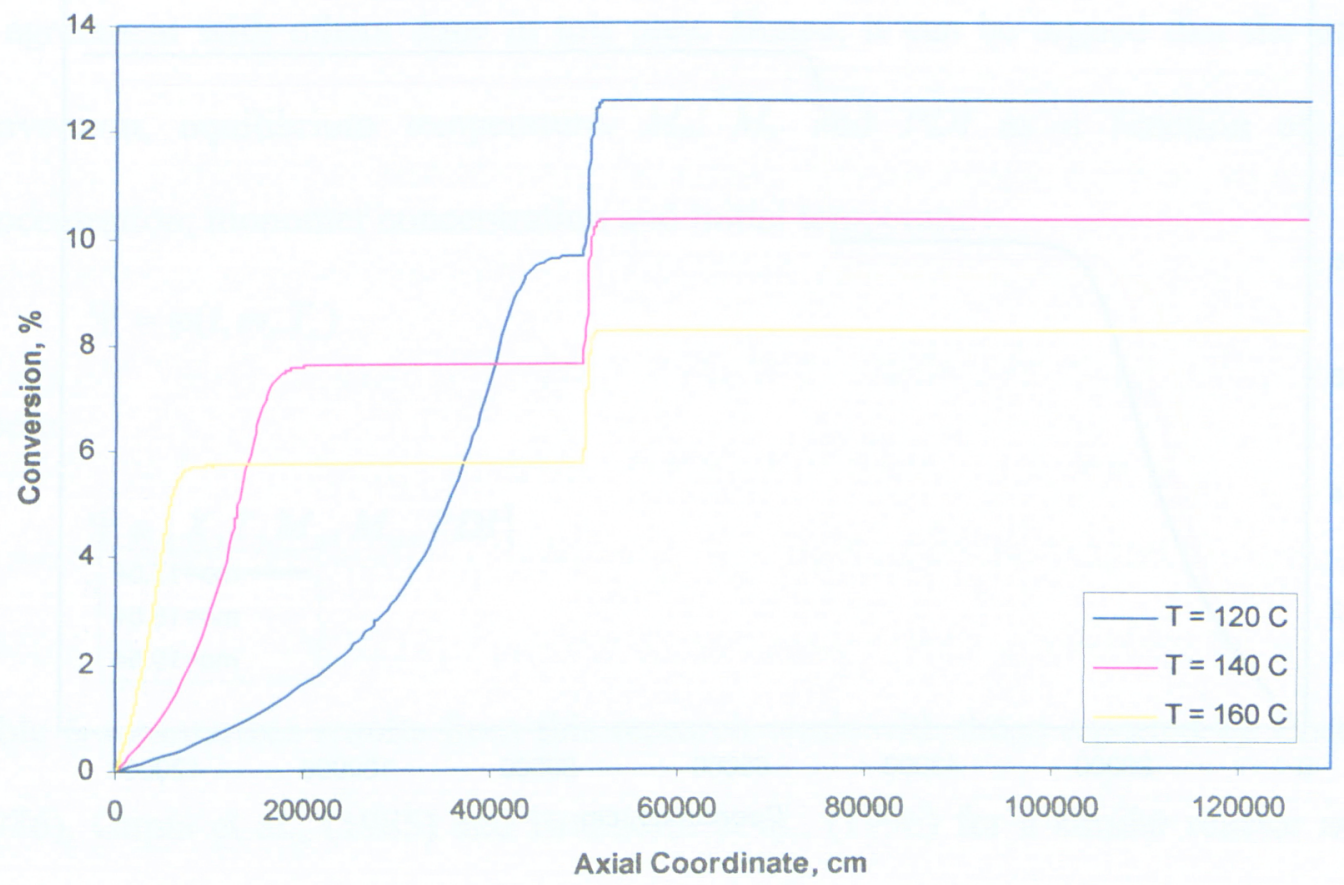

Figure 26. Monomer conversions for different inlet temperatures 
Conversion Comparison for Different Inlet Monomer Concentration

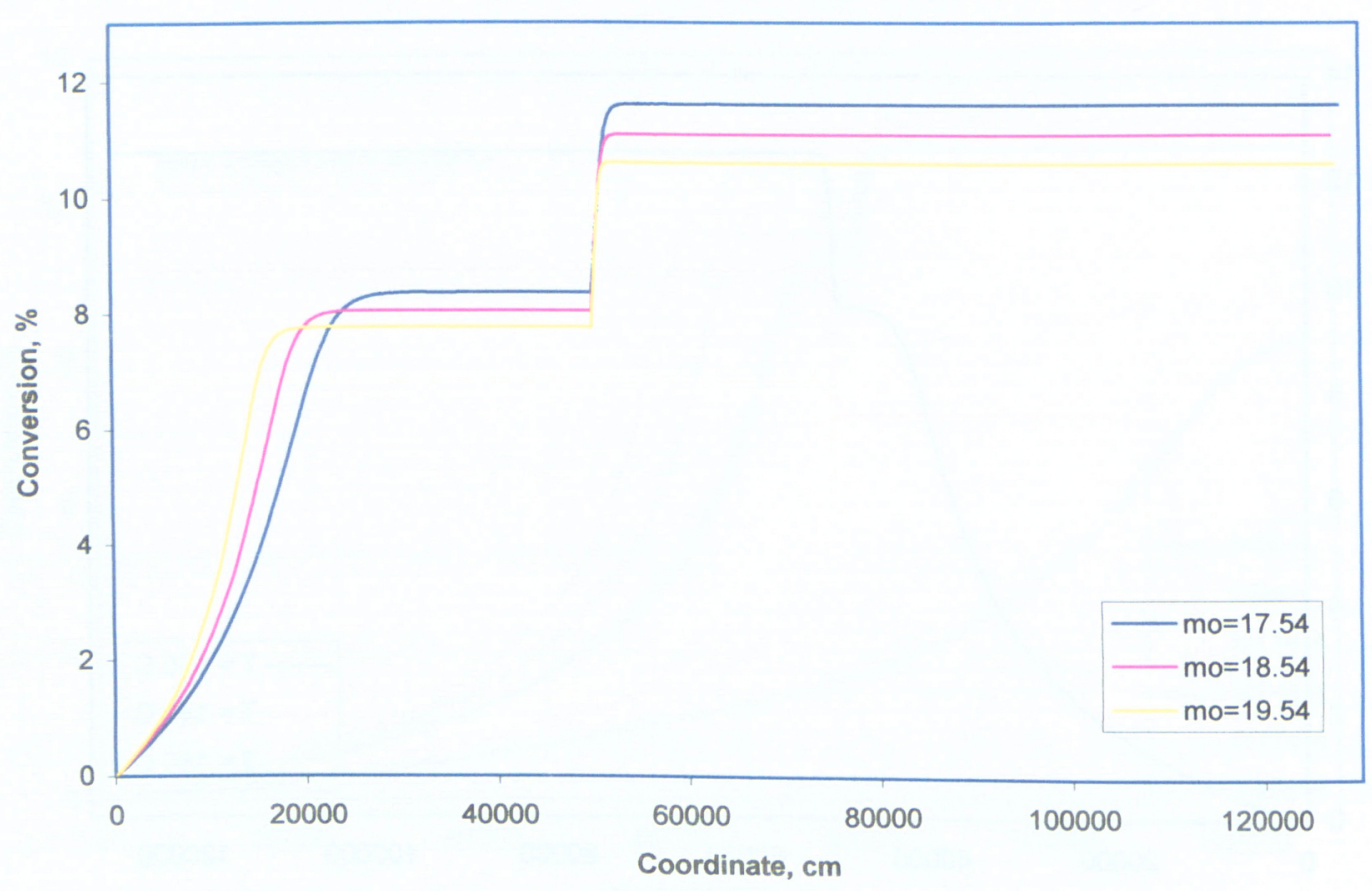

Figure 27. Monomer Conversion for different inlet monomer concentrations 
Hence, it can be concluded that if there are sensitive conditions where any slight disturbances would lead to very large changes in the exothermic reaction of ethylene polymerization, these conditions are the inlet temperature, the concentration distribution of monomer and the initiator.

Yoon and Rhee (1985) also analyzed the effect of inlet initiator concentration on monomer conversion and equilibrium temperatures. Results from this research work are in agreement with others done in this area. Hence, it can be argued that the monomer conversion, equilibrium temperature, $M_{n}, M_{w}$ and $P D I$ as a function of initiator concentration, monomer concentration and initial temperature.

$$
\Psi=\varphi\left(i, m, T_{o}\right)
$$

where

$$
\Psi \in\left\{X, T, M_{n}, M_{w}, P D I\right\}
$$

Table 6 summarizes results from this research work with those reported by Chen et al., (1976), Gupta et al., (1985) and Brandolin et al., (1996) for a similar reactor and inlet conditions. The computed value of $M W D, P D I$ are in the range encountered in the industrial reactors and those reported by Chen et al., (1976), Goto et al., (1981), Zhou et al., (2001) and Zhou et al., (2002). 
Table 6. The comparison with earlier reports

\begin{tabular}{|c|c|c|c|c|c|c|c|}
\hline & $\begin{array}{l}\text { Brandolin, } \\
\text { et al. } 1996\end{array}$ & $\begin{array}{l}\text { Brandolin, } \\
\text { et al. } 1988\end{array}$ & $\begin{array}{c}\text { Gupta, } \\
\text { et al. } \\
1985\end{array}$ & $\begin{array}{c}\text { Mavridis, } \\
\text { et al. } \\
1985\end{array}$ & $\begin{array}{c}\text { Zabisky, } \\
\text { et al. } \\
1992\end{array}$ & $\begin{array}{l}\text { Zhou, } \\
\text { et al. } \\
2001\end{array}$ & $\begin{array}{c}\text { This } \\
\text { Research }\end{array}$ \\
\hline $\begin{array}{c}\text { Reaction } \\
\text { Temperature, } \\
T\left({ }^{\circ} \mathrm{C}\right)\end{array}$ & 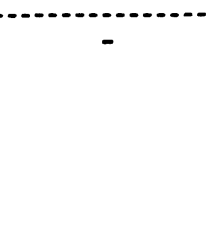 & - & $\begin{array}{l}110- \\
285\end{array}$ & $70-206$ & - & $\begin{array}{l}227= \\
357\end{array}$ & $\begin{array}{l}140- \\
231\end{array}$ \\
\hline $\begin{array}{c}\text { Monomer } \\
\text { Conversion, } \\
X(\%)\end{array}$ & $24.3-29.0$ & $\sim 16$ & $\sim 28$ & $6.4-14.3$ & $\begin{array}{l}16.3- \\
22.9\end{array}$ & $\begin{array}{c}\sim \\
10.05\end{array}$ & $\begin{array}{c}10.5- \\
14.2\end{array}$ \\
\hline$M_{n}$ & $\begin{array}{l}15900- \\
26400\end{array}$ & 19964 & $\begin{array}{l}500- \\
110000\end{array}$ & $\begin{array}{c}39882- \\
39986\end{array}$ & $\begin{array}{l}15900- \\
32700\end{array}$ & - & $\begin{array}{c}32000- \\
54000\end{array}$ \\
\hline$M_{w}$ & $\begin{array}{l}108000- \\
220000\end{array}$ & 133644 & - & - & $\begin{array}{l}38000- \\
115000\end{array}$ & $\begin{array}{c}40000 \\
- \\
87000\end{array}$ & $\begin{array}{l}82300- \\
112100\end{array}$ \\
\hline$P D I$ & $6.79-8.30$ & 6.69 & $\begin{array}{l}2.0- \\
4.6\end{array}$ & $3.0-7.0$ & $2.3-3.5$ & $\begin{array}{l}1.92- \\
2.35\end{array}$ & $\begin{array}{l}2.0- \\
2.78\end{array}$ \\
\hline
\end{tabular}




\section{Optimal Control}

Optimal control is a robust technology and it was well-developed in chemical engineering process in the last 10 years after giving a wide spectrum of optimal control applications (Biegler et al., 2002). Based on variational calculus, these technology uses Pontryagin's maximum principle (Pontryagin et al., 1962), dynamic programming (Luus, 1990), non-linear programming (Biegler et al., 2002), and so on. As recently developed by Upreti, (2003), the programming techniques rely on either gradient information, or enumeration (direct or stochastic). A direct search (Luus and Hennessy 1999), semiexhaustive search (Gupta, 1995), or evolutionary search (Lee et al., 1997; Lee et al., 1999; Wang and Chiou 1997) could be used in researches.

Due to frequent presence of non-linearity in process models, inequality constraints on process variables, and implicit process discontinuities (Barton, et al., 1998), it gives rise to a multimodal, and non-continuous relation, or functional, between a performance index and a control function.

There are several applications (Lee et al., 1999; Dadebo and Mcauley 1995; Crowley and choi 1998; Tieu et al., 1994) focused on optimization of polymerization process, but no report on the ethylene polymerization in a high pressure tubular reactor until this thesis presented.

In Chapter 5 above, the simulation results reveal a strong relation between reactant temperature and monomer conversion, the molecular weight distribution of polymer. Since reactant temperature is affected by the temperature of fluid in reactor jacket, its temperature can be used to achieve desirable monomer conversion and polymer 
properties. This optimization can be even more effective if the jacket temperature is variable along reactor length, i. e. if the temperature is considered as an optimization function rather than a uniform parameter. The optimization strategy that uses optimization function is known as optimal control. The following presents an application of optimal control to an industrial, tubular LDPE reactor based on the model, which has been developed and simulated above.

\subsection{Problem formulation}

According to the new robust technique (Upreti, 2003), the optimal control scheme can be employed to the following steady-state process model:

$$
\frac{d \hat{x}(z)}{d z}=f(\hat{x}(z), \hat{u}(z)), \quad 0 \leq z \leq z_{f}
$$

In Equation (58), $\hat{x}(z)$ is an [ $m \times 1]$ state vector, and $\hat{u}(z)$ is an $[n \times 1]$ control vector within some specified bounds. Both $\hat{x}(z)$ and $\hat{u}(z)$ are functions of location, z, over a given process operation span $z_{f}$. State vector $\hat{x}(z)$ is known at $z=0$. Equation (58) is subject to the satisfaction of $\hat{g}[\hat{x}(z), \hat{u}(z)]$, a vector of constraints on $\hat{x}(z)$ and $\hat{u}(z)$. The objective is to obtain the optimal control function, which would optimize a given performance index $\hat{J}[\hat{x}(z)]$. The discrete step values of $\hat{u}(z)$, equispaced over process operation span, are considered as optimization variables. These step values form a control vector $\hat{u}(z)$. 
In this study, the optimal control objective is to determine the optimal jacket temperature as a function of reactor length that would maximize monomer conversion of the LDPE reactor in the term of monomer concentration. Mathematically, the objective is to maximize the performance index

$$
J=X(L)
$$

by using jacket temperature, $T_{\mathrm{j}}(z)$, as an optimal control function of reactor length $z$. The maximization of $J$ is subject to the mathematical model of the reactor given by the set of algebraic equations, Equations (23)-(25), and the set of differential equations, Equations (29)-(34), (36), (38), (40), (41), (42)-(44) and (50)-(52). There are other additional process constraints in that the optimal control function, $T(z)$, must be such that the reaction temperatures never exceed the maximum prescribed limit and above reaction inhibitor limit, i. e.,

$$
T_{\min }<T<T_{\max } ; \quad 0 \leq z \leq L
$$

Where, $T_{\min }=100^{\circ} \mathrm{C}$ and $T_{\max }=325^{\circ} \mathrm{C}$.

The above differential-algebraic model is highly non-linear. Furthermore, due to the presence of process constraint, the relation between the performance index and jacket temperature cannot be expected to be unimodal and continuous. The reactor was considered to be surrounded by contiguous jackets of equal length, and uniform (but not necessarily equal) temperatures. Thus, the jacket temperature was represented by a series of the step values of temperature (or control stages) equispaced along the reactor length. The number of control stages, the mathematical model of the reactor, and its parameters were input to the optimal control method. Its application generated the optimal control 
function by stochastically applying genetic operations on a set of optimization functions, which were evaluated through the mathematical model of the process to be optimized. Further details of this method may be found in next section (6.2 The New Robust Technique).

\subsection{The New Robust Technique}

Introduced by Upreti (2003), the technique is applied on a problem by randomly initializing a mean control value $\bar{u}_{i}$ for a given $N_{u}$ stages of step values of control function $u$. Followed this initialization, a population of $\Delta u_{2}$ is randomly generated and the mappings are used to calculate control $u$ from $\bar{u}$ and any $\Delta u_{2}$.

The presented technique uses the mapping to relate a binary-coded deviation $\Delta u_{i, 2}$ and $\bar{u}_{i}$ to a control value $u_{i}$ by providing a control vector $\hat{u}(z)$ corresponding to each binarycoded deviation vector $\Delta u_{2}$ in its population. There are two different mappings (Upreti, 2003) employed in this study:

Logarithmic mapping emphasizes the relative order of magnitudes of control values at different stages during the initial iterations. It provides the step value, $u_{i}=b^{y_{1}}$.

Where, $b$ is the logarithmic base, which can be expressed as

$$
b=u_{\max }-u_{\min }
$$

and $y_{i}$ is from

$$
y_{i}=\log _{b} \bar{u}_{i}+\frac{\log _{b} D}{2^{N_{b t}}-1} \Delta u_{i, 2}
$$


In equation (62), $D$ is the variable value of control domain between the limits of $D_{\min }>0$ and b, and $N_{b i t}$ is the number of bits specified to represent any $i$ th element of $\Delta u_{2}$, i.e. $\Delta_{u i, 2}$.

Linear mapping used to refine an optimal control solution straightforward after the initial iterations. This mapping is generally given by

$$
u_{i}=\bar{u}_{i}+\frac{D}{2^{N_{b t}}-1} \Delta u_{i, 2}
$$

The property combined logarithmic and linear mapping leads to an efficient search of robust control solutions in a large control domain with a very low value of $N_{b i t}$.

Table 7 shows the parameters used in the presented optimal control technique.

The algorithm summarized the presented optimal control technique by Upreti (2003) as following:

1. Initialize,

a. $\bar{u}$, the vector of mean values of control function for all $N_{u}$ stages using, $\bar{u}_{i}=u_{\min }+R_{i}\left(u_{\max }-u_{\min }\right) \quad 0 \leq R_{i} \leq 1, \quad i=0,1, \ldots, N_{u}-1$ where $R_{i}$ is the $i$ th pseudo-random number obtained from a pseudo-random number generator.

b. A population of $N_{p o p}$ binary-coded deviation vectors $\Delta u_{2}$ using the pseudorandom number generator, where $N_{\text {pop }}=N_{u} N_{\text {bit }}$.

c. The variable control domain, $D=\left(u_{\max }-u_{\min }\right) / 2$. 
Table 7 Parameters used in the presented optimal control technique

\begin{tabular}{ll}
\hline Number of bits, $N_{b i t}$ & 2 \\
Number of cross-over sites, $N_{x s i t e s}$ & 1 \\
Probability of cross-over, $p_{c}$ & 0.6 \\
Probability of mutation, $p_{m}$ & 0.2 \\
Power index, $n$ & 2 \\
Number of genetic generations, $N_{g e n}$ & 10 \\
Number of inactive iterations, $N_{o}$ & 200 \\
Number of iterations, $N_{i t r}$ & 500 \\
Control factor, $C$ & 0.75 \\
Minimum value of control domin, $D_{\min }$ & $1 \times 10^{-4}$ \\
Integration accuracy, $\varepsilon$ & $1 \times 10^{-10}$ \\
Minimum step of integration, $h_{\min }$ & $1 \times 10^{-7}$ \\
Initial step of integration, $h_{i n i}$ & 0.2 \\
Number of control stage, $N_{u}$ & 6 \\
\hline
\end{tabular}

d. A boolean variable (needed to enable the alternation of logarithmic mapping with linear mapping), ALTERNATE = FALSE.

2. Set logarithmic mapping for the genetic operations of selection, crossover, and mutation.

3. Carry out the following operations on the population of $\Delta u_{2}$ for $N_{g e n}$ generations:

a. Performance index evaluation for each $\Delta u_{2}$. 
b. Selection based on scaled performance index.

c. Crossover with probability $p_{c}$.

d. Mutation with probability $p_{m}$.

4. Store the resulting optimal value of performance index $(\hat{J})$, and corresponding optimal control vector $(\hat{u})$.

5. Replace $\bar{u}$ by $\hat{u}$.

6. If ALTERNATE is TRUE, repeat Steps 3-5 once with linear mapping.

7. If ALTERNATE is FALSE, then if for No consecutive iterations, the fractional change in $\hat{J}$ is less than $1 \%$, set ALTERNATE $=$ TRUE. (This step executes only once.)

8. If $D$ is equal to either $D_{\min }$ or $D_{\max }$, set the size-variation factor for control domain, $C=C^{-1}$. (This step allows the alternation of the successive contraction of D with its successive expansion.)

9. Set $D=C D$. If $D<D_{\min }$, set $D=D_{\min }$. If $D>D_{\max }$, set $D=D_{\max }$. (This step allows the variation of $D$ within its limits.)

10. Go to Step 2 until the specified number of iterations, $N_{i t r}$, are done.

Figure 28 is a flow chart illustrated the algorithm of this new technique. 


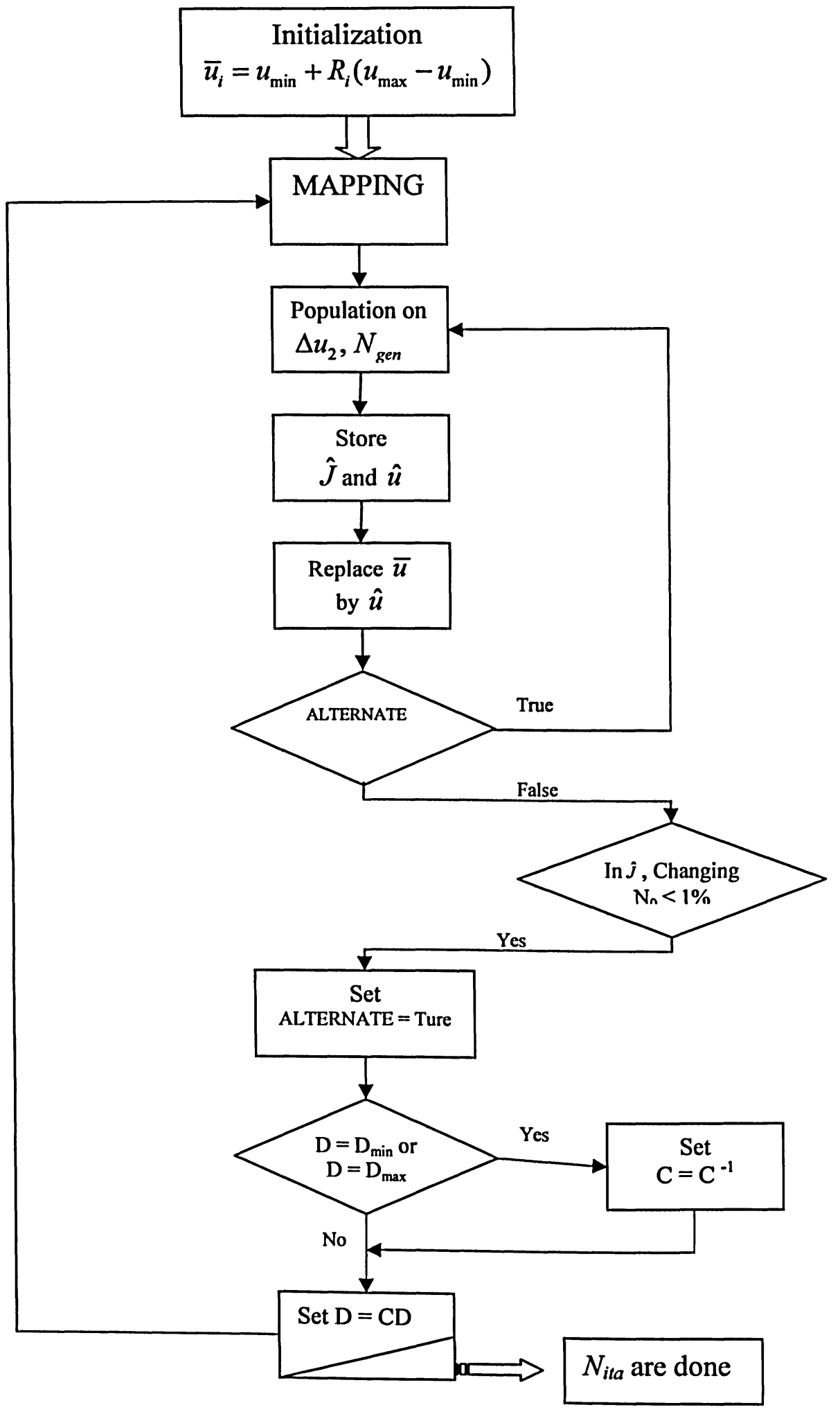

Figure 28. Algorithm Flow Chart 


\subsection{Optimal results}

The result shows the challenges to the industrial tubular reactors in the LDPE product by comparing with modeling results. The accounted $1.577878 \times 10^{4}$ seconds and $4.550633 \times 10^{4}$ seconds of CPU time are used in obtaining optimal jacket temperature for the two cases.

Six control stages of jacket temperatures and two concentrations of initiator injection of $5 \times 10^{-4} \mathrm{~mol} / \mathrm{l}$ and $15 \times 10^{-4} \mathrm{~mol} / \mathrm{l}$ at reactor inlet were considered for this application of optimal control. The model parameters were same as provided earlier in Table 2, 3 and 4. The fractional change in term of monomer concentration is defined as:

$$
\tilde{X}=\left(1-\frac{m}{m_{0}}\right) \times 100
$$

Figure 29 shows the optimal jacket temperature profile for which the final fractional change in monomer concentration gets maximized to $12.6 \%$ and $14.6 \%$.

The comparison of optimized fractional change in monomer concentration with a nonoptimized one-shoot case based on one heat-exchange zone at inlet jacket temperature of $139^{\circ} \mathrm{C}$ is shown in Figure 30 . It is observed that the monomer conversions for the optimized cases are always higher than the non-optimized cases along reactor length. The final optimized monomer conversions in term of monomer concentration are about $40 \%$ and $22 \%$ higher than the non-optimized cases, respectively. 
The reaction temperatures for the optimized and non-optimized cases are shown in Figure 31. It is observed that the temperature constraints of Equation (60) are well satisfied by the optimal control jacket temperature of Figure 29, and the reaction temperature with optimized case is also satisfied by the elevated temperature. With this optimal temperature, the reaction temperatures always stay higher than that for the nonoptimized cases. This is reasonable as higher reaction temperature is responsible for higher polymerization rates. It is worth noting that reaction temperatures for the optimal cases in the second half of reactor length reaches a peak value, drops and then rises again without violating the temperature constraint of Equation (60). This phenomenon can be explained with the help to Figure 29 where the optimal jacket temperature drops in the second half of reactor length to ensure the satisfaction of temperature constraint. Without this temperature drop, the rising reaction temperature for the optimized cases in Figure 31 would have surpassed the maximum temperature limit. The final rise of jacket temperatures in Figure 29 leads to the final rise in reactant temperatures, thereby enhancing final monomer conversion.

As we discussed in simulation section above, higher temperature causes lower molecular weight and larger $P D I$ of final product, which was confirmed by the result shown in Figure 32 and Figure 33 respectively. 
Optimal Profile for Jacket Temperature

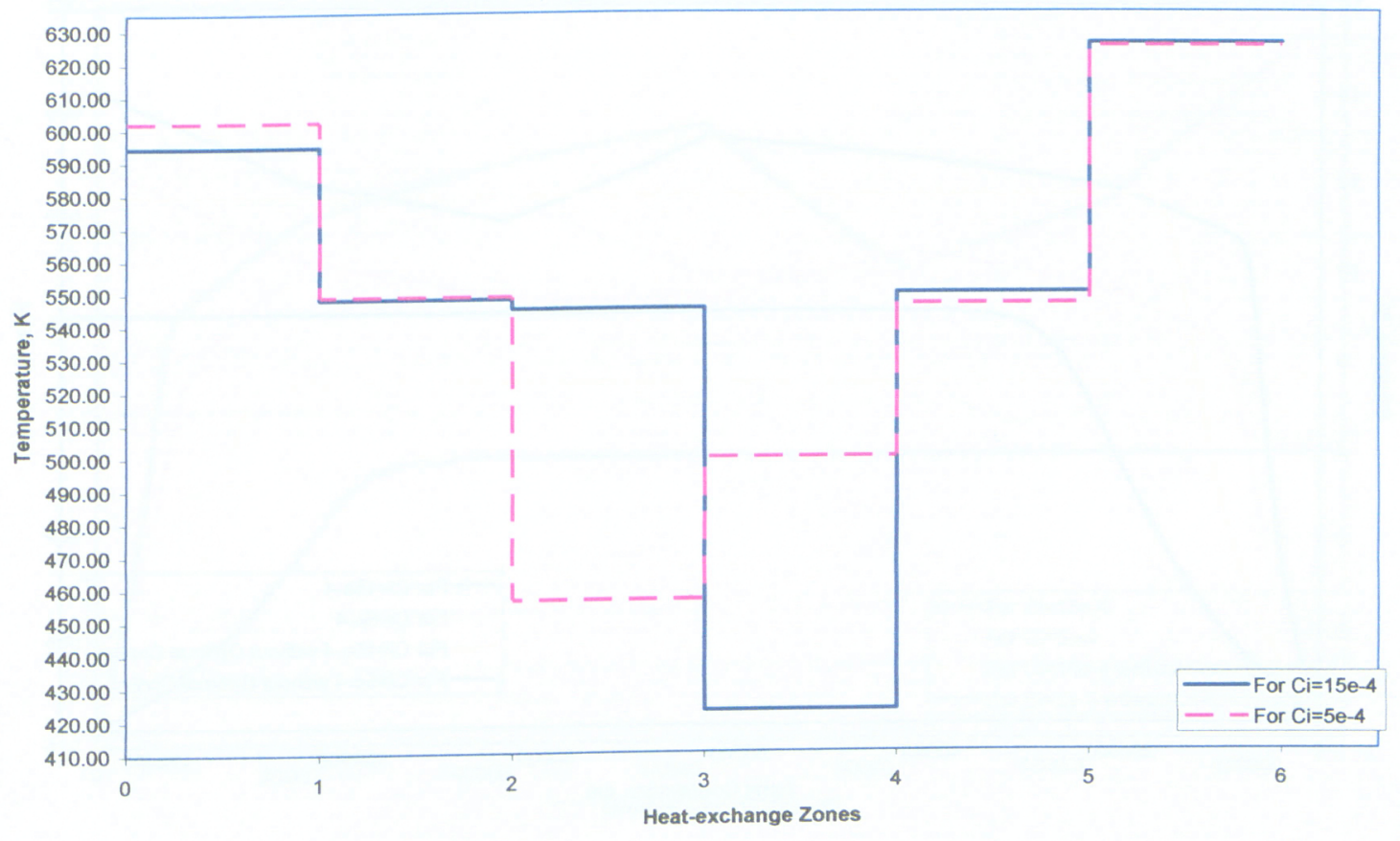

Figure 29. Optimal Profile for Jacket Temperature 
Fractional Change in Monomer Concentration

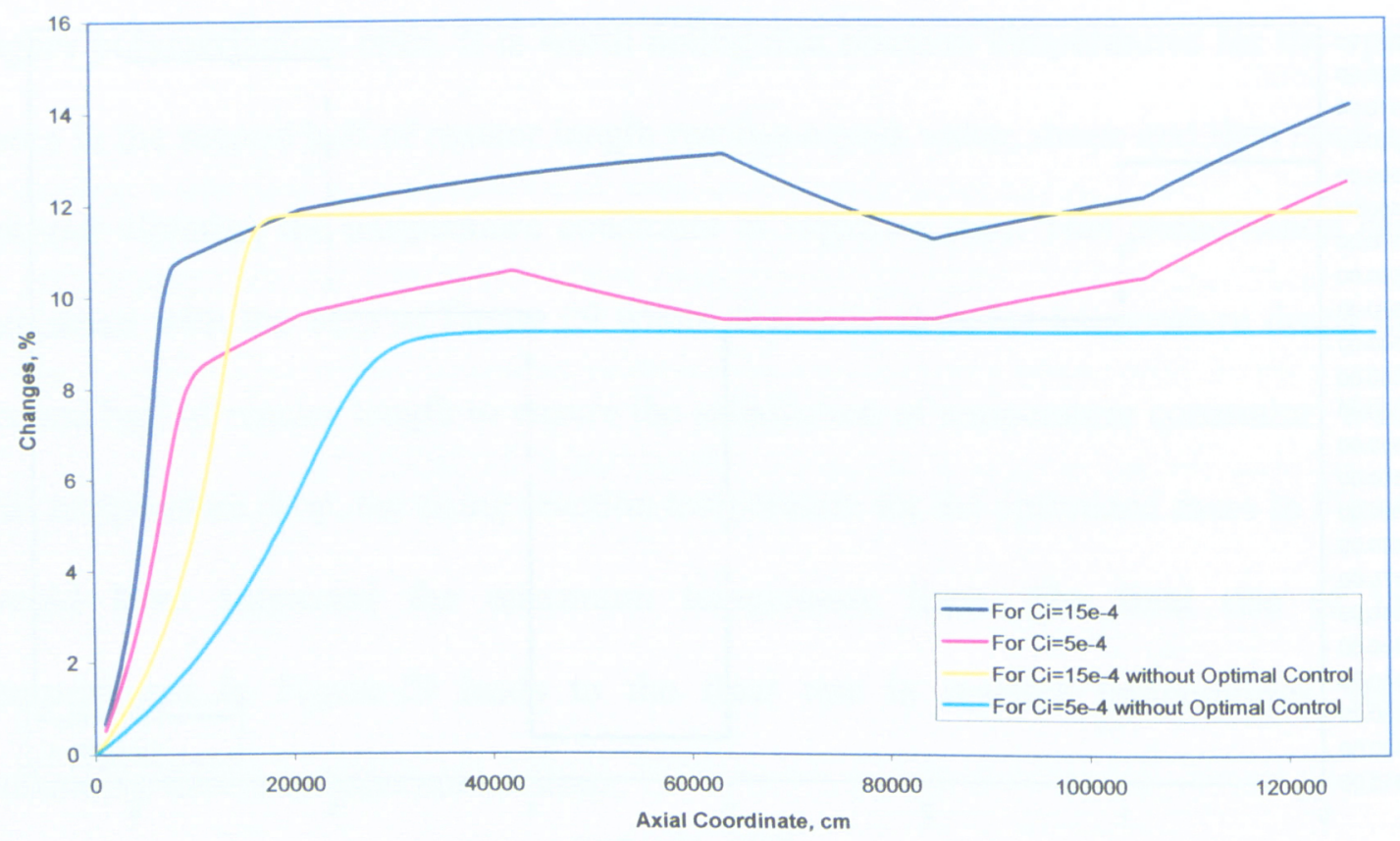

Figure 30. Comparison of Fractional Change in Monomer Concentration with Non-Optimal Control 
Reaction Temperature Profile

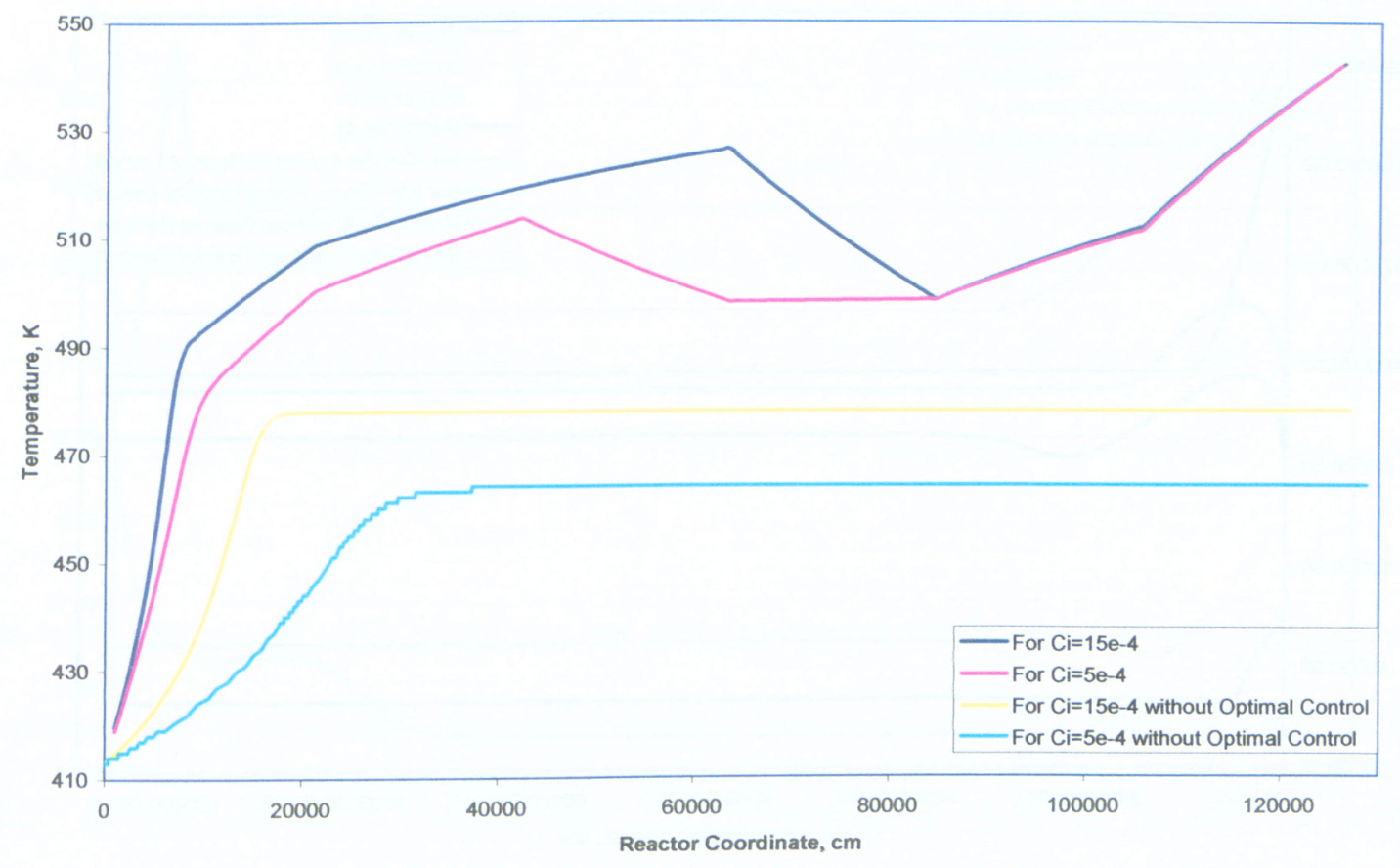

Figure 31. Reaction Temperature between Optimum and Non-optimum 
Molecular Weight Distribution (MWD)

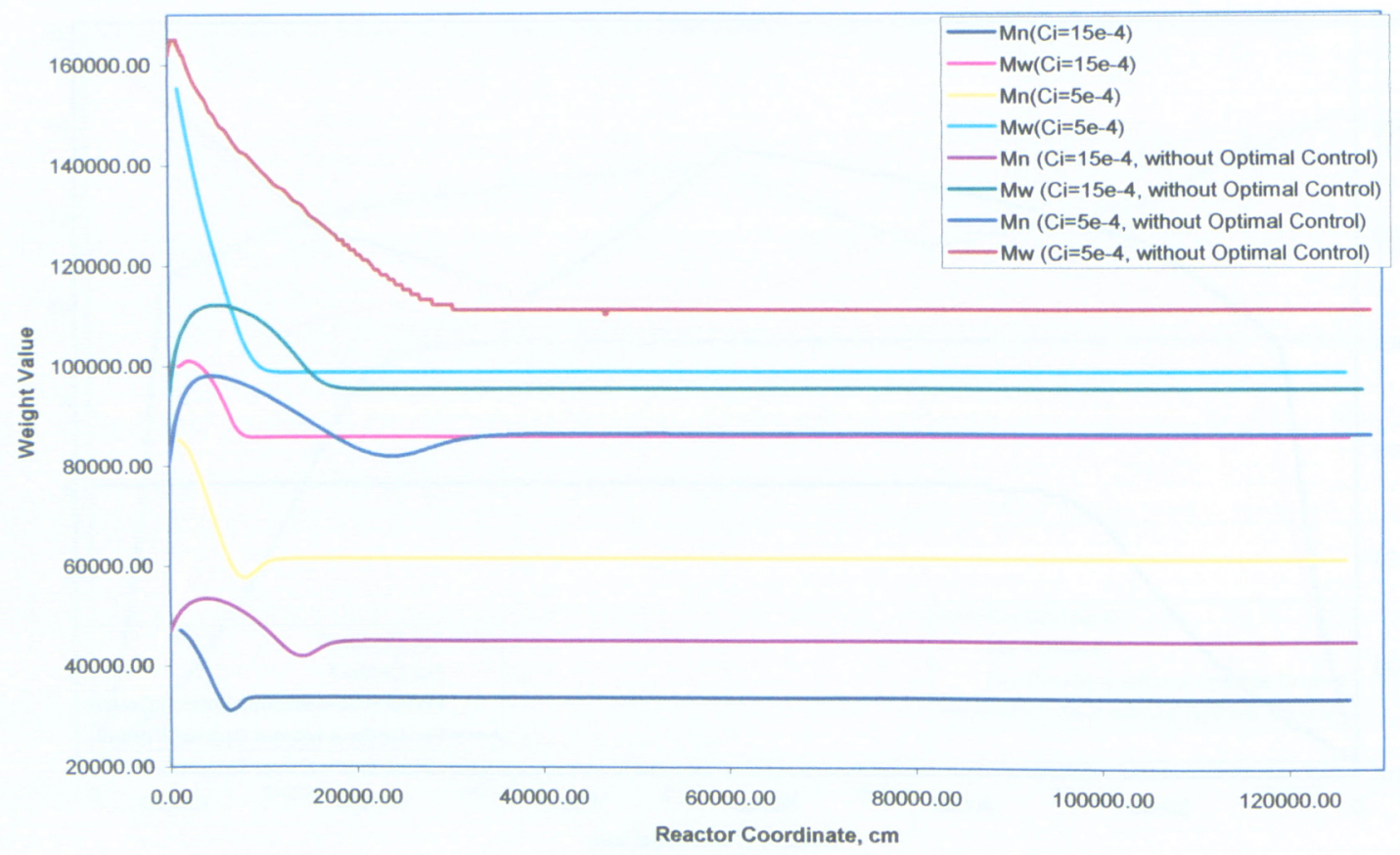

Figure 32. MWD Comparition 
Polydispersity Index (PDI) Distribution

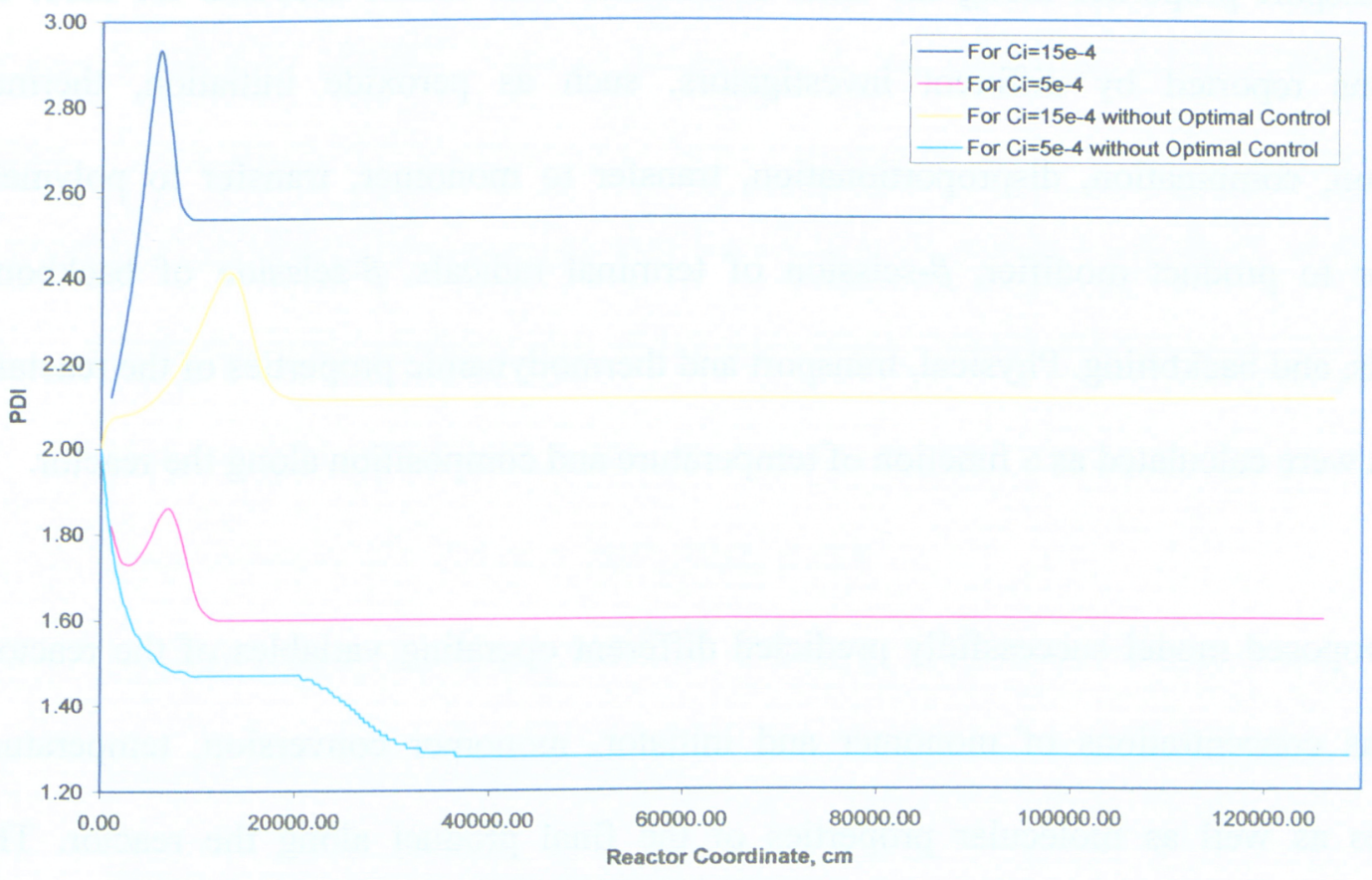

Figure 33. PDI Comparison between State Performance and Optimal Control 


\section{Conclusion Remarks}

A kinetic model for free radical, high-pressure polymerization in a tubular reactor with multi-zone heat exchanges was proposed. The model is based on hypotheses of plug flow, steady state and homogeneous reaction mixture with prediction of thermodynamic and transport properties along the axial coordinate. This model accounts for most of reactions reported by different investigators, such as peroxide initiation, thermal initiation, combination, disproportionation, transfer to monomer, transfer to polymer, transfer to product modifier, $\beta$-scission of terminal radicals, $\beta$-scission of backbone radicals, and backbiting. Physical, transport and thermodynamic properties of the reactant stream were calculated as a function of temperature and composition along the reactor.

The proposed model successfully predicted different operating variables of the reactor, such as concentrations of monomer and initiator, monomer conversion, temperature profiles as well as molecular properties of the final product along the reactor. The simulated temperature profiles for the two cases that were studied show a good agreement with literatures (Table 6). The calculated monomer conversion and molecular properties are also in the ranges reported by several earlier researches. Moreover, the predictions of the profile, value and location of the peaks match the data from earlier reports. All these confirmed that the mechanism, parameters selected are reasonable and are reflected most of factors in a whole. The calculated molecular properties of the product, such as $M W D, P D I$, etc., indicate the model prediction is in agreement with previously reported. 
The model in conjunction with an optimal control algorithm was used to obtain different jacket temperature zones of the reactor in order to maximize monomer conversion at the reactor outlet. It was formed that the monomer conversion decreased by $22-40 \%$ with the application of the optimal control strategy. 


\section{Future Work}

The mathematical model could be used to investigate effect of different initial temperatures and concentrations on the monomer conversion. This can be expanded to study effect of initiator concentration and its temperature on monomer conversion, $P D I$ and MWD performance.

The optimal control algorithm can be expanded to cover number of cooling/heating zones, initial temperature of reactants, initial concentration of reactants and initial temperature at different stages. It is believed that optimal conditions for the ethylene polymerization of tubular reactor can be obtained by manipulating these parameters. 


\section{Notation}

$C_{p} \quad$ Specific heat of reaction mixture, $\mathrm{cal} / \mathrm{g} \cdot \mathrm{K}$

$C_{p c} \quad$ Specific heat of in jacket fluid, cal $/ \mathrm{g} \cdot \mathrm{K}$

$D_{i n} \quad$ Internal diameter of reactor, $\mathrm{cm}$

$f \quad$ Efficiency of reactions

$f_{r} \quad$ The fanning friction factor

$G_{c} \quad$ Volumetric flowrate in jacket, $1 / \mathrm{s}$

I Initiator

$i \quad$ Concentration of initiator, $\mathrm{mol} / \mathrm{l}$

$i_{0} \quad$ Concentration of initiator at inlet point, $\mathrm{mol} / \mathrm{s}$

$k_{b} \quad$ Rate constant of backbiting

$k_{d} \quad$ Rate constant of peroxide initiation

$k_{t h} \quad$ Rate constant of monomer thermal initiation

$k_{p} \quad$ Rate constant of propagation

$K_{T} \quad$ Effective thermal conductivity

$k_{t c} \quad$ Rate constant of termination by combination

$k_{t d} \quad$ Rate constant of termination by thermal degradation

$k_{t r m} \quad$ Rate constant of chain transfer to monomer

$k_{t r p} \quad$ Rate constant of chain transfer to polymer

$k_{t r s} \quad$ Rate constant of chain transfer to solvent 
$k_{\beta 1} \quad$ Rate constant of $\beta$-Scission to tertiary radical

$k_{\beta} \quad$ Rate constant of $\beta$-Scission to secondary radical

$m \quad$ Monomer concentration, $\mathrm{mol} / \mathrm{s}$

$m_{0} \quad$ Monomer concentration at inlet point, $\mathrm{mol} / \mathrm{l}$

$M_{w} \quad$ Molecular weight

$M_{w m} \quad$ Monomer molecular weight

$\overline{M_{w}} \quad$ Weight-average molecular weight

$\overline{M_{n}} \quad$ Number-average molecular weight

$P \quad$ Reaction pressure

$P_{r} \quad$ Dead polymer with chain length $\mathrm{r}$

$p_{r}$ Dead polymer concentration for chain length $\mathrm{r}, \mathrm{mol} / \mathrm{l}$

$P_{s} \quad$ Dead polymer with chain length $\mathrm{s}$

$p_{s}$ Dead polymer concentration for chain length $\mathrm{s}, \mathrm{mol} / \mathrm{l}$

$R_{i n} \cdot \quad$ Primary initiator radical fragment

$R_{r}^{\bullet} \quad$ Radical of chain length $\mathrm{r}$

$R_{r} \quad$ Concentration of radical with chain length $\mathrm{r}, \mathrm{mol} / \mathrm{l}$

$R_{s} \quad$ Radical of chain length $\mathrm{s}$

$R_{s} \quad$ Concentration of radical with chain length $\mathrm{s}, \mathrm{mol} / 1$

$S \quad$ Solvent

$s \quad$ Solvent concentration, $\mathrm{mol} / \mathrm{l}$ 
$R_{p} \quad$ Rate of propagation

T Reaction temperature, $\mathrm{K}$

$t \quad$ Time, second

$T_{c} \quad$ Jacket temperature, $\mathrm{K}$

$t_{p} \quad$ Pulse time, second

$U \quad$ Global heat transfer coefficient, $\mathrm{cal} / \mathrm{m}^{2} \cdot \mathrm{K} \cdot \mathrm{s}$

$v \quad$ Axial velocity of reaction stream, $\mathrm{cm} / \mathrm{s}$

$v_{o}$ Inlet axial velocity of reaction stream, $\mathrm{cm} / \mathrm{s}$

X Monomer conversion, \%

$\tilde{X}$ Conversion in term of fractional change in monomer concentration, \%

$X_{i} \quad$ Initiator conversion, \%

$z \quad$ Axial distance from reactor inlet, $\mathrm{cm}$

\section{Subscripts}

$\begin{array}{ll}\beta & \text { Beta scission } \\ b & \text { Backbitting } \\ d & \text { Decomposition reaction } \\ i & \text { initiation reaction } \\ \text { in } & \text { Inside } \\ j & \text { Order of moment }\end{array}$


m Monomer

$0 \quad$ Initial conditions

$p \quad$ Propagation reaction

pdb Propagation by double - bond reaction

$r \quad$ Chain length

$s \quad$ Chain length

tc Combination termination

th Thermal initiation

trm Chain transfer to monomer

trp Chain transfer to polymer

trs Chain transfer to solvent

\section{Greek Letters}

$\alpha \quad$ Adjustable parameter in pressure pulse equation

$\beta \quad$ Adjustable parameter in pressure pulse equation

$\lambda_{0} \quad$ Zero moment of live polymer radical

$\lambda_{1} \quad$ First moment of live polymer radical

$\lambda_{2}$ Second moment of live polymer radical

$\mu_{0} \quad$ Zero moment of dead polymer

$\mu_{1} \quad$ First moment of dead polymer

$\mu_{2} \quad$ Second moment of dead polymer 
$\mu_{3} \quad$ Third moment of dead polymer

$\omega_{p} \quad$ Weight fraction of polymer

$\rho_{c} \quad$ Coolant density

Acronyms

LDPE Low density polyethylene

$L C B \quad$ Long chain branch

$M_{n} \quad$ Number average molecular weight

$M_{w} \quad$ Weight average molecular weight

MWD Molecular weight distribution

PDI Polydispersity index

$S C B$ Short chain branch

SSH Steady-state hypothesis 
References

Agrawal, S. and Han, C. D. (1975). Analysis of High-Pressure Polyethylene Tubular Reactor with Axial Mixing. AIChE Journals, 21(3), 449-465.

Asteasuain, M., Tonelli, S. M., Brandolin, A. and Bandoni, J. A. (2001). Dynamic simulation and optimization of tubular polymerization reactors in gPROMS. Computers \& chemical Engineering, 25, 509-515.

Baltsas, A., Papadopoulos, E., \& Kiparissides, C. (1998). Application of the PseudoKinetic Rate Constant Method to High Pressure LDPE Tubular Reactors. Computers and Chemical Engineering, 22(suppl.), S95-102.

Barton, P. I., Allgor, R. J., Feehery, W. F., \& Galán, S. (1998). Dynamic optimization in a discontinuous world. Industrial Engineering and Chemical Research, 37, 966-981.

Benedict, M., Webb, G. B. and Rubin, L. C. (1940). An Empirical Equation for Thermodynamic Properties of Light Hydrocarbons and Their Mixtures. Journal of Chemical Physics. 8, 334

Biegler, L. T., Cervantes, A. M., and Wächter, A. (2002). Advances in Simultaneous Strategies for Dynamic Process Optimization. Chemical Engineering Science, 57, 575593.

Bird, R. B., Stewart, W. E., and Lightfoot, E. N., "Transport Phenomena" John Wiley \& Sons, Inc., 1960. 
Baltsas, A., Papadopoulos, E., and Kiparissides, C. (1998). Application of the PseudoKinetic Rate Constant Method to High Pressure LDPE Tubular Reactors. Computers and Chemical Engineering, 22(suppl.), S95-102.

Bojkov, B. and Luus, R. (1996). Optimal Control of Nonlinear Systems with Unspecified Final Times. Chemical Engineering Science, 51(6), 905-919.

Brandolin, A., Capiati N.J., Farber J.N., and Valles, E.M. (1988). Mathematical Model for High-Pressure Tubular Reactor for Ethylene Polymerization. Industrial and Engineering Chemistry Research, 27(5), 784-790.

Brandolin, A., Lacunza, M.H., Ugrin, P.E., and Capiati, N.J. (1996). High Pressure Polymerization of Ethylene. An Improved Mathematical Model for industrial Tubular Reactors. Polymer Reaction Engineering, 4(4), 193-240.

Buback, M. (1980). The High Pressure Polymerization of Pure Ethylene. Makromolecular Chemistry, 181, 373-384

Cervantes, A., Tonelli, S., Brandolin, A., Bandoni, A., and Biegler, L. (2000). Largescale Dynamic Optimization of a Low Density Polyethylene Plant. Computers and Chemical Engineering 24, 983-989. 
Chen, C. H., Bermeychuk, J.G., Howell, J.A., and Ehrlich, P. (1976). Computer Model for Tubular High-Pressure Polyethylene Reactors. AIChE J., 22(3), 463-471.

Crowley, T. J. and Choi, K. Y. (1998). Experimental Studies on Optimal Molecular Weight Distribution Control in a Batch - free Radical Polymerization Process. Chemical Engineering Science, 53(15), pp. 2769-2790.

Dadebo, S. A., and McAuley, K. B. (1995). Dynamic Optimization of Constrained Chemical Engineering Problems using Dynamic Programming. Computer and Chemical Engineering, 19, 513-525.

Dhib, R. and Al-Nidawy, N. (2002). Modeling of Free Radical Polymerization of Ethylene Using Difunctional Initiators. Chemical Engineering Science, 57, 2735-2746

Dittus, F. W. and Boelter, L. M. (1930). "Heat Transfer in Automobile Radiators of the Tubular Type" University of California - Berkeley, Pub. Eng., 2, 443.

Goldman, K. In ethylene and its Industrial Derivatives; Miller, S. A. Ed.; Ernest Benn Limited: London, 1969.

Goto, S., Yamamoto, K., Furui, S., and Sugimoto, M. (1981). Computer Model for Commercial High Pressure Polyethylene Reactor Based on Elementary Reaction Rates Obtained Experimentally. Journal of Applied Polymer Science: Applied Polymer Symposium, 36, 21-40. 
Gupta, S. K., Kumar, A. and Krishnamurthy, M. V. G. (1985). Simulation of Tubular Low-Density Polyethylene. Polymer Engineering Science, 25(1), 37-47.

Gupta, Y. P. (1995). Semiexhaustive Search for Solving Nonlinear Optimal Control Problems. Industrial Engineering and Chemical Research, 34, 3878-3884.

Hollard, W. and Ehrlich, P. (1983). An Improved Model for Temperature and Conversion Profiles in Tubular High Pressure Polyethylene Reactors. Chemical Engineering Communications, 24, 57-70.

Hulburt, H. M. and Katz. S. (1964). Some problems in Particle Technology: A Statistical Mechanical Formulation. Chemical Engineering Science, 19, 555-574.

Katz, S., and Saidel, G. M. (1967). Moments of the Size Distribution in Radical Polymerization. AIChE J., 13, 319.

Konstadinidis, K., Achilias, D. and Kiparissides, C. (1992). Development of a Unified Mathematical Framework for Modeling Molecular and Structural Changes in FreeRadical Homopolymerization Reaction. Polymer, 33(23), 5019-5031.

Lacunza, M. H., Ugrin, P.E., Brandolin, A. and Capiati, N. J. (1998). Heat Transfer Coefficient in a High Pressure Tubular Reactor for Ethylene Polymerization. Polymer engineering and science, Vol.38, No.6, 992-1013 
Lee, K., and Marano, J. (1979). Polymerization Reactors and Processes (ACS Symposium Series 104, Henderson, J. N. and Bouton, T. C. eds.), American Chemical Society, Washington, D.C., p. 221.

Lee, M. H., Han, C. and Chang, K. S. (1999). Dynamic Optimization of a Continuous Polymer Reactor Using a Modified Differential Evolution Algorithm. Industrial Engineering and Chemical Research, 38, 4825-4831.

Lee, M. H., Han, C., and Chang, K. S. (1997). Hierarchical Time-optimal Control of a Continuous Co-polymerization Reactor during Start-up or Grade Change Operation using Genetic Algorithms. Computer and Chemical Engineering, 21, S1037-S1042.

Lorenzini, P., Pons, M. and Villermaux, J. (1992). Free-Radical Polymerization Engineering-IV. Modeling Homogeneous Polymerization of Ethylene: Determination of model Parameters and Final Adjustment of Kinetic Coefficients. Chemical Engineering Science, 47(15/16), 3981-3988.

Lorenzini, P., Pons, M., and villermaux, J. (1992a). Free-Radical Polymerization Engineering-III. Modeling Homogeneous Polymerization of Ethylene: Mathematical

Lorenzini, P., Pons, M.m and Villermaux, J. (1992b). Free-Radical Polymerization Engineering-IV. Modeling Homogeneous Polymerization of Ethylene: Determination of 
Model Parameters and Final Adjustment of Kinetic Coefficients. Chemical Engineering Science, 47(15/16), 3981-3988.

Luft, G., Bitsch, H., and Seidl, H. (1977). Effectiveness of Organic Peroxide Initiators in the High-Presssure Polymerization of Ethylene. J. Macromol. Sci.-Chem., A11(6), 18091112.

Luus, R., and Hennessy, D. (1999). Optimization of Fed-Batch Reactors by the LuusJakola Optimization Procedure. Industrial Engineering and Chemical Research, 38, $1948-1955$.

Luus, R. (1990). Application of Dynamic Programming to High-dimensional Nonlinear Optimal Control Problems. International Journal of Control, 52, 239-250.

Luyben, W. L. (1990). "Process Modeling, Simulation and Control for Chemical Engineers" $2^{\text {nd }}$ ed., McGraw Hall, Inc.

Manousiouthakis, V. and Chmielewski, D. J. (2002). On Constrained Infinite - time Nonlinear Optimal Control. Chemical Engineering Science, 57, 105-114.

Mavridis, H. and C. Kiparissides (1985). Optimization of a High-Pressure Polyethylene Tubular Reactor. Polymer Process Engineering, 3(3), 263-290. 
Metzler, D. E., Harris, C. M., Johnson, R. J., Siano, D. B. and Thomson, J. A. (1973). Spectra of 3-Hydroxypyridines. Brand-Shape Analysis and Evaluation of Tautomeric Equilibra. Biochemistry, 12(26), 5377-5392.

Model and New Method for Obtaining Molecular Weight Distribution. Chemical Engineering Science, 47(15/16), 3969-3980.

Pontryagin, L. S., Boltyanskii, V. G., Gamkrelidge, R., and Mishchenko, E. (1962). The mathematical theory of optimal processes. New York: Interscience.

Ray, W. H. and Laurence, R. L. (1977). Polymerization Reaction Engineering. In Chemical Reactor Theory. L. Lapidus and N. Amoundson (Eds.). Pentice Hall Inc.: Englewood Cliffs, New Jersey, pg. $532-582$.

Reucht, P., Tilger, B., and Luft, G. (1985). Prediction of Molar Mass Distribution, Number and Weight Average Degree of polymerization and Branching of Low Density Polyethylene. Chemical Engineering Science, 40(10), 1935-1942.

Rudin, A. (1999) “The Elements of Polymer Science and Engineering," $2^{\text {nd }}$ ed., Academic Press.

Saidel, G. M. and Katz, S. (1968). Dynamic Analysis of Branching in Radical Polymerization. Journal of Polymer Science, A - 2, 6, 1149. 
Seidl, H. and Luft, G. (1981). Peroxides as Initiators for High-Pressure Polymerization. J. Macromol. Sci.-Chem., A15(1), pp. 1-33.

Shirodkar, P.P., and Tsien, G. O. (1986). A Mathematical Model for the Production of Low Density polyethylene in A Tubular Reactor. Chemical Engineering Science, 41(4), 1031-1038.

Small, P. A. (1972). Effects of Long - chain Branching on Distribution of degree of polymerization. Polymer, 13, 636-540.

Takahashi, T. and Ehrlich, P. (1982). Absolute Rate Constants for the Free Radical Polymerization of Ethylene in the supercritical Phase. Macromolecules, 15(3), 714-719.

Tatsukami, Y., Takahashi, T., and Yoshioka, H. (1980). Reaction Mechanism of Oxygeninitiated Ethylene Polymerization at High Pressure. Makrom. Chem., 181, 1107-1114.

Tieu, D., Cluett, W.R., Penlidis, A. (1994). Optimization of Polymerization Reactor operation: Review and case studies with the End-Point Collocation Method. Polymer Reaction Engineering, 2(3), 275-313.

Upreti, S. R., (2003). A New Robust Technique for Optimization Control of Chemical Engineering Process. Computers and Chemical Engineering, In Press. 
Wang, F., and Chiou, J. (1997). Optimal Control and Optimal Time Location Problems of Differential-algebraic Systems by Differential Evolution. Industrial Engineering and Chemical Research, 36, 5348-5357.

Yao, F. Z., Dhib, R., Lohi, A. and Upreti, S. R. (2004). Modeling, Simulation and Optimal Control of Ethylene Polymerization in a High-Pressure Tubular Reactor. International Journal of Chemical Reactor Engineering, in process.

Yoon, B.J. and Rhee, H., (1985). A Study of the High Pressure Polyethylene Tubular Reactor. Chem. Eng. Commun., Vol. 34 pp. 253-267.

Zabisky, R. C. M., Chan, W.-M., Gloor, P. E. and Hamielec, A. E. (1992). A Kinetic Model for olefine polymerization in high-pressure tubular reactors: a review and update. Polymer, Volume 33, Number 11 pp.2243-2262.

Zhou, W., Marshall, E. and Oshinowo, L. (2001). Modeling LDPE Tubular and Autoclave Reactor. Industry Engineering \& Chemistry Research, 40, 5533-5542.

Zhou, W. and Ray, W. (2002). Modeling of "Living" Free-Radical Polymerization Process. II. Tubular Reactors. Journal of Applied Polymer Science, Vo. 86, 1047-1056. 


\section{Appendix A \\ Fundamental Equations of a tubular reactor}

Let us assume the reaction $A \stackrel{k}{\longrightarrow} B$ occurred in a tubular reactor. Applying molar balance on reactor's differential cylindrical element of thickness $d z$ :

$$
\begin{aligned}
& {\left[\begin{array}{l}
\text { rate of change of moles of } j \text { th } \\
\text { component inside system }
\end{array}\right]} \\
& =\left[\begin{array}{l}
\text { flow of moles of } j \text { th } \\
\text { component int } o \text { system }
\end{array}\right]-\left[\begin{array}{l}
\text { flowo of moles of } j \text { th } \\
\text { component out of system }
\end{array}\right] \\
& +\left[\begin{array}{l}
\text { rate of formation of moles of } j \text { th } \\
\text { component from chemical reactions }
\end{array}\right]
\end{aligned}
$$

gives:

$$
\begin{aligned}
& \frac{\partial\left(A d z C_{A}\right)}{d t}=\left(v A C_{A}+A N_{A}\right)-\left(v A C_{A}+A N_{A}+\frac{\partial\left(v A C_{A}+A N_{A}\right)}{\partial z} d z\right)-k C_{A} A d z \\
& \frac{\partial C_{A}}{\partial t}+\frac{\partial\left(v C_{A}\right)}{\partial z}+\frac{\partial\left(N_{A}\right)}{\partial z}+k C_{A}=0
\end{aligned}
$$

Applying Fick's law: $N_{A}=-D_{A} \frac{\partial C_{A}}{\partial z}$

By assuming a constant $D_{A}$, equation (A3) becomes: 


$$
\frac{\partial C_{A}}{\partial t}+\frac{\partial\left(v C_{A}\right)}{\partial z}+k C_{A}=D_{A} \frac{\partial^{2} C_{A}}{\partial z^{2}}
$$

Similarly, energy balance on the differential element gives:

$$
\begin{aligned}
& \frac{\partial\left(\rho A d z C_{p} T\right)}{\partial t} \\
& =v A \rho C_{p} T-\left[v A \rho C_{p} T+\frac{\partial\left(v A \rho C_{p} T\right)}{\partial z} d z\right]+A d z k C_{A}\left(-\Delta H_{i}\right) \\
& \quad-U\left(\pi D_{i n} d z\right)\left(T-T_{c}\right)+q_{z} A-\left(q_{z} A+\frac{\partial q_{z} A}{\partial z} d z\right)
\end{aligned}
$$

Using Fourier's law, heat flux can be expressed as:

$$
q_{z}=-K_{T} \frac{\partial T}{\partial Z}
$$

Equation (A6) can be rearranged to the following equation (A8) using $A=1 / 4 \pi D_{\text {in }}{ }^{2}$ and assuming constant $K_{T}$ :

$$
\frac{\partial\left(\rho C_{p} T\right)}{\partial t}+\frac{\partial\left(v \rho C_{p} T\right)}{\partial z}-k C_{A}\left(-\Delta H_{i}\right)+\frac{4 U}{D_{i n}}\left(T-T_{c}\right)=K_{T} \frac{\partial^{2} T}{\partial z^{2}}
$$

Similarly, for the jacket:

$$
\begin{aligned}
& \frac{\partial}{\partial t}\left(\rho_{c} G_{c} C_{p c} d z T_{c}\right) \\
& =\rho_{c} G_{c} C_{p c} T_{c}-\left[\rho_{c} G_{c} C_{p c} T_{c}+\frac{\partial\left(\rho_{c} G_{c} C_{p c} T_{c}\right)}{\partial z} d z\right] \\
& +U\left(\pi D_{i n} d z\right)(T-T c)+q_{c} A-\left(q_{c} A+\frac{\partial\left(q_{c} A\right)}{\partial z} d z\right)
\end{aligned}
$$


or

$$
\frac{\partial\left(\rho_{c} G_{c} C_{p c} T_{c}\right)}{\partial t}+\frac{\partial\left(\rho_{c} G_{c} C_{p c} T_{c}\right)}{\partial z}+\pi D_{i n} U\left(T-T_{c}\right)=\frac{\partial\left(q_{c} A\right)}{\partial z}
$$

For an overall mass balance, we have:

$$
\frac{\partial \rho}{\partial t}+\frac{\partial(\rho v)}{\partial z}=0
$$

Hence, the set of equation (A5), (A8), (A10) and (A11) can express the reaction in a one dimension tubular reactor. More commonly, if there are $\mathrm{j}$ reactants and $\mathrm{M}$ reactions occurred in the reactor, the modified equations may be concerned to equation (A5) and (A8). It can be rewritten as:

$$
\begin{aligned}
& \frac{\partial C_{j}}{\partial t}+\frac{\partial\left(v C_{j}\right)}{\partial z}+\sum_{i=1}^{M} \alpha_{i j} r_{i}=D_{j} \frac{\partial^{2} C_{j}}{\partial z^{2}} \\
& \frac{\partial\left(\rho C_{p} T\right)}{\partial t}+\frac{\partial\left(v \rho C_{p} T\right)}{\partial z}-\sum_{i=1}^{M}\left(-\Delta H_{i}\right) r_{i}+\frac{4 U}{D_{i n}}\left(T-T_{c}\right)=K_{T} \frac{\partial^{2} T}{d z^{2}}
\end{aligned}
$$

Where, $\alpha_{i j}$ is the stoichiometric coefficient of species $j$ in reaction $i,\left(-\Delta H_{i}\right)$ is the reaction enthalpy, $D_{i n}$ is the diameter of tubular pipe, $\rho$ and $\rho_{c}$ stand for density of reactants mixture and density of coolant in jacket, respectively. The $C_{p}$ and $C_{p c}$ are specified heat of reactant mixture and specific heat of coolant in jacket, respectively. $k$ is reaction constant, $r_{i}$ is the reaction rate, $K_{T}$ is effective thermal conductivity, $U$ is overall heat transfer coefficient, $T$ and $T_{c}$ are the reaction temperature and temperature on jacket side, respectively. $A$ is the cross section of area of tubular pipe, and $z$ is the axial coordinate of tubular reactor. 


\section{Appendix B}

\section{Physical Properties: Viscosity and Heat Transfer Model}

Physical properties may be expressed as a function of monomer concentration, temperature and pressure along with the axial coordinate of the reactor:

$$
\psi=f(m, p, T, z)
$$

Overall heat transfer coefficient $U$

As reported by Lacunza, et al., (1998), the complex nature of $U$ profiles along the reactor is a well known phenomenon. By the sum of film resistances at the reaction and jacket sides, thermal resistance through the reactor wall and fouling resistance, the overall heat transfer coefficient between the reacting mixture and the jacket fluid may be calculated from the following expression:

$$
\frac{1}{U}=\frac{1}{h_{c}\left(D_{o} / D_{i n}\right)}+\frac{2.3 D_{i}}{2 k_{w}} \log \left(\frac{D_{o}}{D_{i n}}\right)+\frac{1}{h_{i}}+R_{f}
$$

where, the film resistance at the jacket side may be calculated from the follow formula (Dittus et al., 1930):

$$
\frac{1}{h_{c}}=\frac{D_{e}}{0.026 k_{c} \operatorname{Re}_{c}^{0.8} \operatorname{Pr}_{c}^{0.33}\left(\frac{\mu_{c}}{\mu_{w c}}\right)^{0.14}}
$$


The resistance at the reaction side can be expressed similar to the schems used by (Chen et al., 1976; Gupta, et al., 1985; Zabisky et al., 1992):

The viscosity of the monomer in the reactor is given by $\left(T\right.$ in ${ }^{\circ} \mathrm{C}$, from equation (B4) to (B12)):

$$
\eta_{0}=1.98 \times 10^{-4}+1.15 \times 10^{2} / T^{2}
$$

and the relative viscosity is:

$$
\log _{10}\left(\eta_{r}\right)=0.0313 \mu_{1}^{3 / 2} / \mu_{0}^{1 / 2}
$$

where, $\mu_{0}$ and $\mu_{I}$ are the zeroth and the first moments of the polymer molecular-weight distribution.

The solution viscosity is calculated by the following expression if we assume monomer is the solvent:

$$
\eta_{s}=\eta_{r} \eta_{0}
$$

The specific volume of polymer:

$$
V_{p}=0.949+4.988 \times 10^{-4} T
$$

and the specific volume of monomer

$$
V_{m}=\left(0.710-4.475 \times 10^{-4} T\right)^{-1}
$$

The density of reacting mixture is given by:

$$
\rho=\left[1+0.028 m\left(V_{p}-V_{m}\right)\right] / V_{p}
$$

The weight fraction of monomer may be expressed as:

$$
\omega_{m}=0.028 \mathrm{~m} / \rho
$$

The Reynolds number is: 


$$
\operatorname{Re}=2 r_{i} \rho\left(V / A_{c}\right) / \eta_{s}
$$

The specific heat of reacting mixture is defined as:

$$
C_{p}=0.518 \omega_{m}+\left(1.041+8.3 \times 10^{-4} T\right) \omega_{p}
$$

The Prandtl number is given by:

$$
\operatorname{Pr}=C_{p} \eta_{s} / K
$$

The thermal conductivity of polyethylene reaction mixture $\left(\mathrm{cal} \mathrm{cm}^{-1} \mathrm{~s}^{-1} K^{-1}\right)$ is given by:

$$
K=5.0 \times 10^{-4} \omega_{m}+3.5 \times 10^{-4} \omega_{p}
$$

The Nusselt number is given by:

$$
\begin{array}{ll}
N u=0.026 \operatorname{Re}^{0.8} \operatorname{Pr}^{0.33} & \text { for } \operatorname{Re} \geq 10000 \\
N u=0.166\left(\operatorname{Re}^{2 / 3}-125\right) \operatorname{Pr}^{0.33}\left(1+\left(2 r_{i} / L\right)^{2 / 3}\right) & \text { for } \operatorname{Re}<10000
\end{array}
$$

Hence, the inside heat transfer coefficient is given by:

$$
h_{i}=k N u / 2 r_{i}
$$

Then, an established net fouling resistance can be calculated by the follow equation:

$$
R_{f}=\frac{0.01 D_{i n} \omega_{m} e^{0.03 \omega_{m}}\left(\frac{R_{t}}{1.2 \times 10^{-6}}\right)^{\frac{2}{1+\omega_{m}^{0.4}}}}{K}
$$

where, $\omega_{m}$ is fraction of un-reacted monomer in the reacting mixture; $K$ is the thermal conductivity of the reacting mixture.

A typic value of $64.05 \mathrm{~J} / \mathrm{m} . \mathrm{s.} K$ for $K_{w}$ was selected from Lacunza, et al., (1998). 


\section{Appendix C}

Least-Squares Polynomial Regression in Analysis of Density Modeling

Brandolin, et al., (1988) employed a simulation model for the density of reacting mixure feed as following equation:

$$
\rho=a+b T+c T^{2}+d P+e P^{2}+f T P
$$

which can be derived to:

$$
f_{i j}=\rho_{i j}-a-b T_{i}-c T_{i}^{2}-d P_{j}-e p_{j}^{2}-f T_{i} P_{j}
$$

gives a rearranged form by accounting data:

$$
S_{l}=\sum_{i=1}^{5} \sum_{j=1}^{54} f_{i j}^{2}=\sum_{i=1}^{5} \sum_{j=1}^{54}\left(\rho_{i j}-a-b T_{i}-c T_{i}^{2}-d P_{j}-e P_{j}^{2}-f T_{i} P_{j}\right)^{2}
$$

After deriving the equation (B3), we have equations (B4) to (B9) below:

$$
\begin{aligned}
& \frac{\partial S_{l}}{\partial a}=-\sum_{i=1}^{5} \sum_{j=1}^{54} 2\left(\rho_{i j}-a-b T_{i}-c T_{i}^{2}-d P_{j}-e P_{j}^{2}-f T_{i} P_{j}\right)=0 \\
& \frac{\partial S_{l}}{\partial b}=-\sum_{i=1}^{5} \sum_{j=1}^{54} 2\left(\rho_{i j}-a-b T_{i}-c T_{i}^{2}-d P_{j}-e P_{j}^{2}-f T_{i} P_{j}\right) T_{i}=0 \\
& \frac{\partial S_{l}}{\partial c}=-\sum_{i=1}^{5} \sum_{j=1}^{54} 2\left(\rho_{i j}-a-b T_{i}-c T_{i}^{2}-d P_{j}-e P_{j}^{2}-f T_{i} P_{j}\right) T_{i}^{2}=0 \\
& \frac{\partial S_{l}}{\partial d}=-\sum_{i=1}^{5} \sum_{j=1}^{54} 2\left(\rho_{i j}-a-b T_{i}-c T_{i}^{2}-d P_{j}-e P_{j}^{2}-f T_{i} P_{j}\right) P_{j}=0 \\
& \frac{\partial S_{l}}{\partial e}=-\sum_{i=1}^{5} \sum_{j=1}^{54} 2\left(\rho_{i j}-a-b T_{i}-c T_{i}^{2}-d P_{j}-e P_{j}^{2}-f T_{i} P_{j}\right) P_{j}^{2}=0 \\
& \frac{\partial S_{l}}{\partial f}=-\sum_{i=1}^{5} \sum_{j=1}^{54} 2\left(\rho_{i j}-a-b T_{i}-c T_{i}^{2}-d P_{j}-e P_{j}^{2}-f T_{i} P_{j}\right) T_{i} P_{j}=0
\end{aligned}
$$


Hence, we can get the following equations:

$$
\begin{aligned}
& \sum_{i=1}^{5} \sum_{j=1}^{54} \rho_{i j} \\
&= a \sum_{i=1}^{5} \sum_{j=1}^{54} 1+b \sum_{i=1}^{5} \sum_{j=1}^{54} T_{i}+c \sum_{i=1}^{5} \sum_{j=1}^{54} T_{i}^{2}+d \sum_{i=1}^{5} \sum_{j=1}^{54} P_{j}+e \sum_{i=1}^{5} \sum_{j=1}^{54} P_{j}^{2}+f \sum_{i=1}^{5} \sum_{j=1}^{54} T_{i} P_{j} \\
& \sum_{i=1}^{5} \sum_{j=1}^{54} \rho_{i j} T_{i} \\
&= a \sum_{i=1}^{5} \sum_{j=1}^{54} T_{i}+b \sum_{i=1}^{5} \sum_{j=1}^{54} T_{i}^{2}+c \sum_{i=1}^{5} \sum_{j=1}^{54} T_{i}^{3}+d \sum_{i=1}^{5} \sum_{j=1}^{54} T_{i} P_{j}+e \sum_{i=1}^{5} \sum_{j=1}^{54} T_{i} P_{j}^{2}+f \sum_{i=1}^{5} \sum_{j=1}^{54} T_{i}^{2} P_{j} \\
& \sum_{i=1}^{5} \sum_{j=1}^{54} \rho_{i j} T_{i}^{2} \\
&= a \sum_{i=1}^{5} \sum_{j=1}^{54} T_{i}^{2}+b \sum_{i=1}^{5} \sum_{j=1}^{54} T_{i}^{3}+c \sum_{i=1}^{5} \sum_{j=1}^{54} T_{i}^{4}+d \sum_{i=1}^{5} \sum_{j=1}^{54} T_{i}^{2} P_{j}+e \sum_{i=1}^{5} \sum_{j=1}^{54} T_{i}^{2} P_{j}^{2}+f \sum_{i=1}^{5} \sum_{j=1}^{54} T_{i}^{3} P_{j} \\
& \sum_{i=1}^{5} \sum_{j=1}^{54} \rho_{i j} P_{j}^{2} \\
&= a \sum_{i=1}^{5} \sum_{j=1}^{54} P_{j}^{2}+b \sum_{i=1}^{5} \sum_{j=1}^{54} T_{i} P_{j}^{2}+c \sum_{i=1}^{5} \sum_{j=1}^{54} T_{i}^{2} P_{j}^{2}+d \sum_{i=1}^{5} \sum_{j=1}^{54} P_{j}^{3}+e \sum_{i=1}^{5} \sum_{j=1}^{54} P_{j}^{4}+f \sum_{i=1}^{5} \sum_{j=1}^{54} T_{i} P_{j}^{3} \\
& \sum_{i=1}^{5} \sum_{j=1}^{54} \rho_{i j} P_{j} \\
&= a \sum_{i=1}^{5} \sum_{j=1}^{54} P_{j}+b \sum_{i=1}^{5} \sum_{j=1}^{54} T_{i} P_{j}+c \sum_{i=1}^{5} \sum_{j=1}^{54} T_{i}^{2} P_{j}+d \sum_{i=1}^{5} \sum_{j=1}^{54} P_{j}^{2}+e \sum_{i=1}^{5} \sum_{j=1}^{54} P_{j}^{3}+f \sum_{i=1}^{5} \sum_{j=1}^{54} T_{i} P_{j}^{2} \\
&(\mathrm{~B} 12)
\end{aligned}
$$




$$
\begin{aligned}
& \sum_{i=1}^{5} \sum_{j=1}^{54} \rho_{i j} T_{i} P_{j} \\
= & a \sum_{i=1}^{5} \sum_{j=1}^{54} T_{j} P_{j}+b \sum_{i=1}^{5} \sum_{j=1}^{54} T_{i}^{2} P_{j}+c \sum_{i=1}^{5} \sum_{j=1}^{54} T_{i}^{3} P_{j}+d \sum_{i=1}^{5} \sum_{j=1}^{54} T_{i} P_{j}^{2}+e \sum_{i=1}^{5} \sum_{j=1}^{54} T_{i} P_{j}^{3}+f \sum_{i=1}^{5} \sum_{j=1}^{54} T_{i}^{2} P_{j}^{2}
\end{aligned}
$$

(B15)

Therefore, we can get each of coefficient $a, b, c, d, e$ and $f$ by the matrix algorithm using

\begin{tabular}{|c|c|c|c|c|}
\hline$z=[1.261$ & 1.1532 & 1.062 & 0.9187 & 0.8093 \\
\hline 1.5155 & 1.3854 & 1.2762 & 1.103 & 0.9715 \\
\hline 1.7708 & 1.6182 & 1.4903 & 1.2875 & 1.339 \\
\hline 2.0269 & 1.8516 & 1.7048 & 1.4723 & 1.2964 \\
\hline 2.2838 & 1.0855 & 1.9197 & 1.6573 & 1.4589 \\
\hline 2.5415 & 3.2199 & 2.1348 & 1.8425 & 1.6215 \\
\hline 3.189 & 2.908 & 2.674 & 2.306 & 2.029 \\
\hline 3.842 & 3.501 & 3.217 & 2.772 & 2.437 \\
\hline 4.501 & 4.096 & 3.762 & 3.238 & 2.845 \\
\hline 5.164 & 4.696 & 4.309 & 3.706 & 3.255 \\
\hline 5.834 & 5.299 & 4.858 & 4.175 & 3.665 \\
\hline 6.508 & 5.905 & 5.411 & 4.645 & 4.076 \\
\hline 7.875 & 7.13 & 6.524 & 5.59 & 4.9 \\
\hline 9.266 & 8.371 & 7.647 & 6.54 & 5.727 \\
\hline 10.682 & 9.628 & 8.781 & 7.496 & 6.557 \\
\hline 12.123 & 10.901 & 9.926 & 8.458 & 7.39 \\
\hline 13.595 & 12.192 & 11.083 & 9.425 & 8.226 \\
\hline 16.625 & 14.827 & 13.432 & 11.376 & 9.907 \\
\hline 19.784 & 17.539 & 15.83 & 13.35 & 11.6 \\
\hline 23.086 & 20.334 & 18.28 & 15.347 & 13.305 \\
\hline 26.553 & 23.218 & 20.784 & 17.368 & 15.022 \\
\hline 20.205 & 26.195 & 23.346 & 19.415 & 16.752 \\
\hline 40.35 & 34.12 & 30 & 24.65 & 21.13 \\
\hline 52.55 & 42.83 & 37.08 & 30.05 & 25.59 \\
\hline 68.48 & 52.58 & 44.65 & 35.62 & 30.13 \\
\hline 91.77 & 63.65 & 52.77 & 41.36 & 34.74 \\
\hline 352.9 & 76.68 & 61.57 & 47.29 & 39.43 \\
\hline 361.2 & 92.51 & 71.08 & 53.42 & 44.2 \\
\hline 375.3 & 143.8 & 93.23 & 66.3 & 54.01 \\
\hline 385.4 & 235.6 & 119.57 & 79.97 & 64.05 \\
\hline 393.3 & 288.6 & 132.72 & 94.62 & 74.42 \\
\hline 400.1 & 316.2 & 189.5 & 109.97 & 85 \\
\hline 406.1 & 332.8 & 224.7 & 126 & 95.84 \\
\hline 416.2 & 355.4 & 274.1 & 159.1 & 117.97 \\
\hline 424.8 & 371.4 & 306.2 & 191.4 & 140.1 \\
\hline
\end{tabular}
the following Matlab program: 


\begin{tabular}{|c|c|c|c|c|}
\hline 432.1 & 383.9 & 327.9 & 220.4 & 161.8 \\
\hline 438.9 & 394.2 & 344.4 & 245.3 & 182.5 \\
\hline 444.7 & 403 & 357.4 & 266.3 & 201.7 \\
\hline 457.4 & 421 & 382.6 & 305.8 & 243 \\
\hline 468.1 & 435.2 & 401.3 & 333.9 & 275.4 \\
\hline 477.3 & 447 & 415.2 & 355.4 & 301.1 \\
\hline 485.5 & 457.2 & 428.6 & 372.7 & 322 \\
\hline 492.9 & 466.2 & 439.3 & 387.2 & 339.6 \\
\hline 499.8 & 474.3 & 448.5 & 399.8 & 354.9 \\
\hline 511.9 & 88.4 & 465.2 & 420.8 & 379.7 \\
\hline 522.5 & 500.5 & 479 & 437.9 & 399.7 \\
\hline 531.9 & 511.2 & 490.9 & 452.3 & 416.6 \\
\hline 540.3 & 520.4 & 501.4 & 464.8 & 431.1 \\
\hline 548 & 529.2 & 510.9 & 476 & 443.8 \\
\hline 561.9 & 544.4 & 527.5 & 495.5 & 465.6 \\
\hline 574.2 & 557.6 & 541.8 & 511.9 & 483.9 \\
\hline 585.2 & 569.4 & 554.4 & 526 & 499.6 \\
\hline 595.1 & 580 & 565.7 & 538.5 & 513.4 \\
\hline 603.9 & 589.8 & 576 & 550 & 525.9 \\
\hline \multicolumn{5}{|l|}{$\begin{array}{l}] ; \\
x=[1\end{array}$} \\
\hline \multirow{2}{*}{\multicolumn{5}{|c|}{1.2}} \\
\hline & & & & \\
\hline \multicolumn{5}{|l|}{1.4} \\
\hline \multicolumn{5}{|l|}{1.6} \\
\hline \multicolumn{5}{|l|}{1.8} \\
\hline \multicolumn{5}{|l|}{2} \\
\hline \multicolumn{5}{|l|}{2.5} \\
\hline \multicolumn{5}{|l|}{3} \\
\hline \multicolumn{5}{|l|}{3.5} \\
\hline \\
\hline \multicolumn{5}{|l|}{$\begin{array}{l}4.5 \\
5\end{array}$} \\
\hline 5 & & & & \\
\hline \multicolumn{5}{|l|}{6} \\
\hline \multicolumn{5}{|l|}{7} \\
\hline \multicolumn{5}{|l|}{8} \\
\hline \multicolumn{5}{|l|}{9} \\
\hline \multicolumn{5}{|l|}{10} \\
\hline \multicolumn{5}{|l|}{12} \\
\hline \multicolumn{5}{|l|}{14} \\
\hline 16 & & & & \\
\hline 18 & & & & \\
\hline 20 & & & & \\
\hline 25 & & & & \\
\hline 30 & & & & \\
\hline 35 & & & & \\
\hline 40 & & & & \\
\hline 45 & & & & \\
\hline 50 & & & & \\
\hline 60 & & & & \\
\hline 70 & & & & \\
\hline 80 & & & & \\
\hline 90 & & & & \\
\hline 100 & & & & \\
\hline 120 & & & & \\
\hline 140 & & & & \\
\hline 160 & & & & \\
\hline 180 & & & & \\
\hline
\end{tabular}




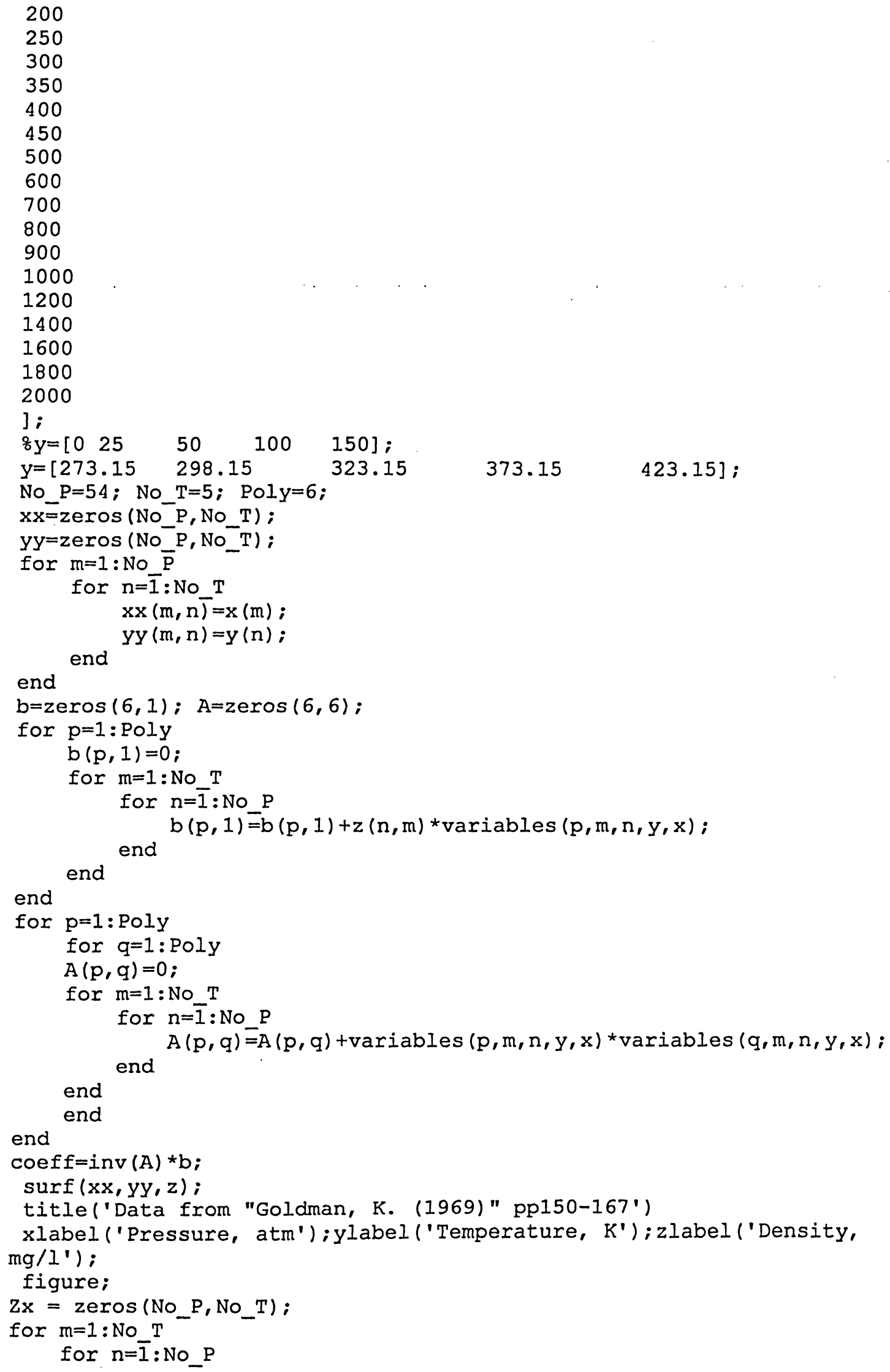




\section{Appendix D}

\section{The Fourth and Fifth-Order Runge-Kutta Algorithm with}

\section{Cash-Carp Development}

Range-Kutta algorithm is one of the most popular methods used in solving set of ordinary partial differential equations, such as:

$$
\begin{gathered}
\frac{d y_{1}}{d x}=f_{1}\left(x, y_{1}, y_{2}, \ldots, y_{n}\right) \\
\frac{d y_{2}}{d x}=f_{2}\left(x, y_{1}, y_{2}, \ldots, y_{n}\right) \\
. \\
\cdot \\
\frac{d y_{i}}{d x}=f_{i}\left(x, y_{1}, y_{2}, \ldots, y_{n}\right)
\end{gathered}
$$

Fourth-Order Runge-Kutta method

Fourth-order is the most popular RK method. The following is the most commonly used form - the classical formula:

$$
y_{i+1}=y_{i}+\frac{1}{6}\left(k_{1}+2 k_{2}+2 k_{3}+k_{4}\right) h
$$

where

$$
k_{1}=f\left(x_{i}, y_{i}\right)
$$




$$
\begin{aligned}
& k_{2}=f\left(x_{i}+\frac{1}{2} h, y_{i}+\frac{1}{2} k_{1} h\right) \\
& k_{3}=f\left(x_{i}+\frac{1}{2} h, y_{i}+\frac{1}{2} k_{2} h\right) \\
& k_{4}=f\left(x_{i}, y_{i}+k_{3} h\right)
\end{aligned}
$$

\section{Fifth-Order Runge-Kutta Method}

In case more accurate results are required, a fifth-order Runge-Kutta method, which was report by Butcher in 1964, should be used:

$$
y_{i+1}=y_{i}+\frac{1}{90}\left(7 k_{1}+32 k_{3}+12 k_{4}+32 k_{5}+7 k_{6}\right) h
$$

where

$$
\begin{aligned}
& k_{1}=f\left(x_{i}, y_{i}\right) \\
& k_{2}=f\left(x_{i}+\frac{1}{4} h, y_{i}+\frac{1}{4} k_{1} h\right) \\
& k_{3}=f\left(x_{i}+\frac{1}{4} h, y_{i}+\frac{1}{8} k_{1} h+\frac{1}{8} k_{2} h\right) \\
& k_{4}=f\left(x_{i}+\frac{1}{2} h, y_{i}-\frac{1}{2} k_{2} h+k_{3} h\right) \\
& k_{5}=f\left(x_{i}+\frac{3}{4} h, y_{i}+\frac{3}{16} k_{1} h+\frac{9}{16} k_{4} h\right) \\
& k_{6}=f\left(x_{i}+h, y_{i}-\frac{3}{7} k_{1} h+\frac{2}{7} k_{2} h+\frac{12}{7} k_{3} h-\frac{12}{7} k_{4} h+\frac{8}{7} k_{5} h\right)
\end{aligned}
$$




\section{Carsh-Carp Runge-Kutta Method}

In order to use RK method in a computer program efficiently, Carsh and Carp developed the particular coefficients in year 1990, by using the following fourth-order formula:

$$
y_{i+1}=y_{i}+\left(\frac{37}{378} k_{1}+\frac{250}{621} k_{3}+\frac{125}{594} k_{4}+\frac{512}{1771} k_{6}\right) h
$$

along with the fifth-order algorithm:

$$
y_{i+1}=y_{i}+\left(\frac{2825}{27,648} k_{1}+\frac{18,575}{48,384} k_{3}+\frac{13,525}{55,296} k_{4}+\frac{277}{14,336} k_{5}+\frac{1}{4} k_{6}\right) h
$$

where

$$
\begin{aligned}
& k_{1}=f\left(x_{i}, y_{i}\right) \\
& k_{2}=f\left(x_{i}+\frac{1}{5} h, y_{i}+\frac{1}{5} k_{1} h\right) \\
& k_{3}=f\left(x_{i}+\frac{3}{10} h, y_{i}+\frac{3}{40} k_{1} h+\frac{9}{40} k_{2} h\right) \\
& k_{4}=f\left(x_{i}+\frac{3}{5} h, y_{i}+\frac{3}{10} k_{1} h-\frac{9}{10} k_{2} h+\frac{6}{5} k_{3} h\right) \\
& k_{5}=f\left(x_{i}+\frac{3}{4} h, y_{i}-\frac{11}{54} k_{1} h+\frac{5}{2} k_{2} h-\frac{70}{27} k_{3} h+\frac{35}{27} k_{4} h\right) \\
& k_{6}=f\left(x_{i}+\frac{7}{8} h, y_{i}+\frac{1,631}{55,296} k_{1} h+\frac{175}{512} k_{2} h+\frac{575}{13,824} k_{3} h+\frac{44,275}{110,592} k_{4} h+\frac{253}{4,096} k_{5} h\right)
\end{aligned}
$$

